\title{
Analysis of Emplacement Borehole Rock and Liner Behavior for a Repository at Yucca Mountain
}

Manuscript Completed: August 1989

Date Published: September 1989

Prepared by

L. J. Lorig, B. Dasgupta

Itasca Consulting Group, Inc.

1313 Fifth Street SE, Suite 210

Minneapolis, MN 55414

Prepared for

Division of High-Level Waste Management

Office of Nuclear Material Safety and Safeguards

U.S. Nuclear Regulatory Commission

Washington, DC 20555

NRC FIN D1016 



\section{DISCLAIMER}

This report was prepared as an account of work sponsored by an agency of the United States Government. Neither the United States Government nor any agency thereof, nor any of their employees, make any warranty, express or implied, or assumes any legal liability or responsibility for the accuracy, completeness, or usefulness of any information, apparatus, product, or process disclosed, or represents that its use would not infringe privately owned rights. Reference herein to any specific commercial product, process, or service by trade name, trademark, manufacturer, or otherwise does not necessarily constitute or imply its endorsement, recommendation, or favoring by the United States Government or any agency thereof. The views and opinions of authors expressed herein do not necessarily state or reflect those of the United States Government or any agency thereof. 


\section{DISCLAIMER}

Portions of this document may be illegible in electronic image products. Images are produced from the best available original document. 
ABSTRACT

This report presents the results of studies aimed at assessing the quasi-static behavior of both the rock surrounding an emplacement borehole and the lining within an emplacement borehole for a nuclear waste repository in tuff. Two-dimensional thermomechanical analyses of conditions similar to those representative of the horizontal emplacement option were performed using a distinct element code. Three different behavior models (equivalent continuum, wedge, and parallel joint) were used to investigate the state of deformation at 0 and 100 years following waste emplacement. Three different rock strength assumptions were studied corresponding to "design," "recommended" and "limit" values given in the Nevada Nuclear Waste Storage Investigation (NNWSI) Project Site Characterization Plan Conceptual Design Report (MacDougall et al., 1987). The ground reaction curve concept is introduced to study the potential liner loading resulting from thermally induced borehole closure.

Analytical solutions for various ring loadings given by Roark and Young (1975) were combined to develop solutions for appropriate liner loading configurations. Results are presented in terms of dimensionless bending stress versus flexibility ratio.

The report concludes that for the conditions and parameters assumed, liners may not be significantly loaded by borehole closure, because predicted closures will likely be less than tolerances required to install the lining. The report also concludes that gravity loading of linings by blocks which fall from the surrounding rock should not over-stress the lining.

The report discusses borehole intersections with drifts and transverse displacement by faults or shear zones as conditions which may lead to significant borehole liner loading. 


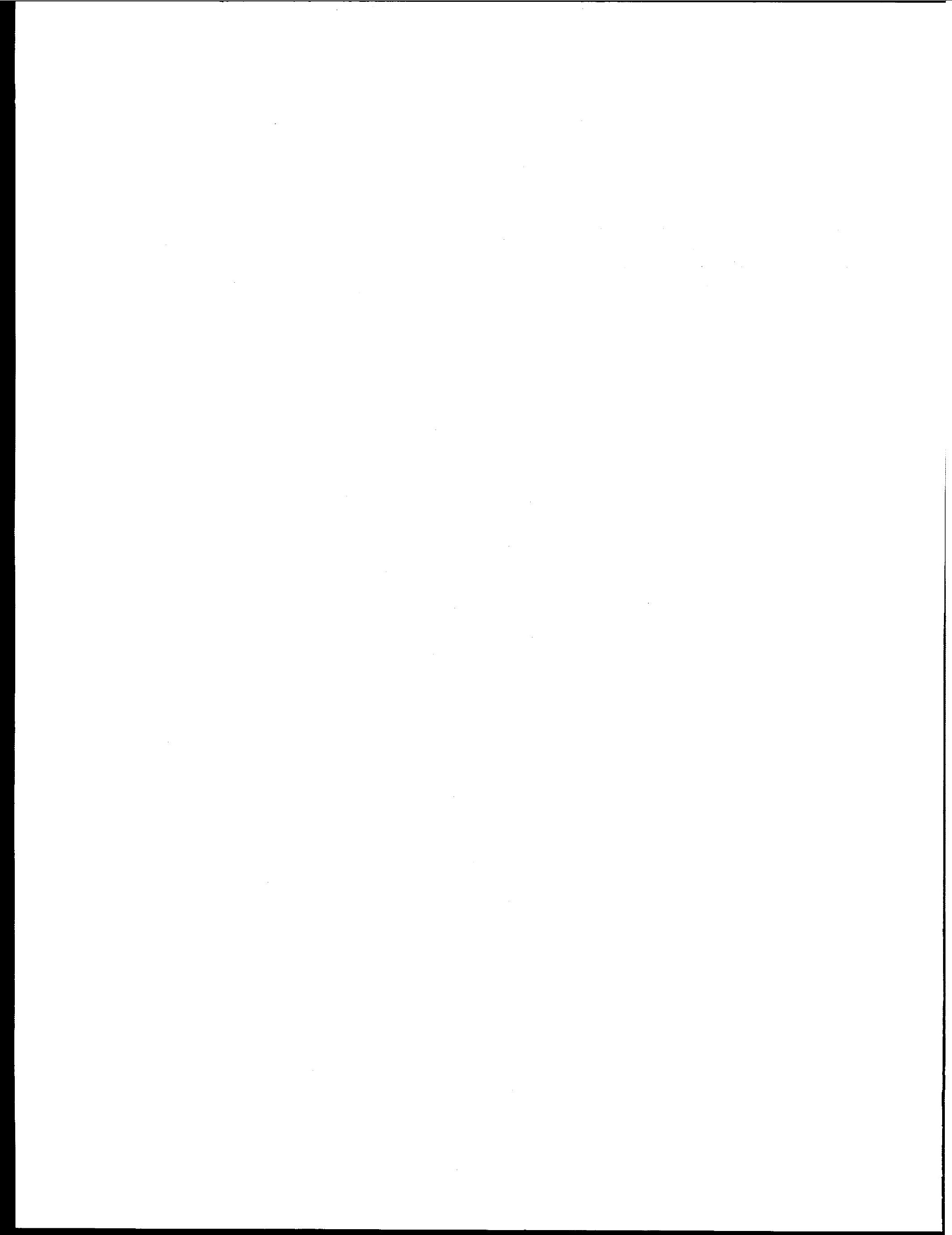


FOREWORD

Reports produced by DOE have generally used SI units for rock mass properties and English units for liner properties and geometry. This report follows this convention but gives SI conversions in parentheses in most cases where English units appear. 

TABLE OF CONTENTS

PAGE

ABSTRACT ....................... . . . . . . . . . . .

FOREWORD . . . . . . . . . . . . . . . . . . v v

LIST OF FIGURES. . . . . . . . . . . . . . . . . . xi

LIST OF TABLES . . . . . . . . . . . . . . . . xvi

1.0 INTRODUCTION. . . . . . . . . . . . . . 1

1.1 Background . . . . . . . . . . . . . 1

1.2 objective. . . . . . . . . . . . 4

1.3 scope. . . . . . . . . . . . . . 5

2.0 EMPLACEMENT BOREHOLE LINER DESIGN . . . . . . . . 6

2.1 Design Criteria. . . . . . . . . . 6

2.2 Design Description... . . . . . . . 6

2.3 Design Considerations. . . . . . . . . 11

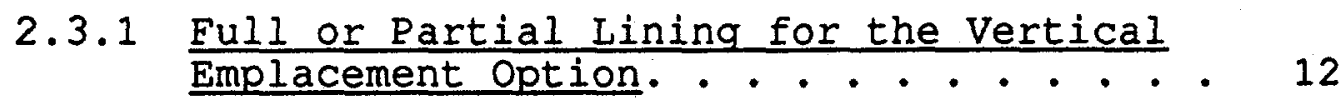

2.3.2 Liner Material Selection. . . . . . 12

2.3.3 Backfilling/Grouting Behind Liner . . . 12

2.3.4 Installation Tolerance. . . . . . . 13

3.0 ANALYSIS APPROACH . . . . . . . . . . . 14 
TABLE OF CONTENTS

PAGE

3.1 Numerical Analysis... . . . . . . . 18

3.1.1 Assumptions and Idealizations . . . . . 18

3.1 .2 Numerical Model . . . . . . . . . 19

3.1.3 Areal Power Density . . . . . . . . . 25

3.1.4 Waste Form Characteristics. . . . . . 25

3.1 .5 Rock Mass Thermal Properties. . . . . . . 27

3.1 .6 Elastic Properties. . . . . . . . . 27

3.1 .7 Strength properties . . . . . . . . 28

3.1 .8 In-Situ Conditions. . . . . . . . . 31

3.1.9 Natural Fracture Frequency. . . . . . 32

3.2 Analytical Method Used for Liner Stress Analysis 34

3.2.1 Analysis of Circular Borehole Liner . . 34

3.2 .2 Load Combinations . . . . . . . . 34

3.2 .3 Analytical Solution . . . . . . . 35

4.0 RESULTS . . . . . . . . . . . . . . . 37

4.1 Results of Numerical Modeling. . . . . . . 37

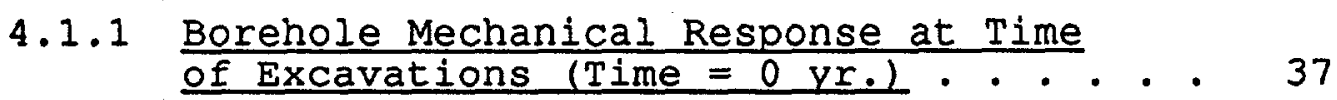

4.1 .2 Thermal Results . . . . . . . . . . 42

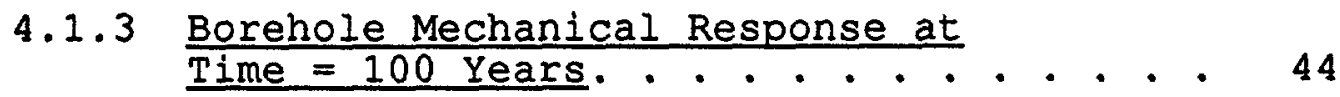


TABLE OE CONTENTS

PAGE

4.2 Results of Analytic Studies... . . . . . . . 54

4.2.1 Verification. . . . . . . . . . 54

4.2.2 Stress Analysis . . . . . . . . . 58

4.2.2.1 Complete Stress Analysis . . . . 58

4.2.2.2 Maximum Stress Analysis. . . . 63

5.0 DISCUSSION. . . . . . . . . . . 67

5.1 Installation Tolerance and Borehole Closure. . . 67

5.2 Gravity Loading of Borehole Iiner. . . . . . . 68

5.3 Intersection of Borehole Iiners and Emplacement

Drifts..................... 70

5. 4 Long-Term Exposure of Tuff to Elevated

Temperatures, Stress and Radiation Levels. . . 70

5.5 Redundancy of Circular Rings . . . . . . . . 71

5.6 Boreholes Intersected by Fault or Shear Zone - . 71

5.7 Borehole Liner Thermal Stress. . . . . . . . 72

6.0 RECOMMENDATION FOR FUTURE STUDIES . . . . . . . . . 73

7.0 REFERENCES. . . . . . . . . . . . . . . . . 74

APPENDIX A: UDEC INPUT COMMANDS . . . . . . . . . . . A-1

APPENDIX B: LINER11 . . . . . . . . . . . . . . . B-1 

LIST OF FIGURES

PAGE

Fig. 1-1 Retrieval Time Erame for Design Purposes [MacDougall et al., 1987] . . . . . . . . . 2

2-1 Conceptual Design of Vertical Borehole

[Fig. 3-12 of the SCPCDR, MacDougall et al.,

$1987]$. . . . . . . . . . . . . . .

2-2 Conceptual Design of Horizontal Borehole

[Fig. 3-13 of the SCPCDR, MacDougall et al., 1987; according to Fig. 4-41 of the SCPCDR, borehole diameter $=37 \mathrm{in.l}$. . . . . . . . .

2-3 Plan and Cross-Sectional Views of the Vertical

Commingled SF and DHLW Emplacement Configura-

tion [SCPCDR, Chapter 4, MacDougall et al., 1987]

2-4 Plan and Cross-Sectional Views of the Horizontal Commingled SF and DHLW Emplacement

Configuration [MacDougall et al., 1987,

Chapter 4]. . . . . . . . . . . . .

2-5 Stress-Elongation Relation for Annealed Low

Carbon steel (The $X$ on the plot indicates the point of rupture.) [after Keyser, 1980] .. .

3-1 Problem Configurations for Analysis of

Emplacement Borehole Behavior . . . . . . . .

3-2 Determination of Liner Loading Based on the Concept of Ground Reaction Curve. . . . . . .

3-3 Model Used to Study Emplacement Borehole

Behavior (compression stresses assumed negative) 20

3-4 Continuum Model - Emplacement Borehole Near-

Field UDEC Problem Geometry . . . . . . . .

3-5 Wedge Model - Emplacement Borehole Near-Field UDEC Problem Geometry . . . . . . . . . . .

3-6 Parallel Joint Model - Emplacement Borehole Near-Field UDEC Problem Geometry. . . . . . . 
LIST OF FIGURES

(continued)

PAGE

3-7 Comparison of Normalized Power Decay

Characteristics for Spent Fuel and Defense

High-Level Waste. . . . . . . . . . . .

3-8 Mechanical Construction for Intact TsW2 Tuff

Based on Data in Nimick and Schwartz (1987) [Upper envelope represents SCPCDR "design" strength parameters. Lower envelope represents SCPCDR "recommended" strength parameters.] 30

3-9 Combination of Load Types to Obtain Uniform Pressure on Top and Uniform Base Reaction

Load Case 1... . . . . . . . . . .

3-10 Combination of Load Types to Obtain Concentrated Load on Top and Uniform Base Reaction

3-11 Internal Axial Force, Shear Force, and Moment

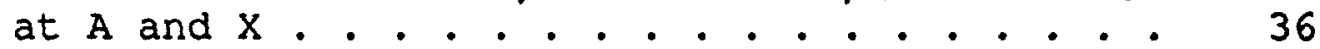

4-1 Excavation Induced Displacements for Continuum Model and All Strength Assumptions. . . . . .

4-2 Excavation Induced Displacements for Wedge Model and "Design" Strength Values. . . . . .

4-3 Location of "Failed" Joints Induced by Borehole Excavation . . . . . . . . .

4-4 Excavation Induced Displacements for Parallel Joint Continuity Model and "Recommended" Strength Values............. 42

4-5 Predicted Induced Borehole Wall Temperatures. . 43

4-6 Induced Temperature Distribution in the Vicinity of the Borehole at 100 Years . . . .

4-7 Thermally-Induced Displacements for Continuum Model with "Recommended" Strength Values at 100 Year 


\section{LIST OF FIGURES}

(continued)

PAGE

4-8 Principal Stress Distribution for Continuum Model with "Recommended" Strength Values at 100 Years . . . . . . . . . . . . . .

4-9 Location of "Failed" Zones for Continuum Model with "Recommended" Strength Values at 100 Years

4-10 Thermally-Induced Displacements for Wedge Model with "Recommended" Strength Values at 100 Years. . . . . . . . . . . . . .

4-11 Principal Stress Distribution for Wedge Model with "Recommended" Strength Values at 100

Years. . . . . . . . . . . . . . .

4-12 Thermally-Induced Displacements for Parallel Joint Model with "Recommended" Strength Values at 100 Years . . . . . . . . . . . . . .

4-13 Joint Displacements for Parallel Joint Model with "Recommended" Strength Values at 100 Years

4-14 Distribution of Principal Stresses for Parallel Joint Model with "Recommended" Strength Values at 100 Years ................

4-15 Ground Reaction Curves for Emplacement Borehole at 100 Years (continuum model, "design" strength values) . . . . . . . . . . . .

4-16 Ground Reaction Curves for Emplacement Borehole at 100 Years (continuum model, "recommended" strength values) . . . . . . . . . . . .

4-17 Ground Reaction Curves for Emplacement Borehole at 100 Years (continuum model, "limit" strength values) ...................

4-18 Ground Reaction Curves for Emplacement Borehole at 100 Years (wedge model, "design" strength values). . . . . . . . . . . . . . . 


\section{LIST OE EIGURES}

(continued)

PAGE

4-19. Ground Reaction Curves for Emplacement Borehole at 100 Years (wedge model, "recommended" strength values) . . . . . . . . . . . .

4-20 Ground Reaction Curves for Emplacement Borehole at 100 Years (wedge model, "limit" strength values). . . . . . . . . . . . . . .

4-21 Ground Reaction Curves for Emplacement Borehole at 100 Years (parallel joint models, "design" strength values) . . . . . . . . . . .

4-22 Ground Reaction Curves for Emplacement Borehole at 100 Years (parallel joint model, "recommended" strength values) . . . . . . .

4-23 Ground Reaction Curves for Emplacement Borehole at 100 Years (parallel joint model, "limit" strength values) . . . . . . . . . . . .

4-24 Dimensionless Bending, Axial and Shear Stresses for 28 in. $(71 \mathrm{~cm})$ Diameter Borehole Liner for Load Case $1,2 \alpha=60^{\circ}$.............. .

4-25 Dimensionless Bending, Axial and Shear Stress for $28 \mathrm{in.}(71 \mathrm{~cm})$ Diameter Borehole Liner for Load Case 2, $2 \alpha=60^{\circ}$.............

4-26 Dimensionless Maximum Bending Stress for 28 in. $(71 \mathrm{~cm})$ Diameter Borehole Liner for Load Case 1

4-27 Dimensionless Maximum Bending Stress for 36 in. $(91 \mathrm{~cm})$ Diameter Borehole Liner for Load Case 1

4-28 Dimensionless Maximum Bending Stress for 28 in. $(71 \mathrm{~cm})$ Diameter Borehole Liner for Load Case 2

4-29 Dimensionless Maximum Bending Stress for 36 in. $(91 \mathrm{~cm})$ Diameter Borehole Liner for Load Case 2 


\section{IIST OF FIGURES}

(continued)

$\underline{\text { PAGE }}$

5-1 Conditions Favorable and Unfavorable for Wedge Stability, Based on Closed Form Solutions.. .

5-2 Problem Geometry and Parameters Used in Deriving Formulae for Determining Force Required to Support an Isolated Wedge . . . . . . . .

5-3 Possible Liner Deformations Due to Rock Displacements in an Emplacement Hole (after Borgesson, 1986). . . . . . . . . . . . . 


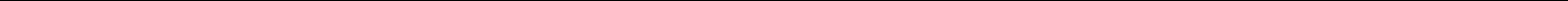


Table 3-1 THERMAL PROPERTIES OF TSW2 TUFF

[MacDougall et al., 1987] . . . . . . . .

3-2 ELASTIC PROPERTIES OF TSW2 TUFF

[MacDougall et al., 1987] . . . . . . . . 28

3-3 STRENGTH PROPERTIES OE TSW2 TUFE

[MacDougall et al., 1987] . . . . . . .

3-4 MEAN VALUES AND RANGES FOR FIELD PRINCIPAL

STRESSES AT YUCCA MOUNTAIN [MaCDougall et al., 1987]

3-5 RECOMMENDED VALUES FOR FRACTURE FREQUENCY IN THERMAL/MECHANICAL UNITS AT YUCCA MOUNTAIN [MacDougall et al., 1987] . . . . . . . . .

4-1 MECHANICAL RESPONSE AT ZERO YEARS RADIAL INWARD DISPLACEMENT $(\mathrm{mm}) \cdot$ • . . . . . . • . . . .

4-2 VERIEICATION OF COMPUTER CODE (IINERI1) FOR LOAD CASE 1. . . . . . . . . . . . . 55

4-3 BENDING MOMENTS AND STRESSES COMPUTED USING LINER11 EOR LOAD CASE 1 . . . . . . . . . .

4-4 BENDING MOMENTS AND STRESSES REPORTED BY MACDOUGALL ET AL. (1987) FOR LOAD CASE 1. . .

4-5 VERIEICATION OF COMPUTER CODE (LINER11) FOR

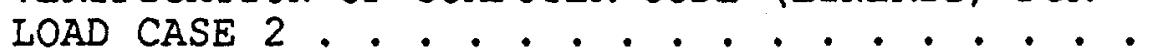

4-6 DIMENSIONLESS BENDING, AXIAL AND SHEAR STRESSES FOR LOAD CASE 1 (Diameter $=28$ in., $2 \alpha=60^{\circ}$ ).

4-7 DIMENSIONLESS BENDING, AXIAL AND SHEAR STRESSES FOR LOAD CASE 2 (Diameter $=28$ in., $2 \alpha=60^{\circ}$ ).

4-8 BENDING STRESS FOR 28 IN. DIAMETER LINER [Bending stresses are in ksi (MPa)] . . . . .

4-9 BENDING STRESS FOR 36 IN. DIAMETER IINER [Bending stresses are in ksi (MPa)] . . . . . 


\subsection{INTRODUCTION}

This report addresses the subject of borehole liner loading and resultant stresses for emplacement holes of a geologic radioactive waste repository. Waste emplacement borehole liners are intended to serve two main purposes. Primarily, they are provided to permit retrieval of any of the emplaced waste packages if this should become necessary. Secondly, the liners are intended to limit mechanical loading on the waste packages themselves for 10,000 years after closure. [See, for example, the Site Characterization Plan (SCP), U.S. DOE, 1988a, p. 8.3.4.2-28.] The concern of this report is mainly with the primary function of borehole liners (i.e., ensuring predictable access to waste packages for retrieval). Therefore, this report is limited to analysis of the behavior of the borehole liner and rock immediately surrounding waste emplacement boreholes. For the purposes of this report, analyses are limited to the first 100 years after initial waste emplacement.

\subsection{Background}

The Nuclear Waste Policy Act of 1982 (NWPA) which mandates the development of repositories for disposal of high-level waste and spent nuclear fuel also requires the repository to be designed and constructed to permit the retrieval of any emplaced radioactive waste. Regulations concerning waste retrieval are also issued by the Nuclear Regulatory Commission (NRC) in $10 \mathrm{CFR} 60$, and by the Environmental Protection Agency (EPA) in 40 CFR 191.14 (f). These regulations dictate specific requirements which affect repository design and performance objectives.

If access to and retrieval of the waste take place through the disposal rooms and boreholes, the two most important elements in complying with the regulations are the unobstructed access to the waste container boreholes, and the unobstructed access to the waste containers inside the boreholes. This means the disposal rooms and the container boreholes must remain structurally stable for the time period required to complete the retrieval process. This report addresses only the role of borehole liners in maintaining structurally stable boreholes.

The candidate repository site is at Yucca Mountain, Nevada, where the repository horizon is proposed to be located in a densely welded tuff. The site is being evaluated by the Nevada Nuclear Waste Storage Investigation (NNWSI) Project as potentially the first radioactive waste repository in the United States. The 
NNWSI project's position paper on waste retrieval is given by Flores (1986), which states that the boreholes are likely to be stable.

The Site Characterization Plan Conceptual Design Report for Yucca Mountain (MacDougall et al., 1987), subsequently referred to as the SCPCDR, and the SCP (U.S. DOE, 1988a) outline a waste retrieval philosophy and provide a list of design criteria. The retrieval time considered in both these documents is shown in Fig. 1-1. The "retrievability period" is defined as "the time during which the ability to initiate a retrieval will be maintained". This period is set to 50 years (U.S. DOE, 1986, Appendix D). The "retrieval period" is defined as "the time period required for removal of the emplaced waste from the underground repository, if a decision to retrieve the waste is made". This period is set to 34 years (Flores, 1986).

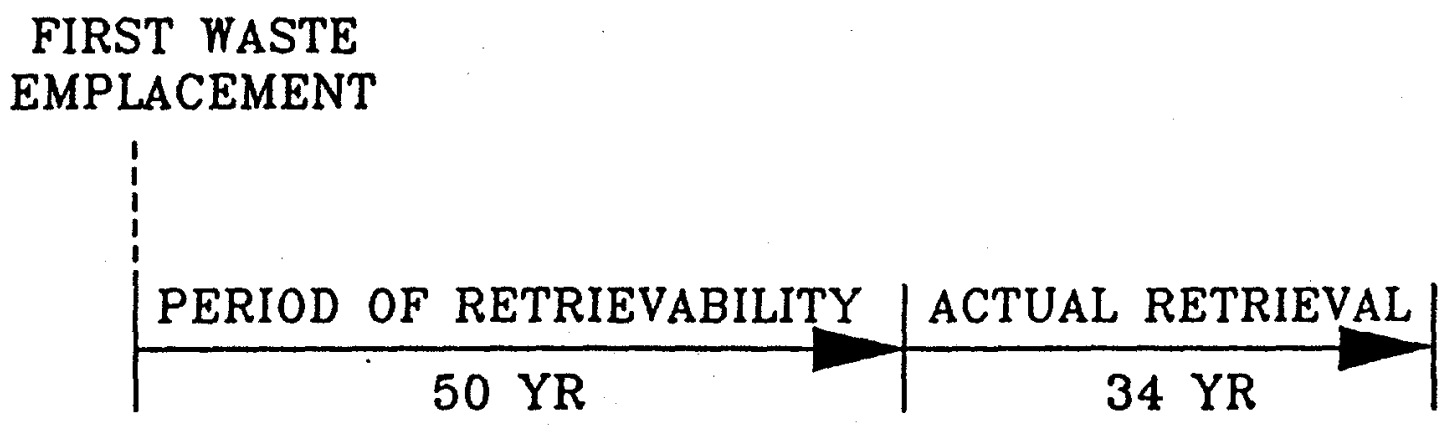

Fig. 1-1 Retrieval Time Frame for Design Purposes [MacDougall et al., 1987]

The results of the present study will contribute to the evaluation of compliance to some of the (DOE) design criteria listed in the SCPCDR and SCP. These are:

(a) rock fall in the emplacement boreholes will average less than $250 \mathrm{lb} / \mathrm{ft}$ of borehole;

(b) displacement of the emplacement borehole wall will be less than 2 inches; 
(c) the lifetime of the borehole liner will be at least 84 years;

(d) the maximum liner deflection is 2 inches in the vertical emplacement concept and 3 inches in the horizontal concept; and

(e) in the horizontal emplacement concept, the minimum allowable radius of curvature for the horizontal axis of the borehole liner is 110 feet.

Additionally, the studies may aid in evaluating potential borehole wall temperatures. The following borehole wall design goals are reported:
(a) $275^{\circ} \mathrm{C}$ (SCP, p. 6-35 and SCP, Table B.3.2.2-4, p. 5.3.2.2-17);
(b) $235^{\circ} \mathrm{C}$ (SCP, p. 6-194); and
(C) $220^{\circ} \mathrm{C}$ (U.S. DOE, CDSCP, 1988b, Appendix P).

Another design goal which may be evaluated is the rock-mass temperature at a point $1 \mathrm{~m}$ from the borehole wall which should not exceed $200^{\circ} \mathrm{C}$ (SCP, Table 8.3.2.2-4, p. 8.3.2.2-17).

These studies may also aid in evaluating the reasonableness of design goals for rock-induced loads on the waste packages. The SCP indicates (p. 8.3.4.2-28) that emplacement holes will be designed and constructed so that the following conditions will be met within a high level of confidence.

1. Less than 0.5 percent of the containers will be breached by anticipated tectonic processes and events during the first 1,000 years after closure. Drifts and boreholes will be inspected for fault and shear zones, and waste packages will not be emplaced across such regions.

2. For 1,000 years after closure, the stability analysis will show, with a high level of confidence, that the rock-induced load on a waste package will be less than $1000 \mathrm{~kg}$. 
3. For 10,000 years after closure, the stability of analysis will show, with a moderate level of confidence, that the rock-induced load on a waste package will be less than $3,000 \mathrm{~kg}$.

4. Emplacement boreholes will be cleaned of debris before use.

Analyses to date of anticipated (horizontal) borehole behavior are given by Arulmoli and St. John (1987). These analyses, however, are not based on the same design shown in the SCPCDR (e.g., 33 inch borehole diameter used instead of the 37 inch diameter assumed in the SCPCDR). The analyses of Arulmoli and St. John (1987) considered elastic and inelastic material models in twodimensional finite element calculations. The analyses predict that the boreholes will be stable, but that some uncertainty exists regarding whether there will be small (bounded by a few centimeters) regions where localized fracturing of intact rock might occur.

Appendix B of the SCPCDR presents preliminary liner stress analyses based on assumed rock loads and simple ring analysis. These analyses show very low stress levels (less than $1.5 \mathrm{ksi}$ ) for all cases in which 0.5-inch thick liners were assumed. Corrosion was considered by repeating analyses with thicknesses as small as 0.15 inches. Even with this thickness, stresses in the liner remained below the minimum yield stress of $30 \mathrm{ksi}$.

\subsection{Objective}

The objective of this report is to provide guidance regarding the types of numerical analyses which may be helpful in evaluating the adequacy/inadequacy of emplacement borehole liners, particularly during the retrieval time frame. Access to and retrieval of the waste are assumed to take place through the borehole liners. 


\subsection{Scope}

The subject of borehole liner loading involves the evaluation of inelastic rock behavior such as the creation of new fractures in the intact rock caused by excessive movement on pre-existing discontinuities (e.g., joints), slip (caused by excessive shear stress), or opening (caused by a reduction in normal stress). These behaviors may result from the initial excavation of the borehole or the continuous heating of the rock because of the presence of radioactive waste. This study does not treat in detail the response of the rock due to borehole excavation. One reason for this is that boreholes (presumably, mainly vertical boreholes) will likely be cleared of debris before use (See, for example, $p$. 8.3.4.2-28 of the SCP.), and therefore will not significantly load the borehole liners.

Rigorous thermomechanical analyses of the rock mass surrounding boreholes are provided for only the horizontal waste emplacement scheme. The reasons for this are that :

(1) present design concepts for the vertical emplacement option consider only partial liners (i.e., from the floor of the emplacement drift to the top of the waste container); and

(2) the horizontal emplacement scheme is more amenable to two-dimensional plane strain analysis.

The heat transfer associated with the first 100 years of heating by spent fuel (SF) is predicted, along with induced thermal stresses, displacements, and inelastic rock behavior. Behavior of boreholes in which Defense High-Level Waste (DHLW) is emplaced is not studied because DHLW has a lower power output compared to SE.

Static stress analysis is given for several likely liner loading assumptions. Results of liner stress analyses are provided in dimensionless form and, therefore, are applicable to either the horizontal or vertical waste emplacement scheme. Liner stress analyses are mainly limited to consideration of elastic stress levels. 


\subsection{EMPLACEMENT BOREHOLE IINER DESIGN \\ 2.1 Design Criteria}

The mechanical design constraints for borehole liners given in the SCPCDR relate only to retrievability requirements. Section 2.4.4.3 of the SCPCDR describe the development of the design criteria from performance goals. The design criteria related to the borehole liners in that section are listed below (MacDougall et al., 1987).

- Rockfall in the emplacement boreholes will average less than $250 \mathrm{lb} / \mathrm{ft}$ of [the] borehole.

- Displacement of the emplacement borehole wall will be less than 2 in.

- The lifetime of the borehole liner will be at least 84 yr.

- The maximum liner deflection is 2 in. in the vertical emplacement concept and 3 in. in the horizontal concept.

- In the horizontal emplacement concept, the minimum allowable radius of curvature for the horizontal axis of the borehole liner is $110 \mathrm{ft}$.

It should be noted that these criteria are DOE-generated criteria, and have not been the subject of any rigorous examination by the NRC.

\subsection{Design Description}

The SCP and SCPCDR describe both vertical and horizontal emplacement options, as shown Figs. 2-1 and 2-2. Presently, the vertical borehole is envisioned to "be partially lined to provide support for the shield plug, to prevent rock from falling onto the top of the waste container, and to provide a fitting for installing the shielding closure" (MacDougall et al., 1987, p. 3-92). For vertical emplacement, a borehole of sufficient length to accommodate a single waste container is excavated in the floor of an emplacement drift. Excavation of the borehole involves the following steps: (1) drilling a small diameter pilot hole; (2) reaming the top section of the borehole to accommodate the partial liner, and (3) reaming the remainder of the borehole to the design depth at a smaller diameter. 


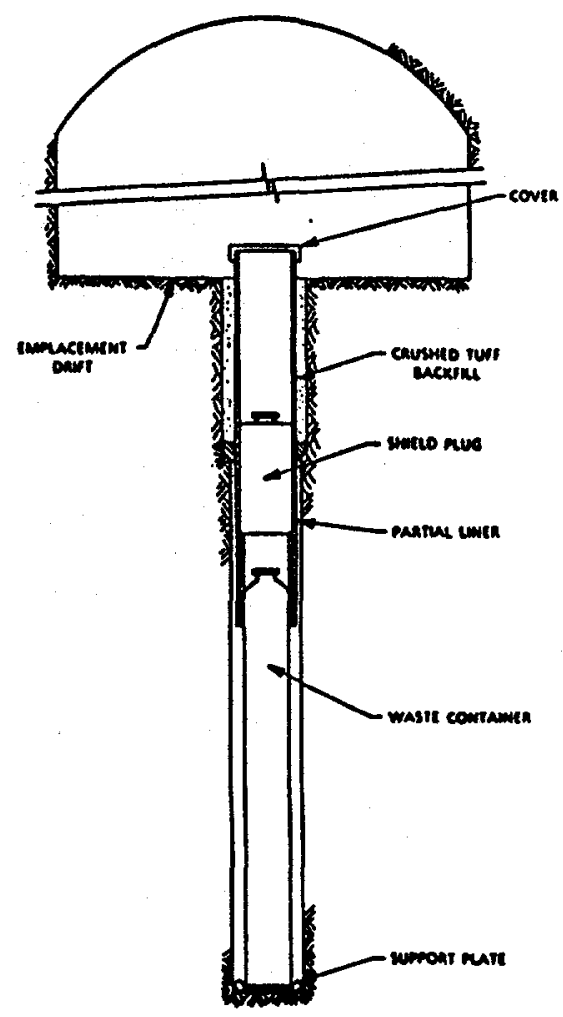

Fig. 2-1 Conceptual Design of Vertical Borehole [Fig. 3-12 of the SCPCDR, MacDougall et al., 1987]

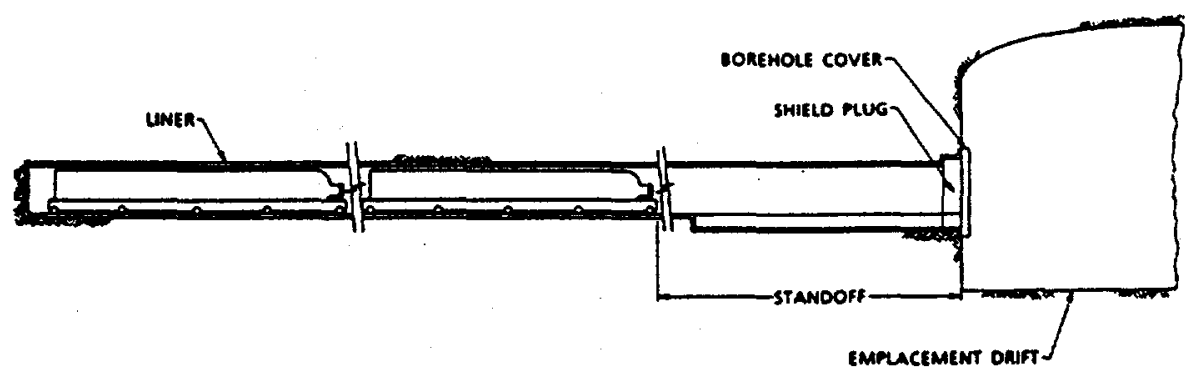

Fig. 2-2 Conceptual Design of Horizontal Borehole [Fig. 3-13 of the SCPCDR, MaCDougall et al., 1987; according to Fig. 4-41 of the SCPCDR, borehole diameter $=37 \mathrm{in.}$ 
The exact planned diameter and thickness of the partial liner for the vertical emplacement hole was not found in the SCPCDR or in supporting documents. However, in Fig. 4-34 of the SCPCDR, it is noted that the borehole diameter is $29 \mathrm{in.} \mathrm{The} \mathrm{outer} \mathrm{diameter} \mathrm{of}$ the waste container is given as 26 in. (SCPCDR, p. 2-3). Based on this information, a borehole liner outer diameter of 28 in. is assumed in this report for the vertical emplacement mode.

No explicit reference to vertical borehole liner thickness is given. However, in section 7.3.3.1 of the SCP, it is stated that the "liner will probably consist of welded units having a wall thickness of approximately $0.24 \mathrm{in}$. to $0.4 \mathrm{in.} 10.6 \mathrm{~cm}$ to $1.0 \mathrm{~cm}$ based on the expected maximum load imposed by any rock that sloughs from the borehole walls or based upon loads imposed during Iiner installation" (SCP, p. 7-33). A wall thickness of 0.5 in. $(1.27 \mathrm{~cm})$ is assumed in this report. The arrangement of vertical boreholes within a typical panel is shown in Fig. 2-3.

In the horizontal emplacement scheme, a number of waste containers are emplaced in a long horizontal borehole. The steel liner is installed during drilling, and extends the entire length of the horizontal borehole. DOE acknowledges that excavation and lining of long horizontal boreholes will require development of new equipment based on existing technology. The procedure for constructing a horizontal borehole consists of the following:

(1) installing a collar in the outer portion of the borehole and installing the first liner section and in-hole power unit;

(2) lengthening the borehole by drilling and adding liner sections;

(3) withdrawing the drilling equipment from the borehole; and

(4) preparing the collar for attaching shielding closure.

Most information concerning the present design for horizontal borehole liners is given in Appendix B of the SCPCDR. Based on this appendix, it is assumed that the liner radius is 18.0 in., that the liner thickness is $0.5 \mathrm{in.}$, and the borehole radius is 37 in. These values have also been used in this report. The arrangement of horizontal boreholes within a typical panel are shown in Fig. 2-4. Appendix B of the SCPCDR also assumes that the liner is composed of low carbon steel with a yield stress of at least $30 \mathrm{ksi}$. A stress-strain relation for annealed low carbon steel is shown in Fig. 2-5. 

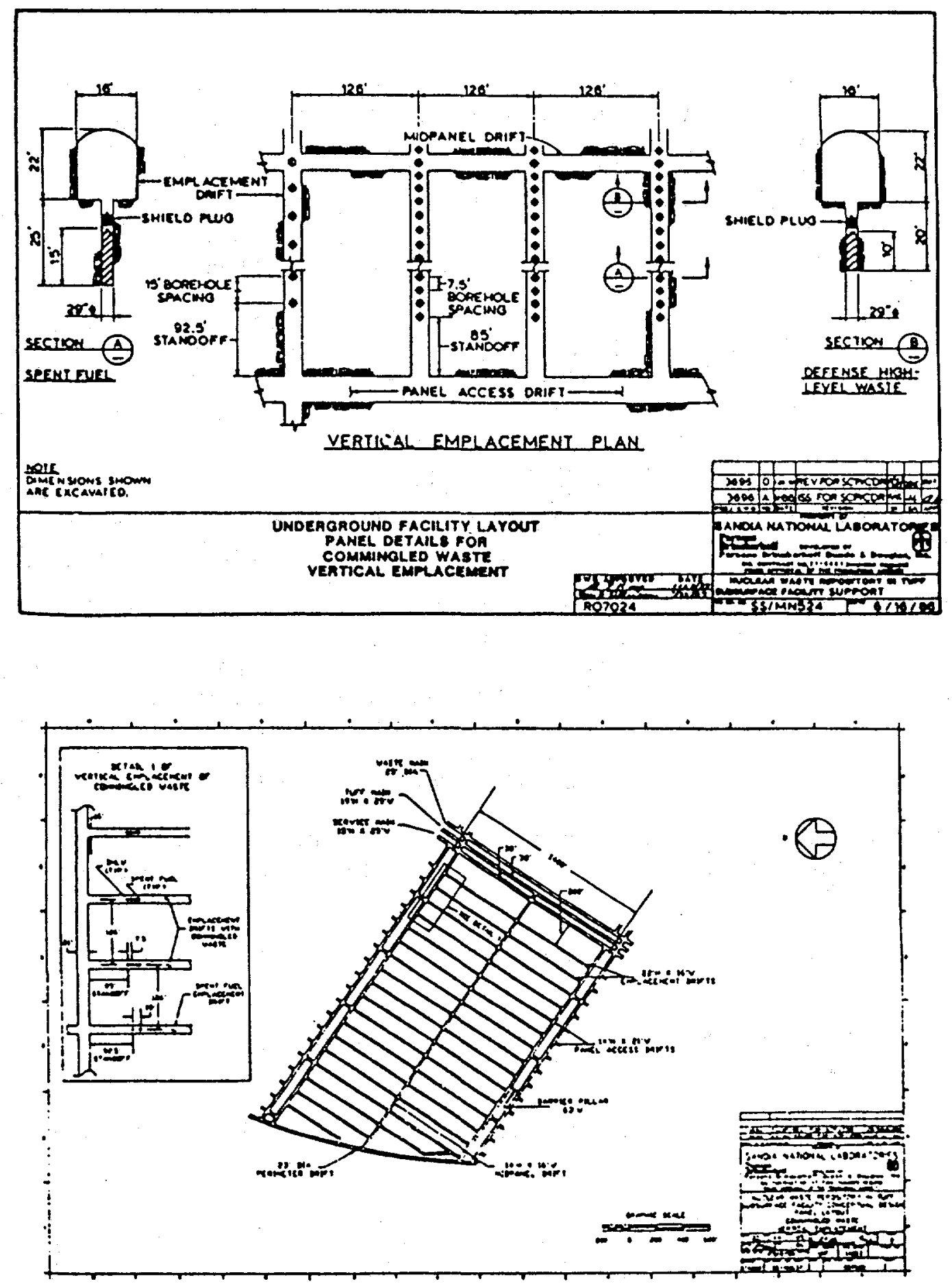

Fig. 2-3 Plan and Cross-Sectional Views of the Vertical Commingled SE and DHLW Emplacement Configuration [SCPCDR, Chapter 4, MacDougall et al., 1987] 

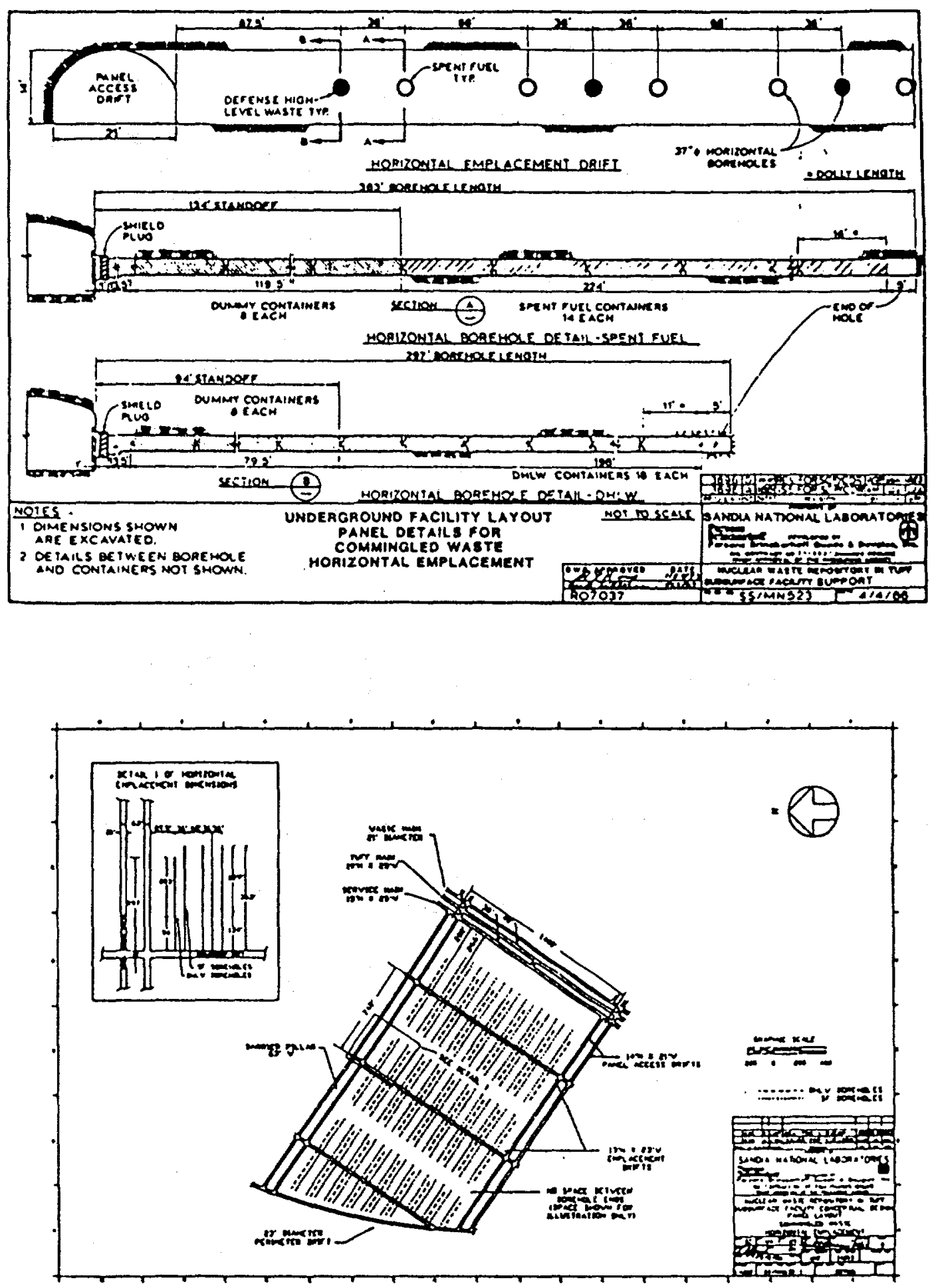

Fig. 2-4 Plan and Cross-Sectional Views of the Horizontal Commingled SE and DHLW Emplacement Configuration [MacDougall et al., 1987, Chapter 4] 


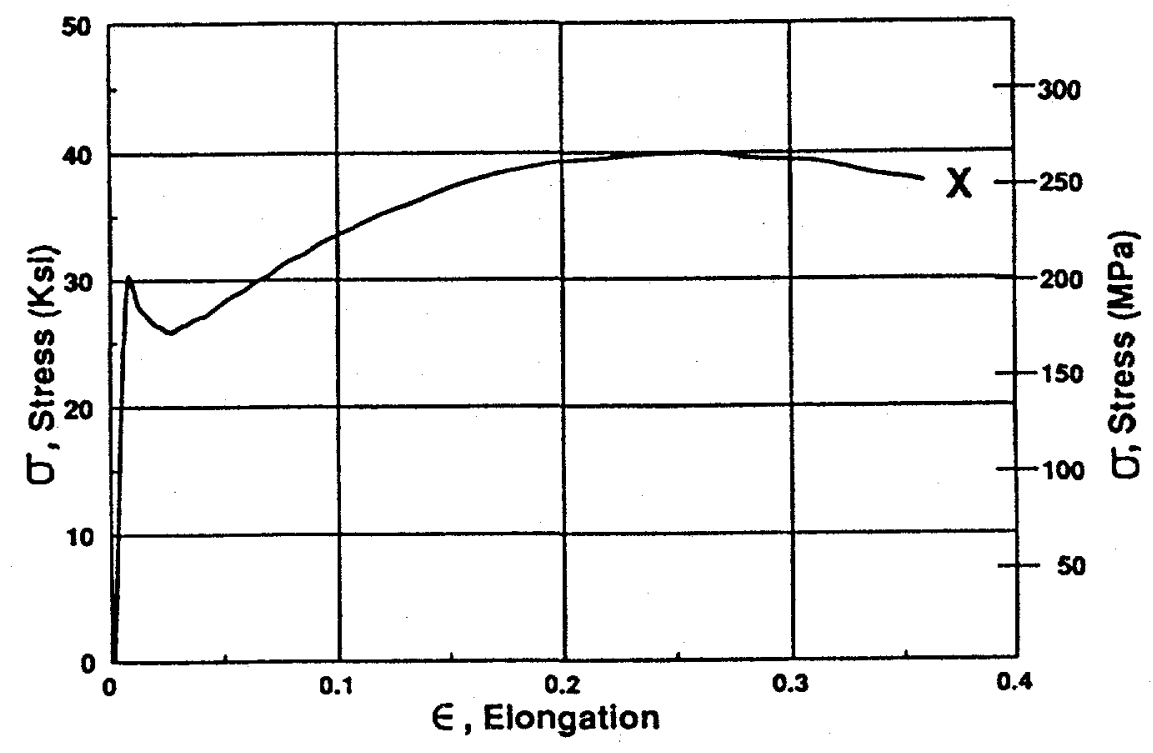

Fig. 2-5 Stress-Elongation Relation for Annealed Low Carbon Steel (The $X$ on the plot indicates the point of rupture.) [after Keyser, 1980]

\subsection{Design Considerations}

Design of borehole liners involves considerably more than specifying the liner radius, length, and thickness. However, as previously discussed, even these basic dimensions have not been selected yet. Some considerations which may be part of the liner design include:

(1) full or partial liner for the vertical emplacement option;

(2) Iiner material selection;

(3) backfilling/grouting behind the liner; and

(4) installation tolerances.

Each of these design considerations is discussed separately below. 


\subsubsection{Full or Partial Lining for the Vertical Emplacement Option}

The reference design for vertical emplacement in the SCP and SCPCDR shows only a partial liner extending from the emplacement drift floor to the top of the waste container. Flores (1986) indicates that in one design being considered, no liner is used, and the hole in simply backfilled with crushed tuff. Full lining for vertical emplacement boreholes may also be necessary (see, for example, p. 8.3.4.2-27 of the SCP), depending on the stability of the boreholes.

\subsubsection{Liner Material Selection}

The liner material must be selected to satisfy structural requirements as well as being compatible with the environment in which it is emplaced. The SCP gives the following two design goals for the borehole liner (see SCP, page 8.3.4.2-31):

(1) The corrosion rate of the borehole liner by uniform corrosion will be within a factor of 2 of that for the container material.

(2) The borehole liner shall be a member of the same alloy family as the container material (i.e., if the container material is an austenitic stainless steel, then the liner will also be an austenitic stainless steel).

Appendix $B$ of the SCPCDR assumes a corrosion rate on the order of 2 mpy (mills per year) for a low carbon steel liner. At issue here is the required amount of "superficial" material needed to service the 84 year expected lifetime. Sealing of the liner had also been suggested (Flores, 1986) to inhibit corrosion. The role of stress in enhancing corrosion is apparently not discussed in the SCPCDR or supporting documents.

\subsubsection{Backfilling/Grouting Behind Liner}

Various enhancements to improve the structural performance of the liner have been suggested. Flores (1986) mention a preliminary study indicating that grouting the liner is possible. According to Flores (1986), grouting could serve to improve resistance to corrosion and increase structural support but that there are potentially undesirable aspects associated with grouting which is detrimental to many materials over the long term. 


\subsubsection{Installation Tolerance}

Neither the SCP or the SCPCDR or supporting documents discuss the tolerance required to install borehole liners. Appendix $B$ of the SCPCDR assumes the following:

$$
\begin{aligned}
& \text { Borehole diameter }=37.0 \mathrm{in} . \\
& \text { Liner diameter }=36.0 \mathrm{in} . \\
& \text { Liner thickness }=0.5 \mathrm{in} .
\end{aligned}
$$

Depending on how the liner diameter is defined, the installation tolerance could range from zero to 0.5 inches. As will be discussed later, the installation tolerance could be significant in determining the liner loading for cases where the borehole converges and contacts the lining. 


\subsection{ANALYSIS APPROACH}

The analysis is divided into two parts. In the first part, the thermomechanical behavior of the rock immediately surrounding the emplacement borehole is studied using the distinct element numerical method. In the second part the mechanical behavior of the borehole liner is studied using analytic expressions.

As noted earlier, behavior of emplacement borehole linings is important:

(1) during construction;

(2) following waste emplacement but prior to closure when the retrieval option must be maintained; and

(3) for the 1,000 year period following closure when "substantially complete" containment is required.

The design of the borehole liner and waste packages require assessment of possible loads resulting from displacement of rock surrounding the emplacement borehole.

Emplacement borehole thermomechanical analysis for either the vertical or horizontal emplacement option is similar. Loading of the liner and/or waste package could result from either failure of the intact rock or by movement on discontinuities. Discontinuities in the rock mass divide the rock into individual blocks which may slide or separate relative to each other.

The analyses presented here consider the following three possible modes of behavior for rock surrounding an emplacement borehole.

Continuum Model - In this case the rock mass surrounding an emplacement borehole is treated as an equivalent continuum using rock mass properties. Discontinuities are not explicitly considered [see Fig. 3-1(a)].

Wedge Model - In this case wedges with $90^{\circ}$ apex angles are present at the borehole crown, invert, and springline [see Fig. 3-1(b)].

Parallel Joint Model - In this case parallel joints with $0.1 \mathrm{~m}$ spacing are present around the borehole [see Fig. 3-1(c)]. 


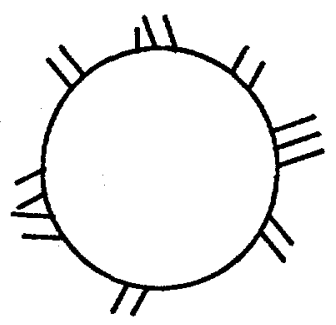

(a) continuum model

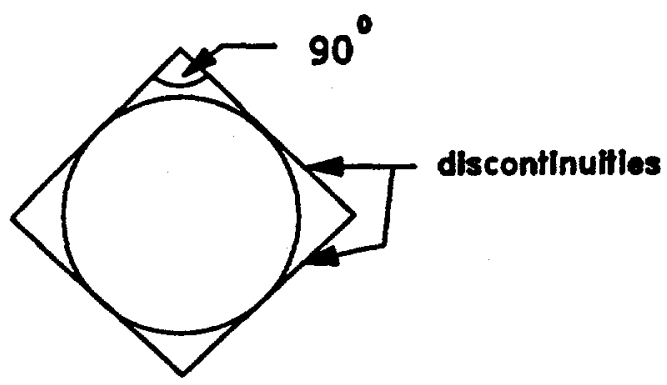

(b) wedge model

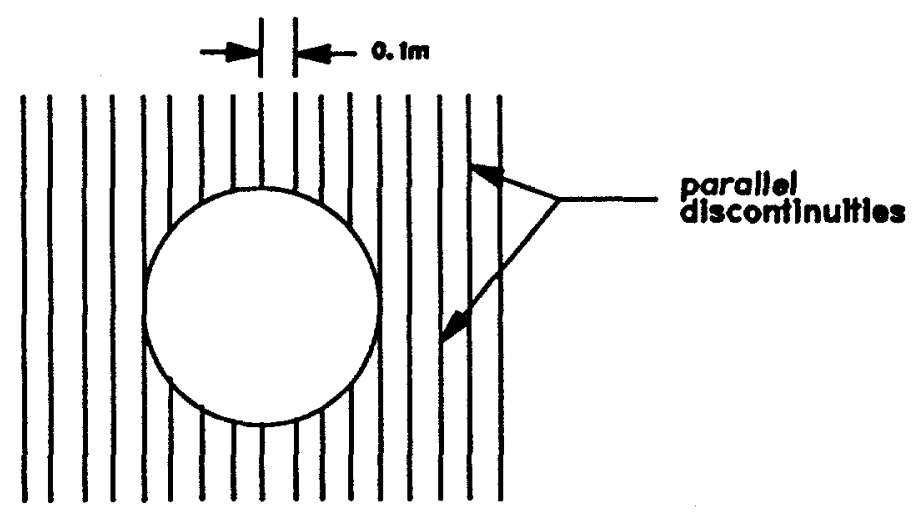

(c) parallel joint model

Fig. 3-1 Problem Configurations for Analysis of Emplacement Borehole Behavior 
The concept of a ground reaction curve is used to quantify the mechanical behavior of the borehole periphery. The concept of a ground reaction curve is frequently used to describe the behavior of tunnel closure resulting from insitu stresses subject to varying amounts of internal pressure. In this study, it is assumed that borehole closure used to compute ground reaction curves results only from heating of the rock mass. The ground reaction curve is obtained by supplying different internal pressure to the borehole periphery and computing the amount of radial displacement at several points on the borehole periphery. Note that different points in the borehole periphery may have different ground reaction curves. Nevertheless, the concept of a ground reaction curve provides a convenient method for evaluating the mechanical effect of any air gaps between the borehole liner and the rock. It should be noted that the air gap at any time must take into account the thermal expansion of the liner.

The liner loading is evaluated by graphical intersection of the ground reaction curve and the liner reaction curve as shown in Fig. 3-2. The ground reaction curve must be determined numerically for problems involving non-linear material behavior, whereas the liner curve is derived from standard analytic solutions for the circular ring, as shown below. As shown in Fig. 32 , the ground reaction curve may consist of a linear (elastic) part at high internal pressures, and a non-linear part at low internal pressures. At equilibrium, the borehole liner (external) pressure equals the borehole (internal) pressure. The liner external pressure can then be used as input to analytic expressions to determine axial stresses, bending stresses, etc., in the borehole liner.

The preceding procedure requires that the liner support reaction curve or stiffness be known. The stiffness of an emplacement liner can be assumed to be that of a hollow cylinder of the thickness $t$ and external radius a. For a thick wall cylinder in plane strain the expression for the stiffness is:

$$
\mathrm{K}_{S S}=\frac{\mathrm{P}_{i}}{\mathrm{u}_{\mathrm{a}}}=\frac{\mathrm{E}(2 \mathrm{a}-\mathrm{t}) t}{(1+v) \mathrm{a}\left[(1-2 v) \mathrm{a}^{2}+(a-t)^{2}\right]}
$$




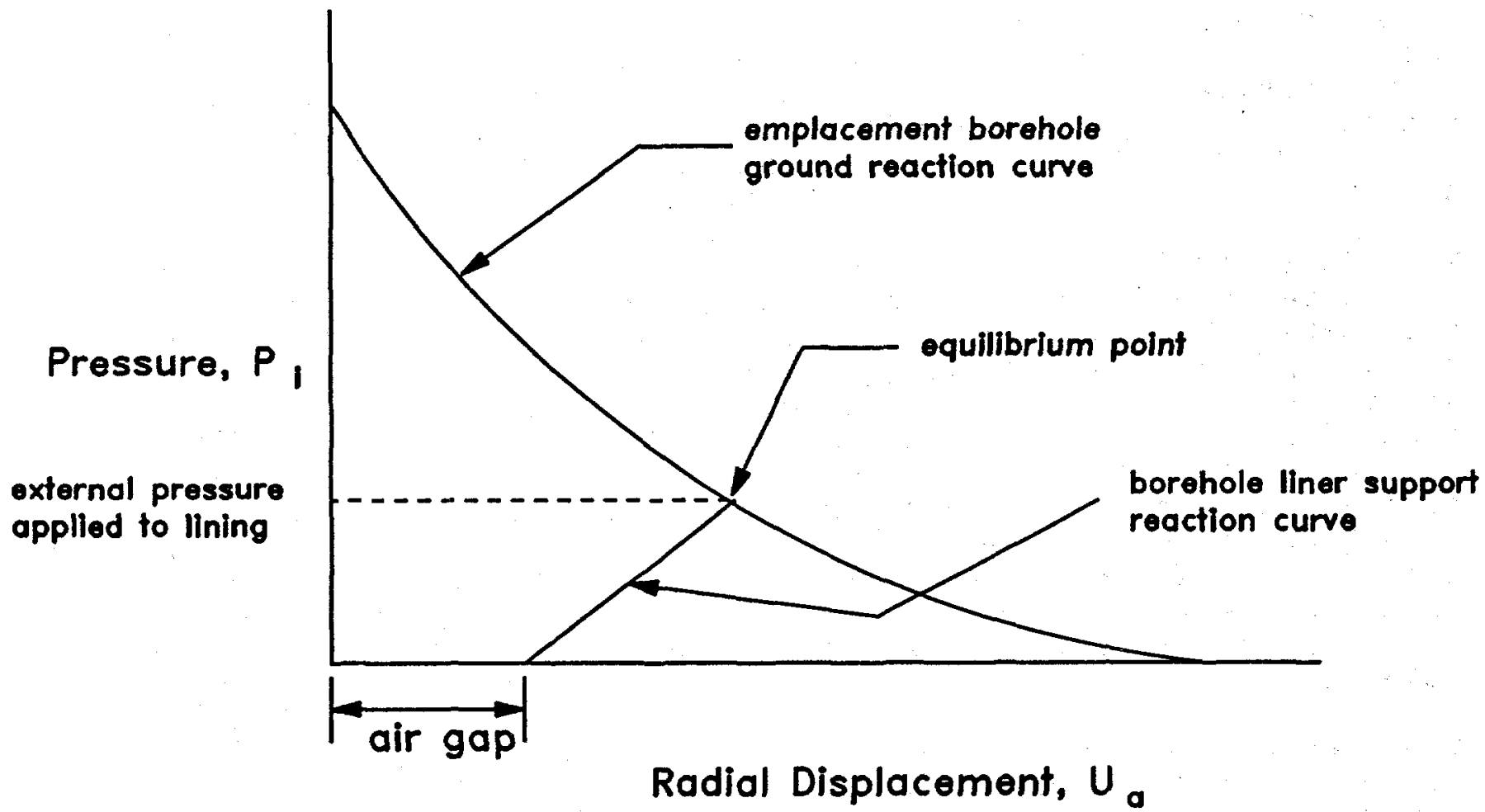

Fig. 3-2 Determination of Liner Loading Based on the Concept of Ground Reaction Curve 
For a thin wall cylinder ( $\leq 0.04 a$ ) this can be reduced to:

$$
K_{S S}=\frac{E t}{a^{2}}
$$

where $E$ is the elastic modulus of the borehole liner, and

$v$ is the Poisson's ratio.

3.1 Numerical Analysis

\subsubsection{Assumptions and Idealizations}

The emplacement borehole being modelled is assumed to be in the center of a waste emplacement panel consisting of continuous parallel holes for spent fuel emplacement. The holes are assumed to be infinite in length and spaced $20.7 \mathrm{~m}$ center to center. This spacing corresponds to the spacing between adjacent spent fuel also shown in Fig. 2-4. By ignoring the presence of Defense High Level Waste, assuming that all boreholes are spaced $20.7 \mathrm{~m}$ apart and assuming that all waste is emplaced instantaneously in the panel, symmetry can be imposed to reduce computation time. Board (1988) showed that explicit consideration of the Defense High Level Waste in a horizontal commingled array does not significantly affect the temperatures near spent fuel boreholes. Assuming that all waste is emplaced instantaneously results in higher predicted temperatures throughout the rock than if sequential waste emplacement is performed. This is because instantaneous waste emplacement imposes an adiabatic boundary condition mid-way between two emplacement holes, thereby reducing the volume of rock which is being heated.

The analyses neglect any affects of discontinuities on the thermal conductivity of the rock mass. Based on the results of the G-Tunnel Heated Block Test (Zimmerman et al., 1986) and other tests involving thermal conductivity of rock masses, this assumption appears reasonable. The analyses ignore the effects of fluid (i.e., air and water) convection in the rock mass and emplacement borehole. The analyses also ignore affects of boiling of pore water, which could effect heat transfer rates. 
The welded tuff at the proposed repository horizon is expected to be about $80 \%$ saturated (SCPCDR, Chapter 2). Therefore, when the rock temperature reaches approximately $100^{\circ} \mathrm{C}$, the pore water can be expected to boil (assuming atmospheric pressure). If pore water boiling is not included in the analysis, the predicted rock temperature will be conservative because the energy that would have been expended in the phase change (liquid to vapor) is available to elevate rock temperatures instead.

The thermal properties used assume fully saturated conditions. Board (1988) showed that using saturated properties resulted in borehole wall temperatures slightly (less than 10\%) lower than temperatures predicted using dry properties.

A linear stiffness Mohr-Coulomb joint model is used for all analyses involving explicit representation of joints. While more complex models exist, such as the continuously yielding model (Cundall and Lemos, 1988) and the Barton Bandis Model (Barton, 1982), the fundamental effects are similar to the simple MohrCoulomb model.

\section{1 .2 Numerical Model}

The computer code UDEC [Universal Distinct Element Code (Itasca, 1989)] was used to simulate the thermomechanical response of the rock. The UDEC model considers a two-dimensional section of an emplacement borehole perpendicular to the hole axis (i.e., plane strain conditions are assumed).

As discussed previously, three different conceptual behavior models are considered (i.e., continuum, wedge and parallel joint). The UDEC representation of each of these models is discussed separately below. All UDEC models have initial and boundary conditions as shown in Fig. 3.3. Each model is one quadrant of the hole and surrounding rock. The bottom and left boundaries shown in the figure are lines of symmetry. Each model is divided into a series of concentric "rings", with increasing spacing between "ring" cuts. In this way, the block zoning can be increased away from the hole. Because temperature and stress gradients are greatest near the hole, this zoning provides improved solution accuracy. The joints forming the rings are "glued" by setting the cohesion and tensile strength of the contacts to values much higher than the anticipated stresses. These "glued" joints are also assigned high stiffness parameters. Therefore, the presence of "glued" joints does not significantly affect overall mechanical behavior. 


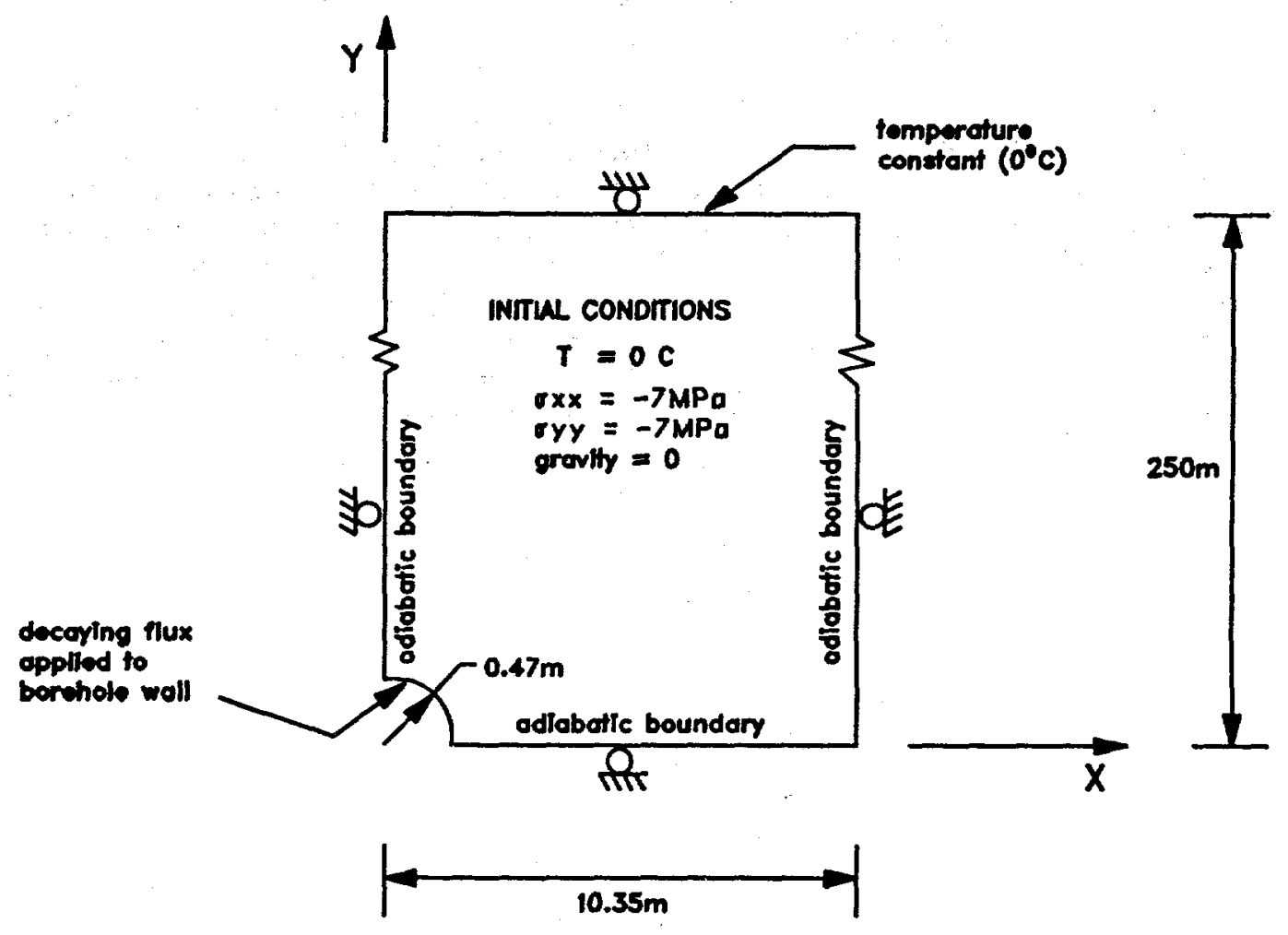

Fig. 3-3 Model Used to Study Emplacement Borehole Behavior (compression stresses assumed negative) 
The problem geometry for the continuum behavior model is shown in Fig. 3-4. In this model, behavior of the rock is assumed to be that of an isotropic material with a Mohr-Coulomb constitutive relation. The material parameters used are those of the rock mass. Joints are not explicitly modeled, but are generally assumed to be accounted for by the rock mass parameters.

The problem geometry for the wedge behavior is shown in Fig. 3-5. In this model, the rock mass parameters and a Mohr-Coulomb constitutive relation are used to describe the solid material. However, intersecting orthogonal joints are introduced around the borehole to study the behavior of rock blocks which potentially may detach and load the lining.

The problem geometry for the parallel joint model is shown in Fig. 3-6. In this model, vertical parallel joints introduced with 0.1 meter spacing are introduced in the emplacement borehole near field (within 2 meters of the borehole). On the emplacement borehole near field, intact rock properties are used for the rock between joints. The far field is represented by a continuum with rock mass properties. As shown in section 3.1.9, the parallel joint model may be the most realistic, given the mainly vertical jointing expected at repository depth at Yucca Mountain. 


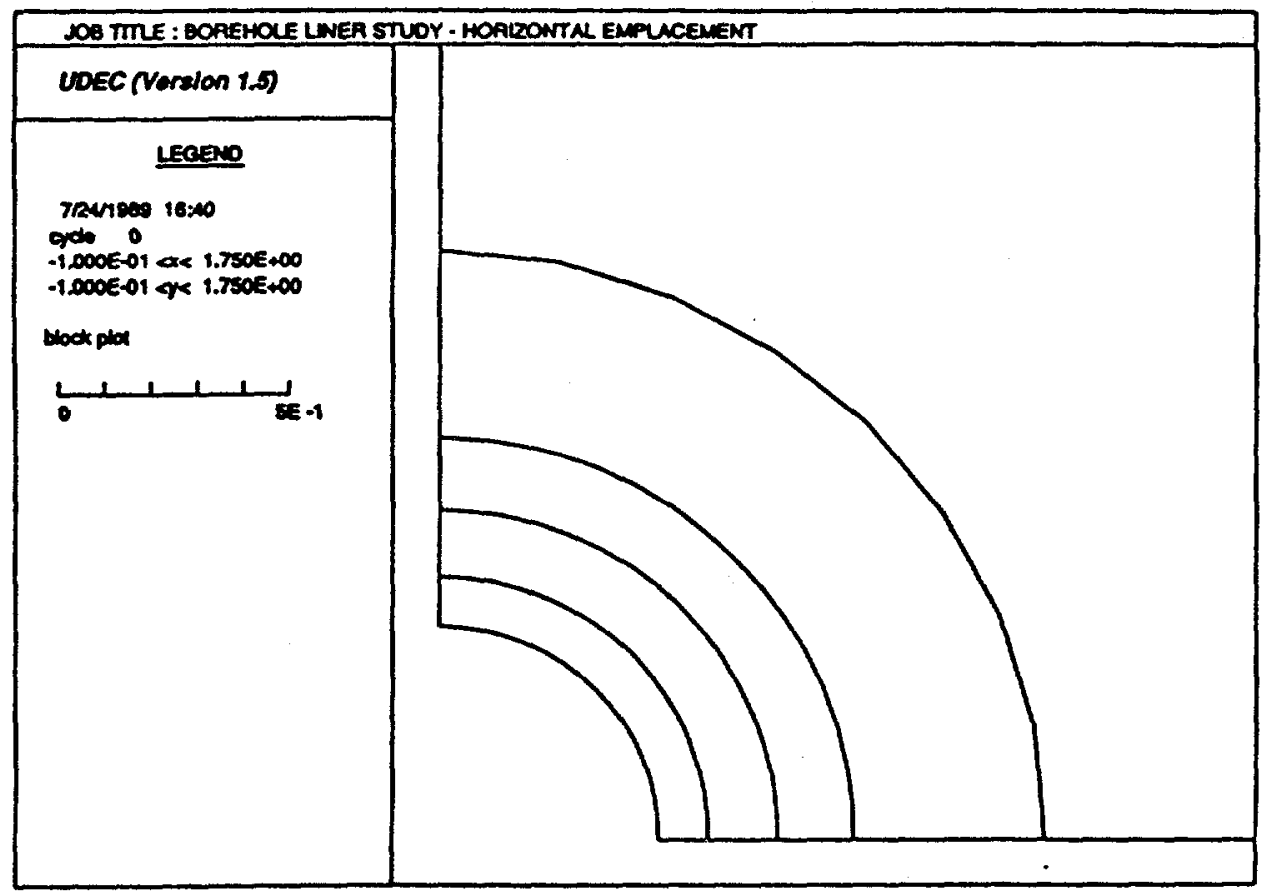

(a) location of "glued" joints used to improve discretization

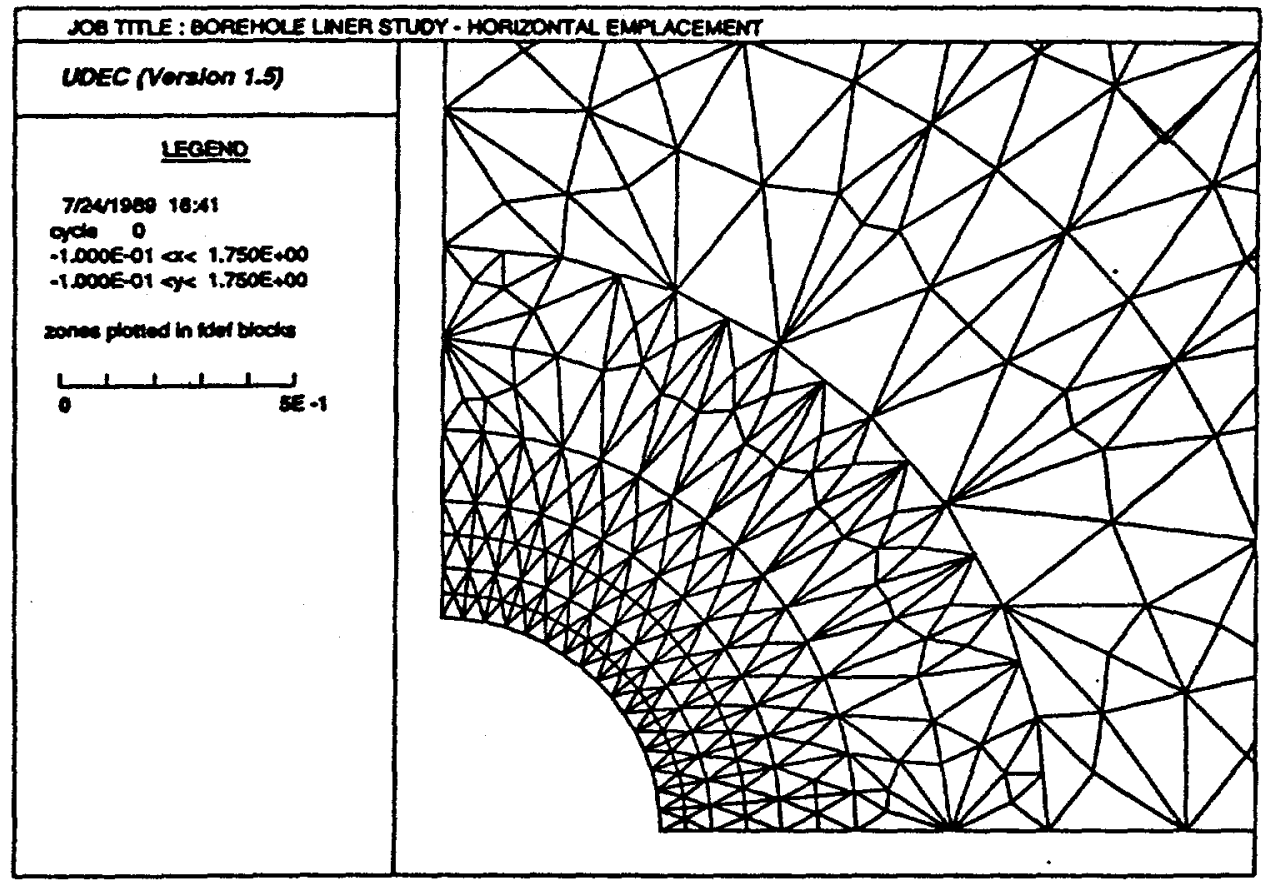

(b) discretization into finite difference zones

Eig. 3-4 Continuum Model - Emplacement Borehole Near-Field UDEC - Problem Geometry 


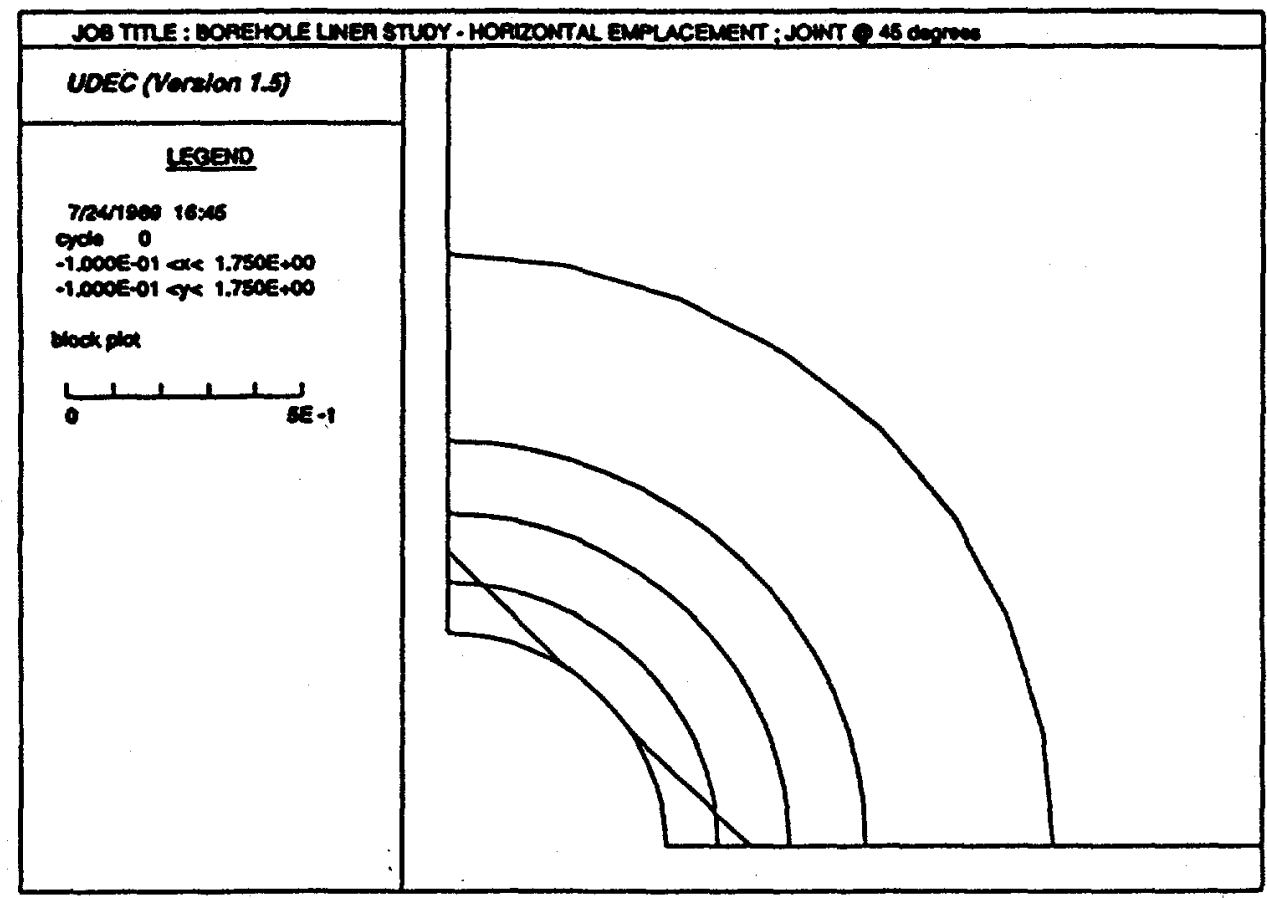

(a) location of "glued" joints and joints forming wedges

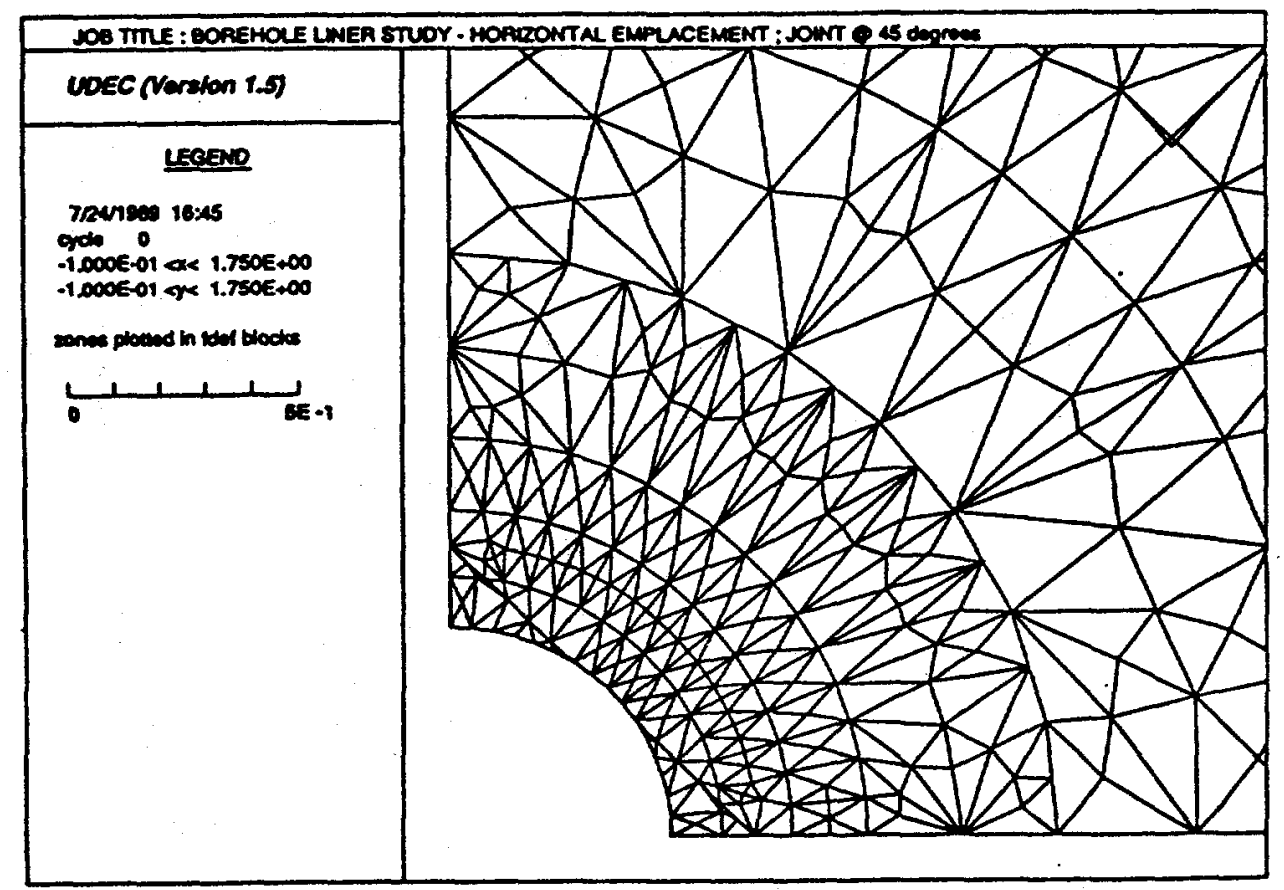

(b) discretization into finite difference zones

Fig. 3-5 Wedge Model - Emplacement Borehole Near-Eield UDEC - Problem Geometry 


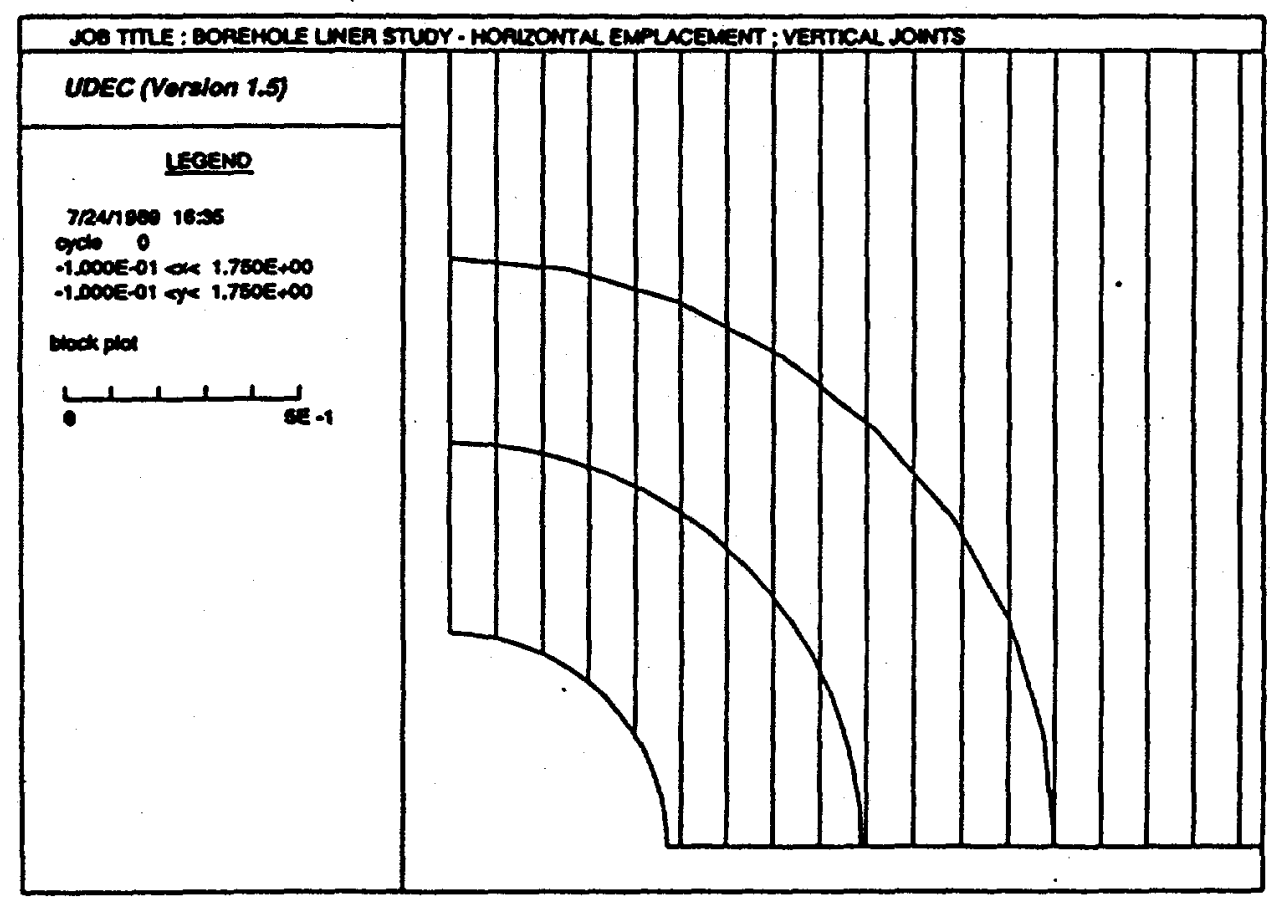

(a) location of "glued joints and parallel joints

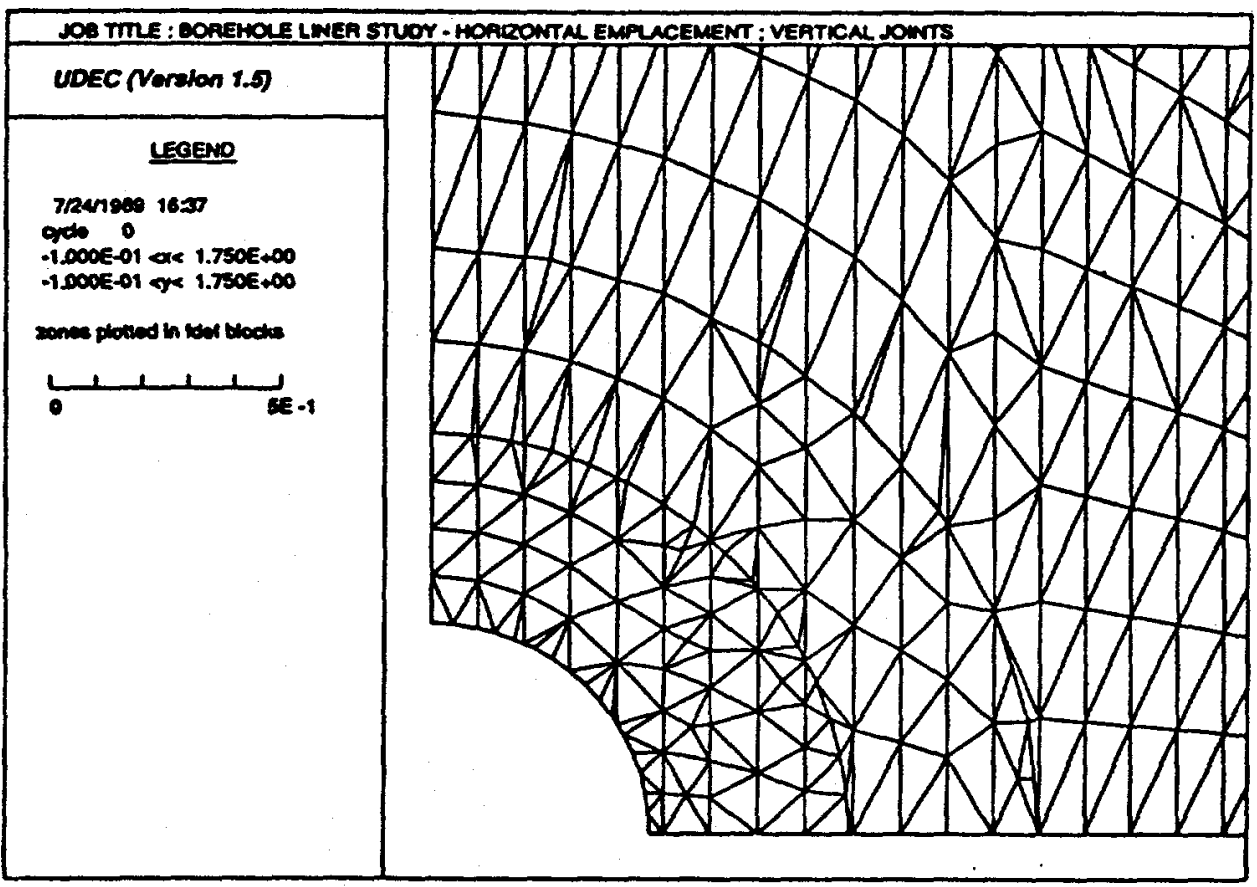

(b) discretization into finite difference zones

Fig. 3-6 Parallel Joint Model - Emplacement Borehole Near-Field UDEC Problem Geometry 


\subsubsection{Areal Power Density}

The Areal Power Density (APD), also called thermal loading (expressed in terms of $\mathrm{W} / \mathrm{m}^{2}$ or $\mathrm{kW} / \mathrm{acre}$ ), may vary depending on the geometric scale of the problem domain being considered. On a far-field scale, which includes the total repository area, the APD currently considered for design and performance assessment purposes is $14.1 \mathrm{~W} / \mathrm{m}^{2}(57 \mathrm{~kW} / \mathrm{acre}$ ) (Johnstone et al., 1984). On the scale of the problem domain considered in this work (i.e., one waste emplacement borehole), the APD is approximately 31.7 $\mathrm{W} / \mathrm{m}^{2}$ (128 $\mathrm{kW} /$ acre) for the layout consisting only of spent fuel. Because waste emplacement panel stand-off distances, Defense High Level Waste, etc., are not included in the present model, the APD is higher than for the far-field analysis.

\subsubsection{Waste Form Characteristics}

The initial power of a SF container at the time of emplacement may range from $2.3 \mathrm{~kW}$ to $3.4 \mathrm{~kW}$. In this study, the initial power was taken as $3.2 \mathrm{kw}$.

According to peters (1983), the normalized thermal decay characteristics of SF for waste ten years after removal from the reactor are described by the following expressions:

$$
\text { Spent Fuel } \quad \mathrm{P}(\mathrm{t})=0.54 \exp (\ln (0.5) t / 89.3)+
$$

where $\mathrm{P}(\mathrm{t})$ = normalized power, and

$$
t=\text { time in years. }
$$

Variation of the normalized power with time, as described by the above expression and as stated by Mansure (1985) for SF, is illustrated in Fig. 3-7. It is observed from the plots that the two approximations for heat output from spent fuel SF are similar. 


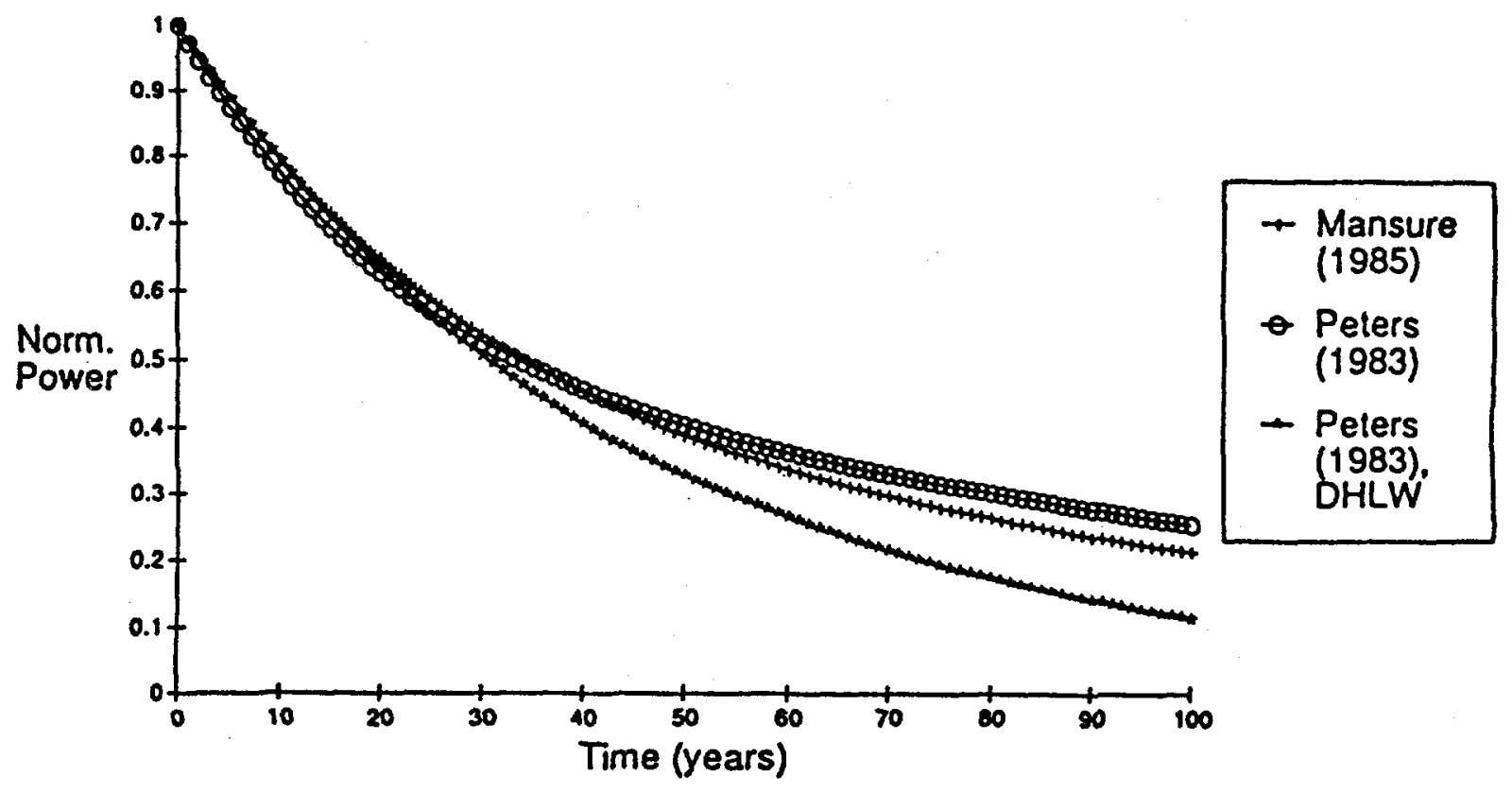

Fig. 3-7 Comparison of Normalized Power Decay Characteristics for Spent Fuel and Defense High-Level Waste 


\subsubsection{Rock Mass Thermal Properties}

The thermal properties used in the numerical studies in this work were the "recommended" values taken from Chapter 2 of the SCPCDR. They are specific to the rock at the repository horizon, designated as thermal/mechanical unit TSw2 in the SCPCDR, Chapter 2.

The values of the thermal properties used in the analyses are given in Table $3-1$.

Table 3-1

THERMAL PROPERTIES OF TSW2 TUFE

[MacDougall et al., 1987]

Property

Thermal Conductivity

Specific Heat Capacity

Coefficient of Thermal Expansion

Density $\left(\mathrm{kg} / \mathrm{m}^{3}\right)$
Value

2.29

931

8.8

2320

\subsubsection{Elastic Properties}

The rock elastic properties used in the numerical studies were the "recommended" values taken from Chapter 2 of the SCPCDR for unit TSw2. The values used in the mechanical analyses are given in Table $3-2$. 
Table 3-2

ELASTIC PROPERTIES OF TSW2 TUFF

[MacDougall et al., 1987]

$\begin{array}{lr}\text { Property } & \text { Value } \\ \text { Rock Mass Deformation Modulus (GPa) } & 15.2 \\ \text { Rock Mass Poisson's Ratio } & 0.22 \\ \text { Joint Normal Stiffness (GPa/m) } & 100 \\ \text { Joint Shear Stiffness (GPa/m) } & 100 \\ \text { Intact Rock Elastic Modulus (GPa) } & 30.4 \\ \text { Intact Rock Poisson's Ratio } & 0.22\end{array}$

\subsubsection{Strength Properties}

Considerable uncertainty exists concerning the strength parameters for welded tuff at repository depth. In order to evaluate various assumptions concerning strength parameters, three sets of values were used as reprinted in Chapter 2 of the SCPCDR. One set of parameters represent the "design" parameters. The "design" parameters are those on which the Conceptual Design is based. Another set of data are the "recommended" values, these values represent more current estimates for the properties. The third set of parameters are referred to here as the "limit" values. The "limit" values are the "recommended" values minus the "range". Table 3-3 summarizes the strength parameters used in this study.

In the present study, joints which fail in tension or shear have their cohesion strength component of joint shear strength reduced to zero in subsequent calculations. The friction angle is assumed constant throughout the analysis. 
Table 3-3

STRENGTH PROPERTIES OF TSW2 TUFE

[MacDougall et al., 1987]

\begin{tabular}{|c|c|c|c|}
\hline \multirow[b]{2}{*}{ Property } & \multicolumn{3}{|c|}{ Value } \\
\hline & "Design" & "Recommended" & "Limit" \\
\hline $\begin{array}{l}\text { Rock Mass Internal } \\
\text { Friction Angle }\end{array}$ & $29.2^{\circ}$ & $23.5^{\circ}$ & $15.9^{\circ}$ \\
\hline Rock Mass Cohesion (MPa) & 22.1 & 17.8 & 12.1 \\
\hline $\begin{array}{l}\text { Intact Rock Internal } \\
\text { Friction Angle }\end{array}$ & $29.2^{\circ}$ & $23.5^{\circ}$ & $15.9^{\circ}$ \\
\hline Intact Rock Cohesion & 50.0 & 34.0 & 22.6 \\
\hline $\begin{array}{l}\text { Intact Rock Tensile } \\
\text { Strength (MPa) }\end{array}$ & 16.9 & 19.2 & NA \\
\hline Joint Friction Angle & $38.7^{\circ}$ & $28.4^{\circ}$ & $11.3^{\circ}$ \\
\hline Joint Cohesion (MPa) & 1.0 & 0.1 & 0.0 \\
\hline
\end{tabular}

It is apparent from Table 3-3 that strength values may not be as high as initially thought. However, all of the data presented in the SCPCDR are based on very limited information. In order to give a better understanding of the strength values presently being used, reported test data for intact TSW2 material have been plotted in Fig. $3-8$.

Figure 3-8 shows the Mohr circle construction using data from Table 16 of Nimick and Schwartz (1987). Two tests with $5 \mathrm{MPa}$ confining pressure have been omitted. Superimposed on the plot are the Mohr-Coulomb failure envelopes for intact rock given in the SCPCDR. The upper envelope with $c=50 \mathrm{MPa}$ and $\phi=29.2 \mathrm{de}-$ grees corresponds to the "design" values for TSw2. The lower envelope represents "recommended" strength parameters. 
It should also be noted that the SCP reports the same "design" properties in Table 6-12. The SCP refers to the "recommended" values as "expected" values on p. 8.3.2.5-16.

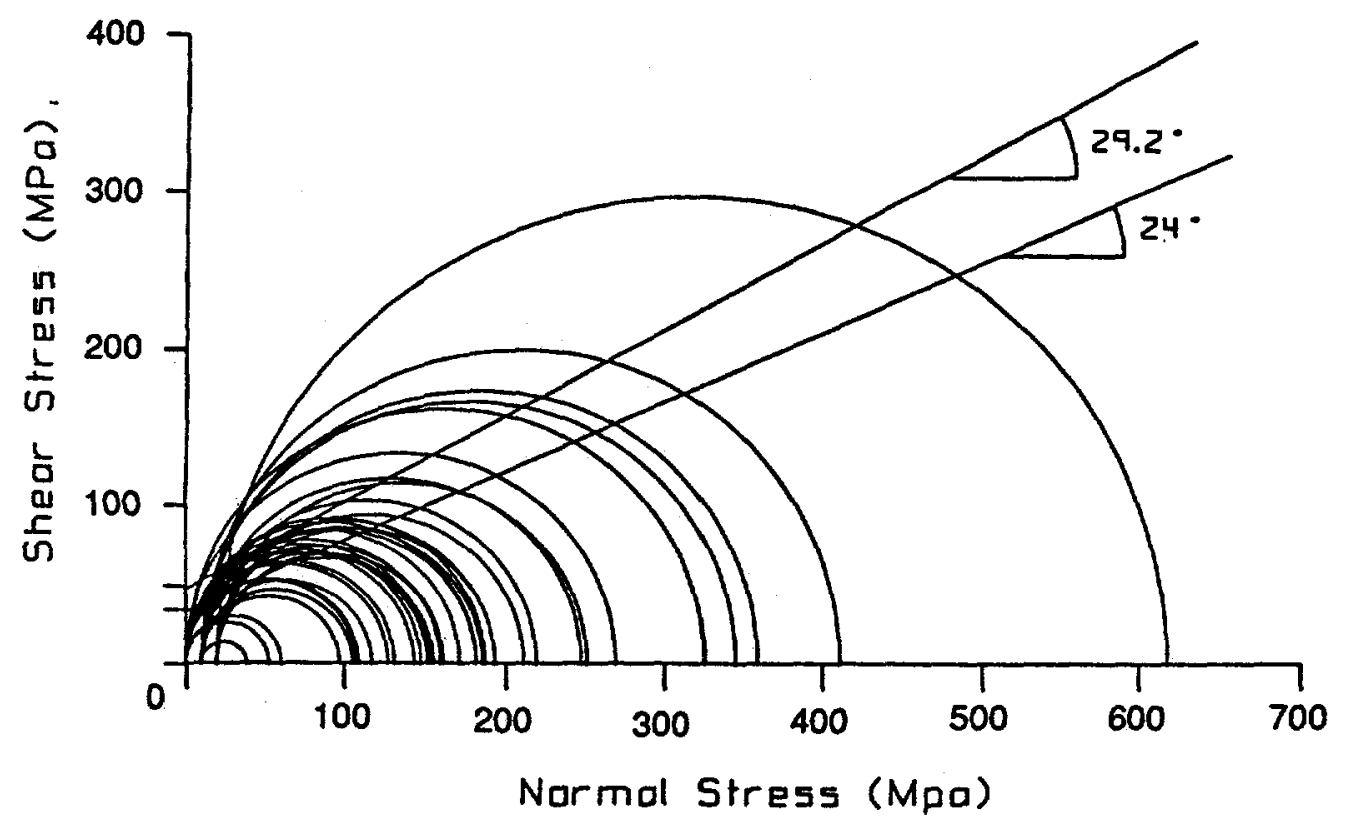

Fig. 3-8 Mechanical Construction for Intact TsW2 Tuff Based on Data in Nimick and Schwartz (1987) [Upper envelope represents SCPCDR "design" strength parameters. Lower envelope represents SCPCDR "recommended" strength parameters.] 


\subsubsection{In-Situ Conditions}

Parameters describing in-situ conditions at the Nevada Test Site which have been used for this study were obtained from Chapter 2 of the SCPCDR. The reported temperature range for the repository horizon is $23^{\circ} \mathrm{C}$ to $29^{\circ} \mathrm{C}$. An initial temperature of $0^{\circ} \mathrm{C}$ was assumed for this study. Therefore, temperatures reported as results are "induced" temperatures, to which initial temperatures must be added to obtain total temperatures. The reported in-situ stresses are presented in Table 3-4. In the current work, field principal stresses were assumed to be equal at $7 \mathrm{MPa}$. Although the field principal stresses are not likely to be equal, the induced thermal stresses will likely be much larger than the field stresses. Christianson and Brady (1989) showed the mechanical behavior around a horizontal borehole would not be significantly different if ratios of vertical-to horizontal in-situ stress of 1.0 or 3.0 were assumed. By ignoring the effect of gravity, a constant in-situ stress throughout the region could be modeled (i.e., initial stress gradient could be ignored). These assumptions are reasonably justified because only near-field behavior is considered in this study. The effect of gravity cannot be ignored when considering the loading of horizontal borehole liners by loosened blocks, as discussed later.

$$
\text { Table 3-4 }
$$

MEAN VALUES AND RANGES FOR FIELD PRINCIPAL STRESSES AT YUCCA MOUNTAIN

[MacDougall et al., 1987]

\begin{tabular}{|c|c|c|}
\hline Perameter & Ben value* & Ranse \\
\hline Vertical stress (MPa) & 7.0 & 5.0 to 10.0 \\
\hline $\begin{array}{l}\text { Ratio of Minimum } \\
\text { Horizontal Stress to } \\
\text { Vortical Stress }\end{array}$ & 0.5 & 0.3 to 0.8 \\
\hline $\begin{array}{l}\text { Retio of Haximum } \\
\text { Horlzontal stress to } \\
\text { Vertical stress }\end{array}$ & 0.6 & 0.3 to 1.0 \\
\hline $\begin{array}{l}\text { Boaring of Minimas } \\
\text { Horizontal stross }\end{array}$ & $457^{\circ} \mathrm{W}$ & $850^{\circ} \mathrm{H}$ to $865^{\circ} \mathrm{W}$ \\
\hline $\begin{array}{l}\text { Bearing of Kaximum } \\
\text { Horizontel strese }\end{array}$ & $\mathbf{4 3 2} \cdot \mathrm{E}$ & $\mathrm{N} 25^{\circ} \mathrm{E}$ to $\mathrm{N} 4 \mathrm{O}^{\circ} \mathrm{E}$ \\
\hline
\end{tabular}




\subsubsection{Natural Eracture Frequency}

Current knowledge of rock structure at the Yucca Mountain site is summarized in the SCPCDR. Table 3-5, obtained from the report, indicates the values for fracture frequency for joints of various orientations in the Tuff units at Yucca Mountain, recommended for design and performance assessment studies. The table indicates that the jointing for the TSw2 unit is mostly vertical. For three or more fractures to intersect an emplacement borehole, a fracture frequency greater than 1.0 is required. Using the values in Table 3-5 for the TSw2 unit, it is unlikely that joints of dip less than $70^{\circ}$ are frequent enough to consistently form potentially unstable blocks in horizontal boreholes. However, because Table 3-5 is generated from only four exploratory boreholes, implying that the data base is rather limited, joint angles of $90^{\circ}$ and $45^{\circ}$ have been considered in the analyses. In order for the joints to form blocks which could potentially slip into borehole, it would require at least two (and more likely, three) intersections of that joint set with the excavation in addition to crosscutting joints of another orientation. 
Table 3-5

RECOMMENDED VALUES FOR FRACTURE FREQUENCY IN THERMAL/MECHANICAL
UNITS AT YUCCA MOUNTAIN
[MaCDougall et al., 1987]

\begin{tabular}{|c|c|c|c|c|c|c|c|c|c|c|c|c|c|c|c|c|c|c|}
\hline \multirow{2}{*}{$\begin{array}{l}\text { moromll } \\
\text { mochenleel } \\
\text { Unlte } \\
\end{array}$} & \multicolumn{18}{|c|}{ 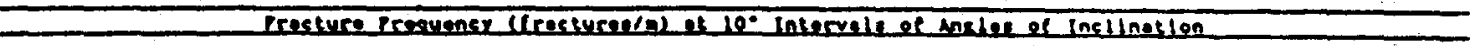 } \\
\hline & \multicolumn{2}{|c|}{$0 \cdot-10^{*}$} & \multicolumn{2}{|c|}{$10^{\circ}-20^{*}$} & \multicolumn{2}{|c|}{$20^{\circ}-30^{\circ}$} & \multicolumn{2}{|c|}{$30 \cdot-40^{\circ}$} & \multicolumn{2}{|c|}{$40^{\circ}-50^{\circ}$} & \multicolumn{2}{|c|}{$30^{\circ}-60^{\circ}$} & \multicolumn{2}{|c|}{$60 \cdot-10^{\circ}$} & \multicolumn{2}{|c|}{$30 \cdot-80 *$} & \multicolumn{2}{|c|}{$10 \div-10^{\circ}$} \\
\hline 4 & $0.40^{\circ}$ & $\begin{array}{l}0.90^{8} \\
0.05^{5}\end{array}$ & 0.80 & $\begin{array}{l}1.90 \\
0.09\end{array}$ & 0.50 & $\begin{array}{l}1.00 \\
0.05\end{array}$ & 0.30 & $\begin{array}{l}1.00 \\
0.05\end{array}$ & 0.10 & $\begin{array}{l}0.60 \\
0.10\end{array}$ & 0.50 & $\begin{array}{l}0.90 \\
0.20\end{array}$ & 1.20 & $\begin{array}{l}1.00 \\
0.10\end{array}$ & 2.1 & $\begin{array}{l}2.00 \\
1.20\end{array}$ & 15.1 & $\begin{array}{r}20.0 \\
1.8\end{array}$ \\
\hline$n$ & 0.20 & $m^{n}$ & 0.30 & $\mathbf{m}$ & 0.20 & $m$ & 0.10 & $m$ & 0.20 & $\begin{array}{l}w_{\boldsymbol{n}} \\
\boldsymbol{u}\end{array}$ & 0.10 & $\begin{array}{l}\mathbf{y} \\
\mathbf{y}\end{array}$ & 0.40 & $\begin{array}{l}\mathrm{wa} \\
\mathrm{u}\end{array}$ & 0.3 & $m_{k}$ & 2.8 & $\mathbf{m}$ \\
\hline $2^{4,1}$ & 0.20 & $\begin{array}{l}0.50 \\
0.05\end{array}$ & 0.20 & $\begin{array}{l}0.10 \\
0.05\end{array}$ & 0.20 & $\begin{array}{l}0.60 \\
0.05\end{array}$ & 0.10 & $\begin{array}{l}0.30 \\
0.05\end{array}$ & 0.20 & $\begin{array}{l}0.10 \\
0.05\end{array}$ & 0.20 & $\begin{array}{l}0.50 \\
0.05\end{array}$ & 0.30 & $\begin{array}{l}0.10 \\
0.10\end{array}$ & 2.8 & $\begin{array}{l}2.10 \\
0.70\end{array}$ & 23.2 & $\begin{array}{r}22.5 \\
2.5\end{array}$ \\
\hline$=2^{4,1}$ & .20 & $\begin{array}{l}0.50 \\
0.05\end{array}$ & 0.20 & $\begin{array}{l}0.10 \\
0.05\end{array}$ & 0.20 & $\begin{array}{l}0.60 \\
0.05\end{array}$ & 9.10 & $\begin{array}{l}0.30 \\
0.05\end{array}$ & 0.20 & $\begin{array}{l}0.10 \\
0.05\end{array}$ & 0.20 & $\begin{array}{l}0.50 \\
0.05\end{array}$ & 0.30 & $\begin{array}{l}0.10 \\
0.10\end{array}$ & 1.2 & $\begin{array}{l}2.60 \\
0.70\end{array}$ & 23.2 & $\begin{array}{r}32.5 \\
2.5\end{array}$ \\
\hline 1 & 20 & $\begin{array}{l}0.50 \\
0.05\end{array}$ & .20 & $\begin{array}{l}0.10 \\
0.05\end{array}$ & .20 & $\begin{array}{l}0.60 \\
0.03\end{array}$ & .10 & $\begin{array}{l}0.30 \\
0.05\end{array}$ & .20 & $\begin{array}{l}0.10 \\
0.05\end{array}$ & .20 & $\begin{array}{l}0.50 \\
0.05\end{array}$ & 0.30 & $\begin{array}{l}0.10 \\
0.10\end{array}$ & 1.8 & $\begin{array}{l}2.10 \\
0.10\end{array}$ & 13.2 & $\begin{array}{r}32.5 \\
2.5\end{array}$ \\
\hline niv & .0s & $\begin{array}{l}0.05 \\
0.05\end{array}$ & 0.05 & $\begin{array}{l}0.05 \\
0.05\end{array}$ & .05 & $\begin{array}{l}0.05 \\
0.05\end{array}$ & .05 & $\begin{array}{l}0.05 \\
0.05\end{array}$ & .05 & $\begin{array}{l}0.05 \\
0.05\end{array}$ & .05 & $\begin{array}{l}0.05 \\
0.05\end{array}$ & 0.00 & $\begin{array}{l}0.09 \\
0.05\end{array}$ & 0.3 & $\begin{array}{l}1.50 \\
0.05\end{array}$ & 0.1 & $\begin{array}{l}1.2 \\
0.2\end{array}$ \\
\hline 12: & .05 & $\begin{array}{l}0.05 \\
0.05\end{array}$ & 0.05 & $\begin{array}{l}0.05 \\
0.05\end{array}$ & 0.05 & $\begin{array}{l}0.05 \\
0.05\end{array}$ & .03 & $\begin{array}{l}0.05 \\
0.05\end{array}$ & .05 & $\begin{array}{l}0.05 \\
0.05\end{array}$ & .05 & $\begin{array}{l}0.05 \\
0.05\end{array}$ & 0.08 & $\begin{array}{l}0.09 \\
0.05\end{array}$ & 0.5 & $\begin{array}{l}1.30 \\
0.05\end{array}$ &. & $\begin{array}{l}1.2 \\
0.1\end{array}$ \\
\hline 4 & 05 & $\begin{array}{l}0.05 \\
0.05\end{array}$ & 0.05 & $\begin{array}{l}0.05 \\
0.05\end{array}$ & 0.05 & $\begin{array}{l}0.05 \\
0.05\end{array}$ & .05 & $\begin{array}{l}0.05 \\
0.05\end{array}$ & os & $\begin{array}{l}0.05 \\
0.05\end{array}$ & .03 & $\begin{array}{l}0.05 \\
0.05\end{array}$ & 0.08 & $\begin{array}{l}0.08 \\
0.05\end{array}$ & 0.5 & $\begin{array}{l}1.50 \\
0.05\end{array}$ & 0.1 & $\begin{array}{l}1.2 \\
0.1\end{array}$ \\
\hline$m s^{*}$ & OS & $\begin{array}{l}0.05 \\
0.05\end{array}$ & .05 & $\begin{array}{l}0.05 \\
0.05\end{array}$ & 03 & $\begin{array}{l}0.05 \\
0.05\end{array}$ & .05 & $\begin{array}{l}0.05 \\
0.05\end{array}$ & .05 & $\begin{array}{l}0.05 \\
0.05\end{array}$ & 1.05 & $\begin{array}{l}0.05 \\
0.05\end{array}$ & 0.01 & $\begin{array}{l}0.09 \\
0.05\end{array}$ & 0.5 & $\begin{array}{l}1.50 \\
0.05\end{array}$ & 0.1 & $\begin{array}{l}1.2 \\
0.1\end{array}$ \\
\hline & 05 & $\begin{array}{l}0.05 \\
0.05\end{array}$ & 10 & $\begin{array}{l}0.20 \\
0.03\end{array}$ & .08 & $\begin{array}{l}0.10 \\
0.05\end{array}$ & 10 & $\begin{array}{l}0.20 \\
0.05\end{array}$ & of & $\begin{array}{l}0.10 \\
0.05\end{array}$ & 10 & $\begin{array}{l}0.20 \\
0.05\end{array}$ & 0.30 & $\begin{array}{l}0.50 \\
0.05\end{array}$ & .6 & $\begin{array}{l}0.10 \\
0.30\end{array}$ & 1.0 & $\begin{array}{l}1.8 \\
0.2\end{array}$ \\
\hline Un & .05 & 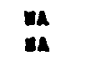 & 0.05 & $w a$ & 0.03 & $m$ & 0.05 & $\begin{array}{l}\mathbf{u} \\
\boldsymbol{u}\end{array}$ & 0.05 & $m a$ & 0.05 & $\begin{array}{l}u \\
u A\end{array}$ & 0.10 & $m$ & 0.1 & $\boldsymbol{m}_{\boldsymbol{m}}$ & 0.4 & $m$ \\
\hline 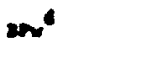 & .05 & $\begin{array}{l}0.05 \\
0.05\end{array}$ & 0.03 & $\begin{array}{l}0.05 \\
0.05\end{array}$ & 0.05 & $\begin{array}{l}0.05 \\
0.05\end{array}$ & 0.05 & $\begin{array}{l}0.06 \\
0.05\end{array}$ & 0.20 & $\begin{array}{l}0.10 \\
0.05\end{array}$ & 0.30 & $\begin{array}{l}0.50 \\
0.05\end{array}$ & 0.60 & $\begin{array}{l}1.30 \\
0.05\end{array}$ & 1.4 & $\begin{array}{l}3.20 \\
0.10\end{array}$ & 6.3 & $\begin{array}{r}12.4 \\
0.2\end{array}$ \\
\hline $\mathrm{ml}$ & .05 & $\mathbf{u}$ & .05 & m & 0.05 & u & .05 & $\stackrel{m}{a}$ & 0.05 & wa & 0.50 & $w$ & 0.05 & $m$ & 0.1 & wh & 0.4 & $m$ \\
\hline$m x$ & 0.05 & $\begin{array}{l}\boldsymbol{u} \\
\boldsymbol{u}\end{array}$ & 0.05 & $m$ & 0.05 & $\boldsymbol{u}$ & 0.05 & $\mu$ & 0.05 & $w$ & 0.50 & $m$ & .05 & $\begin{array}{l}\mathbf{m} \\
\mathbf{m}\end{array}$ & 0.1 & $m$ & 0.4 & ma \\
\hline נוח & 0.05 & $m$ & 0.05 & $w$ & 0.05 & $m A$ & 0.05 & $\frac{u}{u}$ & 0.05 & $m$ & 0.30 & wh & 0.05 & $m$ & 0.1 & $\underset{m a}{\mathbf{m a}}$ & 0.4 & $m$ \\
\hline & 0.07 & $\begin{array}{l}0.09 \\
0.05\end{array}$ & 0.06 & $\begin{array}{l}0.08 \\
0.05\end{array}$ & 0.05 & $\begin{array}{l}0.06 \\
0.05\end{array}$ & 0.05 & $\begin{array}{l}0.05 \\
0.05\end{array}$ & 0.05 & $\begin{array}{l}0.05 \\
0.05\end{array}$ & 0.03 & $\begin{array}{l}0.05 \\
0.05\end{array}$ & 0.30 & $\begin{array}{l}0.50 \\
0.05\end{array}$ & 0.2 & $\begin{array}{l}0.20 \\
0.20\end{array}$ & 3.7 & 1.0 \\
\hline
\end{tabular}

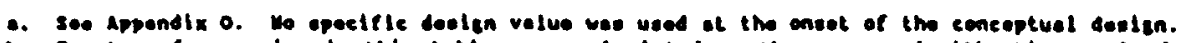

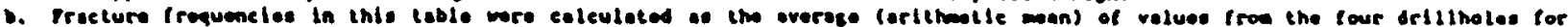

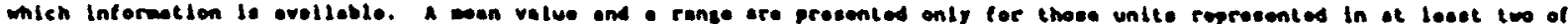

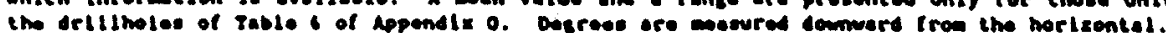

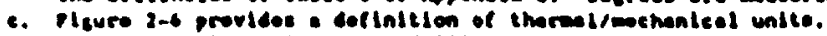

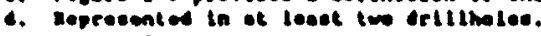

a Man volue.

1. Upper beund.

1. Lower tound.

h. Ma--not evelloblo.

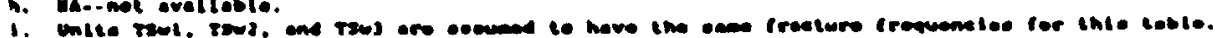




\subsection{Analytical Method Used for Liner Stress Analysis}

\subsubsection{Analysis of Circular Borehole Liner}

The stress analysis of the circular borehole liner by analytical method is presented here. Two loading cases are considered: uniform radial pressure on top of the liner and uniform base reaction; and (2) concentrated load on top and uniform base reaction. Analytical solutions for various ring loadings are given by Roark and Young (1975). The appropriate loading configuration is obtained by combining the desired loading cases based on the concept of superposition.

\subsubsection{Load Combinations}

Load Case 1: Uniform radial pressure on top and bottom of the liner is obtained by combining three load types, as shown in Fig. 3-9. Figure 3-9(a) shows the concentrated load applied on top and bottom corresponding to load type number 1 in Table 17 of Roark and Young (1975). Figures $3-9(b)$ and (c) correspond to load type number 12 in the same table.

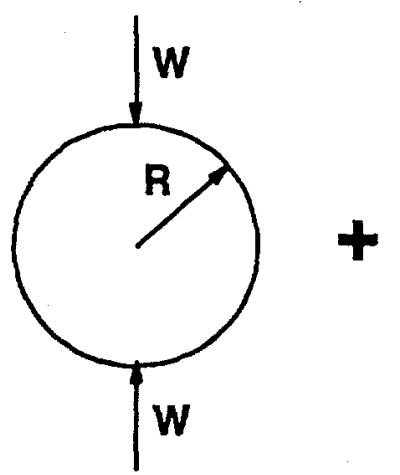

a) Load Type \#1 Concentrated load top and bottom

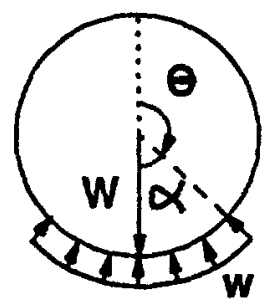

b) Load Type \#12 Uniform base reaction
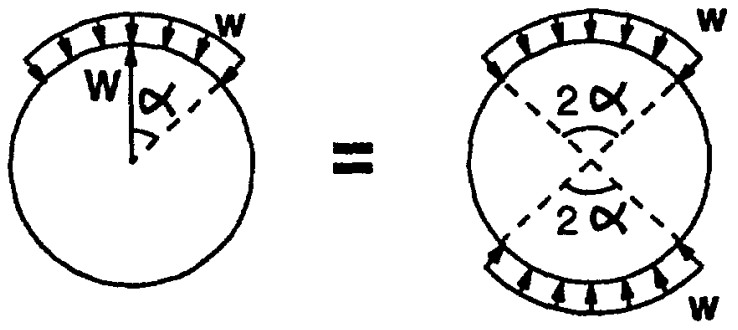

c) Load Type \#12 (Inverted) d) Combined load

Fig. 3-9 Combination of Load Types to Obtain Uniform Pressure on Top and Uniform Base Reaction - Load Case 1 
Load Case 2: Concentrated load on top and uniform base reaction is obtained by combining load types 1 and 12 , as shown in Fig. 3-10.

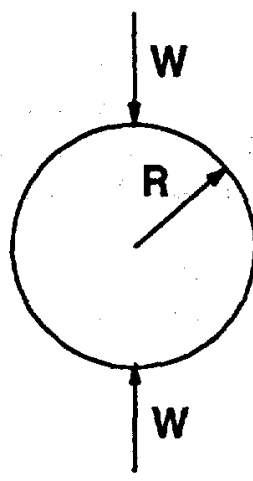

a) Load Type \#1 Concentrated load top and bottom
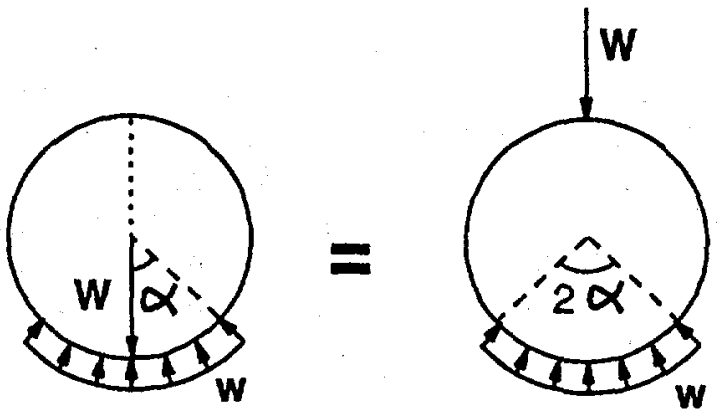

b) Load Type \#12 Uniform base reaction

Fig. 3-10 Combination of Load Types to Obtain Concentrated Load on Top and Uniform Base Reaction

\subsubsection{Analytical Solution}

The general formulas for moment, axial thrust and radial shear at any position at an angle $x$ (shown in Fig. 3-11) are given by Roark and Young (1975):

$$
\begin{aligned}
& M_{X}=M_{A}-T_{A} R(1-u)+V_{A} R z+L T_{M} \\
& T_{X}=T_{A} u+V_{A} z+L T_{T} \\
& V_{X}=-T_{A} z+V_{A} u+L T_{V}
\end{aligned}
$$

where for load type number $1, M_{A}=W R / \pi$,

$$
\begin{aligned}
& T_{A}=0, \\
& v_{A}=0,
\end{aligned}
$$




$$
\begin{aligned}
& \mathrm{LT}_{\mathrm{M}}=-\mathrm{WRz} / 2, \\
& \mathrm{LT}_{\mathrm{T}}=-\mathrm{Wz} / 2, \\
& \mathrm{~L} \mathrm{~T}_{\mathrm{V}}=-\mathrm{Wu} / 2 \text { and }
\end{aligned}
$$

and for load type number 2,

$$
\begin{aligned}
& M_{A}=-w^{2}[1 / \pi(\theta+2 s-\theta c)-1+c], \\
& \mathrm{T}_{\mathrm{A}}=-\mathrm{WR}[1 / \pi(s-\theta c)+c] \text {, } \\
& \mathrm{v}_{\mathrm{A}}=0, \\
& L T_{M}=-w^{2}[1-\cos (x-\theta)]<x-\theta>0, \\
& L T_{T}=-w R[1-\cos (x-\theta)]\langle x-\theta\rangle^{0} \text { and } \\
& \left.L T_{V}=-w R \sin (x-\theta)<x-\theta\right\rangle^{0}, \\
& \text { where } \theta=\pi-\alpha \text {, } \\
& z=\sin x, \\
& \mathrm{u}=\cos \mathrm{x}, \\
& c=\cos \theta \text {, } \\
& s=\sin \theta \text {, and } \\
& \langle x-\theta\rangle^{0}=1 \text {, if } x>\theta \\
& =0 \text {, if } x<\theta \text {. }
\end{aligned}
$$

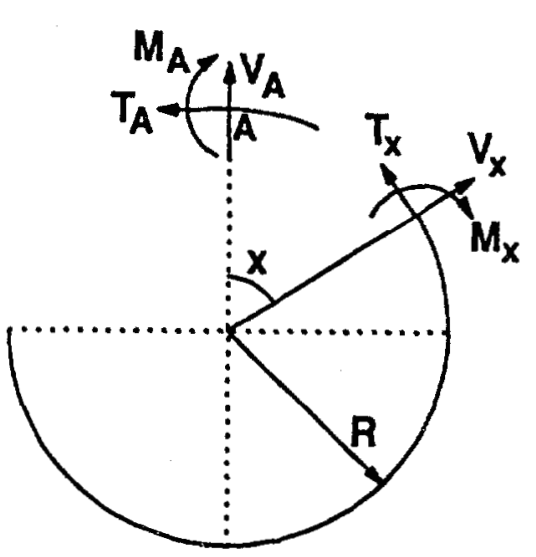

Fig. 3-11 Internal Axial Force, Shear Force, and Moment at $A$ and $X$ 
4.0 RESULTS

4.1 Results of Numerical Modeling

4.1.1 Borehole Mechanical Response at Time of Excavations

Predicted borehole closures (i.e., inward radial displacement) for each of the three models and for the three strength assumptions discussed previously are shown in Table 4-1. It should be noted that the results shown in the Table and all subsequent results are presented in terms of radial closure or radial displacement. In all cases, the sense of displacement is inward, unless otherwise noted. In addition, closure refers to the displacement of the modeled periphery. Due to symmetry, it is assumed that identical radial displacements would occur in other quadrants. Minor differences between crown and springline stresses for the continuum and wedge models likely result from differences in discretization and boundary location.

$$
\text { Table 4-1 }
$$

MECHANICAL RESPONSE AT ZERO YEARS RADIAL INWARD DISPLACEMENT (mm)

Model $\begin{gathered}\text { Strength } \\ \text { Values }\end{gathered}$

Continuum

Wedge

Parallel

Discontinuity
Design

Recommended

Limit

Design

Recommended

Limit

Design

Recommended

Iimit
Springline

0.266

0.266

0.266

0.685

0.647

0.629

0.456

0.522

0.683 $\underline{\theta}=45^{\circ}$

0.267

0.267

0.267

0.407

0.407

0.407

0.270

0.326

0.517
Crown

0.268

0.268

0.268

0.687

0.648

0.629

0.151

0.171

0.286 
In all continuum cases, the mechanical results at time $=0 \mathrm{yr}$. indicate mainly elastic behavior. The analytic expression for radial displacement of a cylindrical hole in a uniformly stressed linear elastic medium is given as

$$
\mathrm{U}_{r}=\frac{\mathrm{Pa}}{2 \mathrm{G}}
$$

where $U_{r}=$ radial displacement of hole periphery,

$$
\begin{aligned}
& P=\text { in-situ stress, } \\
& a=\text { hole radius, and } \\
& G=\text { shear modulus. }
\end{aligned}
$$

For the continuum model, with $\mathrm{G}=6.23 \mathrm{GPa}, \mathrm{a}=0.17 \mathrm{~m}$ and $\mathrm{P}=7$ $\mathrm{MPa}$ a displacement of $2.64 \mathrm{e}-4 \mathrm{~m}$ is predicted. The UDEC results were $2.67 e^{-4} \mathrm{~m}$, or a difference of less than 18 compared to the analytic expression. These results indicate that the "glued" joints, problem discretization, etc., were chosen reasonably. The displacement field for the continuum model at $t=0$ years is shown in Fig. $4-1$.

It is interesting to note, that in the case of the wedge model, the greatest displacements occurred for the case of the "design" properties. The likely reason for this is that in the case of the "design" properties, the rock mass and particularly the wedge itself had higher strength values than the other strength assumptions. For all strength assumptions, the shear strength of the discontinuity bounding the wedge is exceeded. Therefore, the larger displacements occur for the more rigid wedges, which in this case are the "design" properties.

Figure 4-2 shows the displacement field surrounding the emplacement borehole at zero years for the "design" strength values. The figure indicates that the joints forming the wedge "fail" and that the wedges move essentially as rigid blocks toward the excavation. 


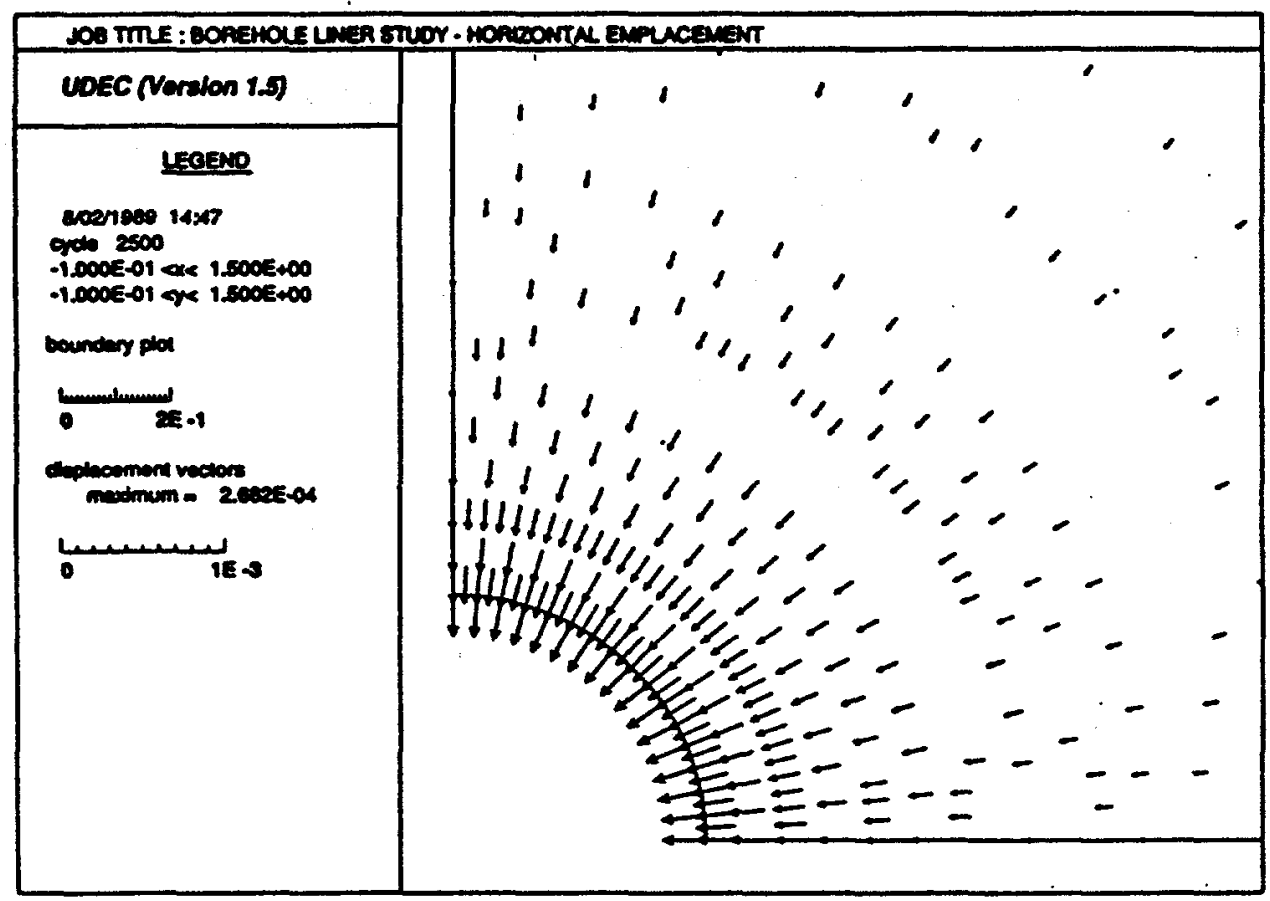

Fig. 4-1 Excavation Induced Displacements for Continuum Model and All Strength Assumptions

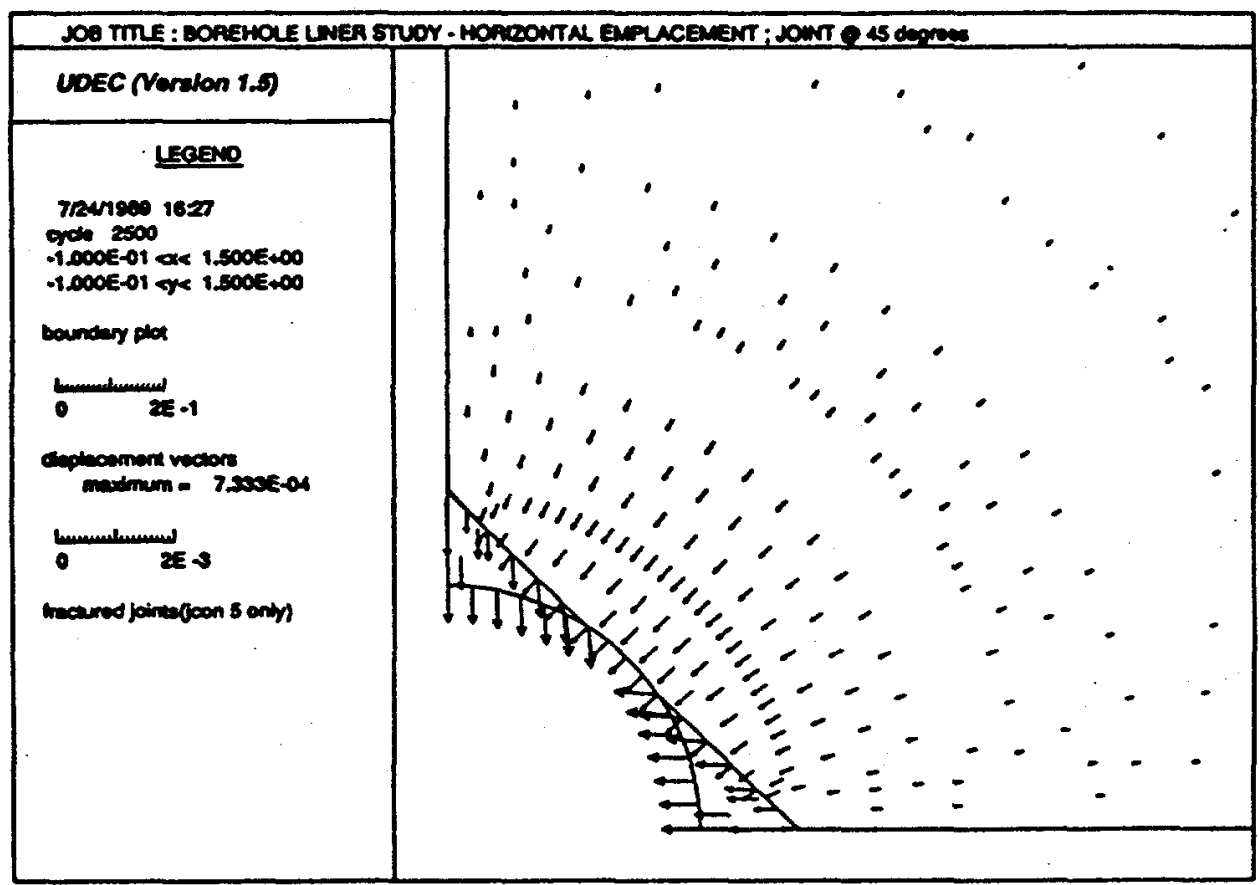

Fig. 4-2 Excavation Induced Displacements for Wedge Model and "Design" Strength Values 
Figures $4-3(a)$ through $4-3$ (c) show the extent of "failed" vertical joints for the parallel joint model for the various strength assumptions. The figures show increasing extent of "failed" joint with decreasing strength. The region of failed joints is similar to the region predicted by post-processing boundary element results (see Fig. 38(a) of Christianson and Brady, 1989).

The boundary element results were "post-processed" in the sense that the boundary element code was used to predict the liner elastic stress distribution. The resultant stress distribution was then evaluated based on postulated joint orientation (vertical in this case) and strength to determine the region where joint shear strength would be exceeded. The post-processing procedure does not, therefore, take explicit account of joint location or stress redistribution due to joint slip as done in UDEC. Nevertheless, the two procedures yield similar results. The displacement field for the parallel joint model with "recommended" design strengths is shown in Fig. 4-4. 


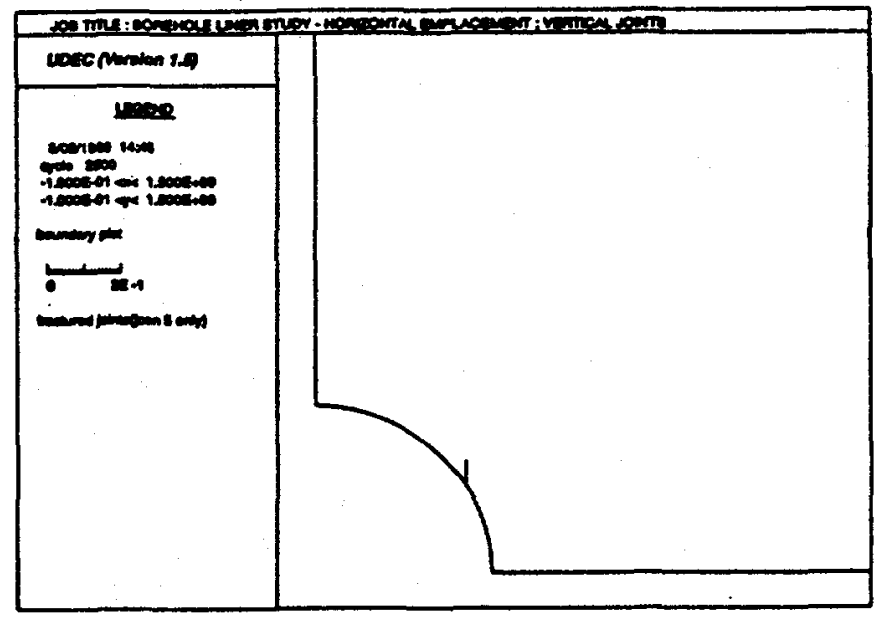

(a) "design" strength

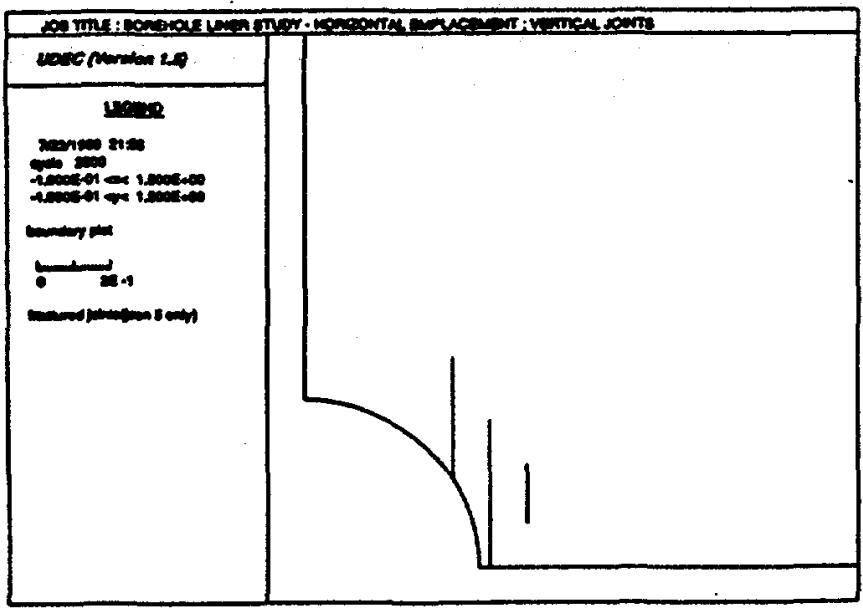

(b) "recommended" strength

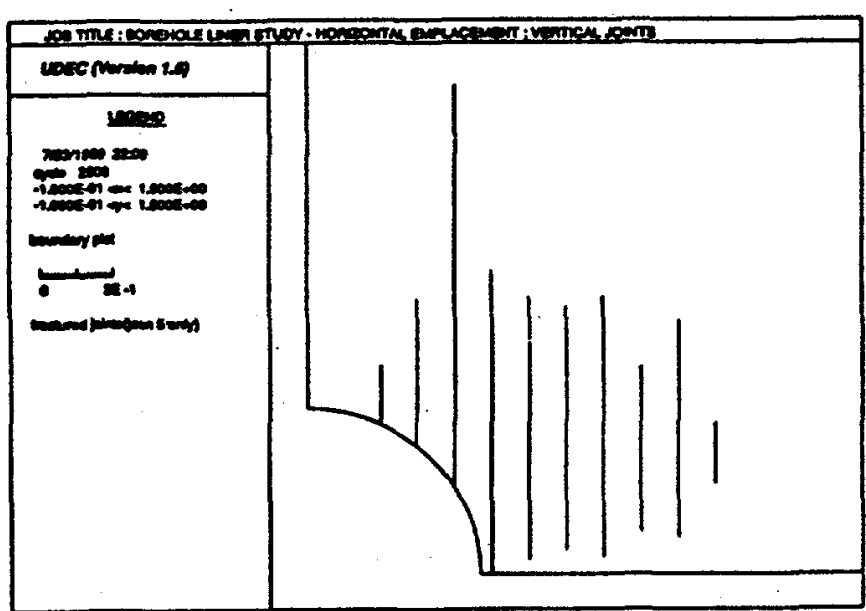

(c) "limit" strength

Fig. 4-3 Location of "Failed" Joints Induced by Borehole Excavation 


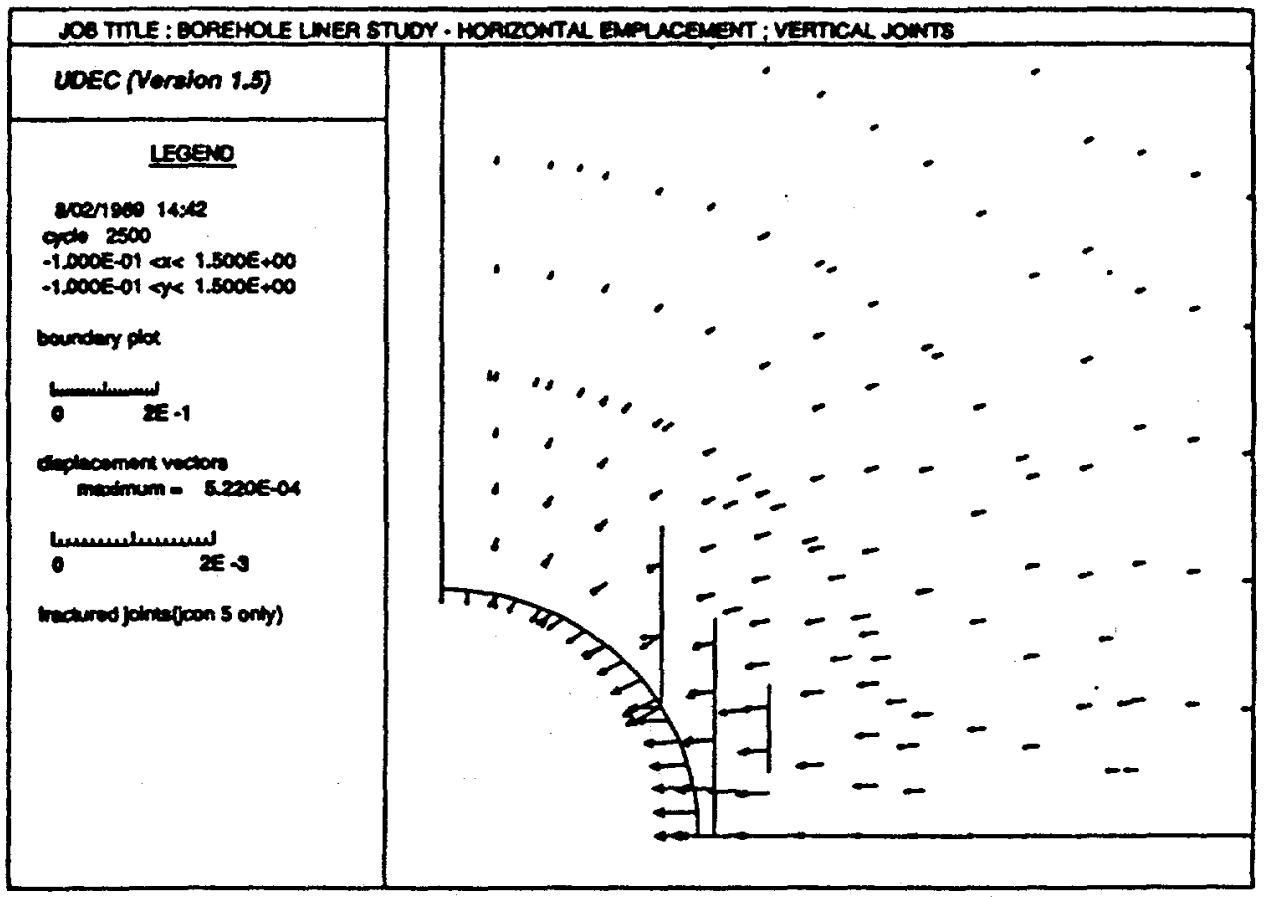

Fig. 4-4 Excavation Induced Displacements for Parallel Joint Continuity Model and "Recommended" Strength Values

\subsubsection{Thermal Results}

The calculated induced temperatures at the borehole wall and at a distance of $1.13 \mathrm{~m}$ from the borehole wall are shown in Fig. 4-5. If assumed initial temperatures of $23^{\circ} \mathrm{C}$ to $26^{\circ} \mathrm{C}$ are added to the temperature shown in Fig. 4-5, they would agree closely with those shown in Fig. 32 of Christianson and Brady (1989). Christianson and Brady used the program STRES3D* to model an entire waste emplacement panel. In STRES3D, each waste container is represented by one or more point heat sources, and the effects of the emplacement drifts are ignored. Christianson and Brady (1989) calculated a maximum borehole wall temperature of $226^{\circ} \mathrm{C}$ for the horizontal emplacement scheme. For a point $1 \mathrm{~m}$ distant from the hole wall, they calculated $196^{\circ} \mathrm{C}$. These temperatures satisfy the previously stated DOE design goals. It is noted that the borehole temperatures determined in this study and the study of Christianson and Brady (1989) are slightly different from

\footnotetext{
*STRES3D is a three-dimensional analytical thermoelastic program based on a superposition of point heat sources (St. John and Christianson, 1980).
} 


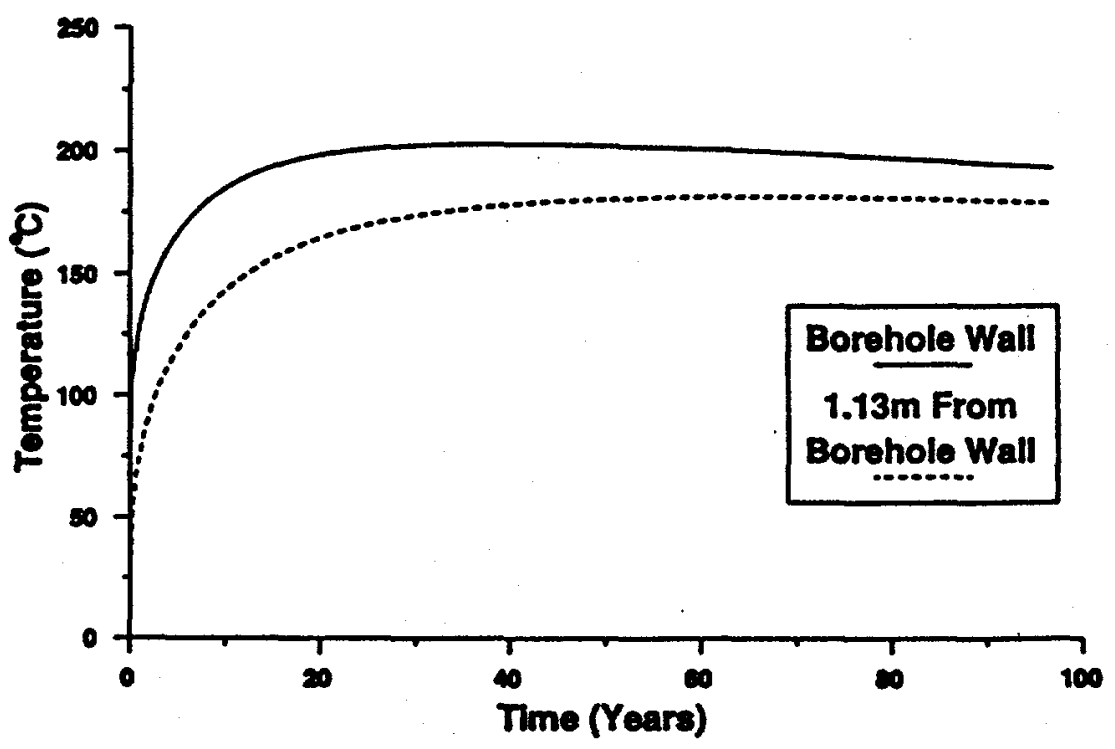

Fig. 4-5 Predicted Induced Borehole Wall Temperatures

those reported by Arulmoli and St. John (1987). The discrepancies can be explained by slightly different waste emplacement configurations and waste power and decay characteristics assumed in the various studies. The near field distribution of induced temperatures at $100 \mathrm{yr}$. are shown in Fig. 4-6.

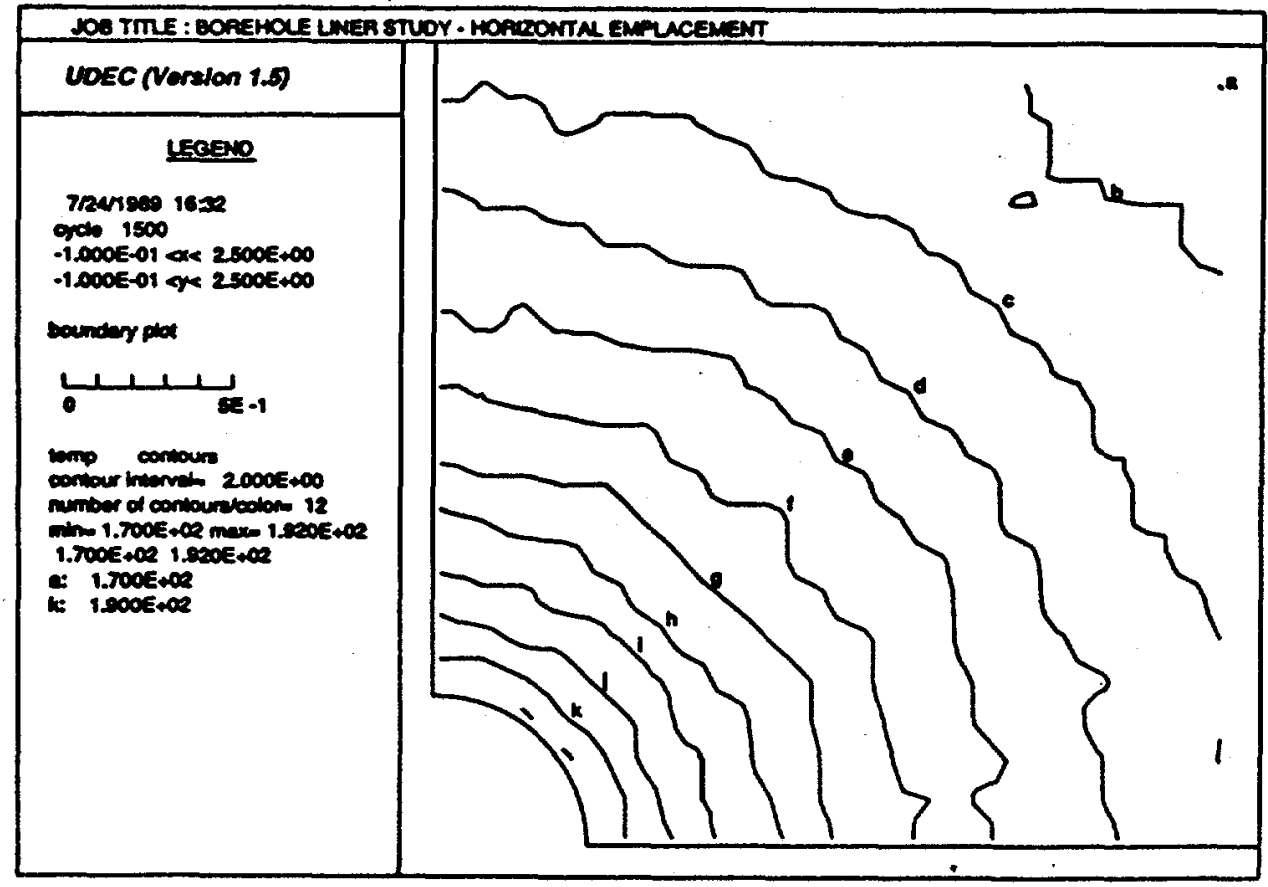

Fig. 4-6 Induced Temperature Distribution in the Vicinity of the Borehole at 100 Years 


\subsubsection{Borehole Mechanical Response at Time $=100$ Years}

Borehole heating and mechanical boundary conditions induce higher horizontal stresses compared to vertical stresses. For all models and strength assumptions this means greater closure at the springline (i.e., along the horizontal axis) compared to the crown. In fact, for many models, and strength assumptions, displacement at the crown (1.e., along the vertical axis) were outward.

The induced displacements for the continuum case assuming "recommended" strength values are shown in Fig. 4-7. The figure shows mainly inward horizontal displacements near the springline and mainly outward vertical displacements near the crown. Figure 4-8 shows the equilibrium stress state for this model, and Fig. 4-9 shows the extent of rock mass failure. The extent of rock mass failure appears to be limited, that is within about one-tenth meter from the borehole periphery.

The induced displacement field for the "wedge" model with "recommended" strength values is shown in Fig. 4-10. Essentially rigid block movement of wedges is indicated. The equilibrium stresses for this case are shown in Fig. 4-11, which shows that the wedges are unstressed.

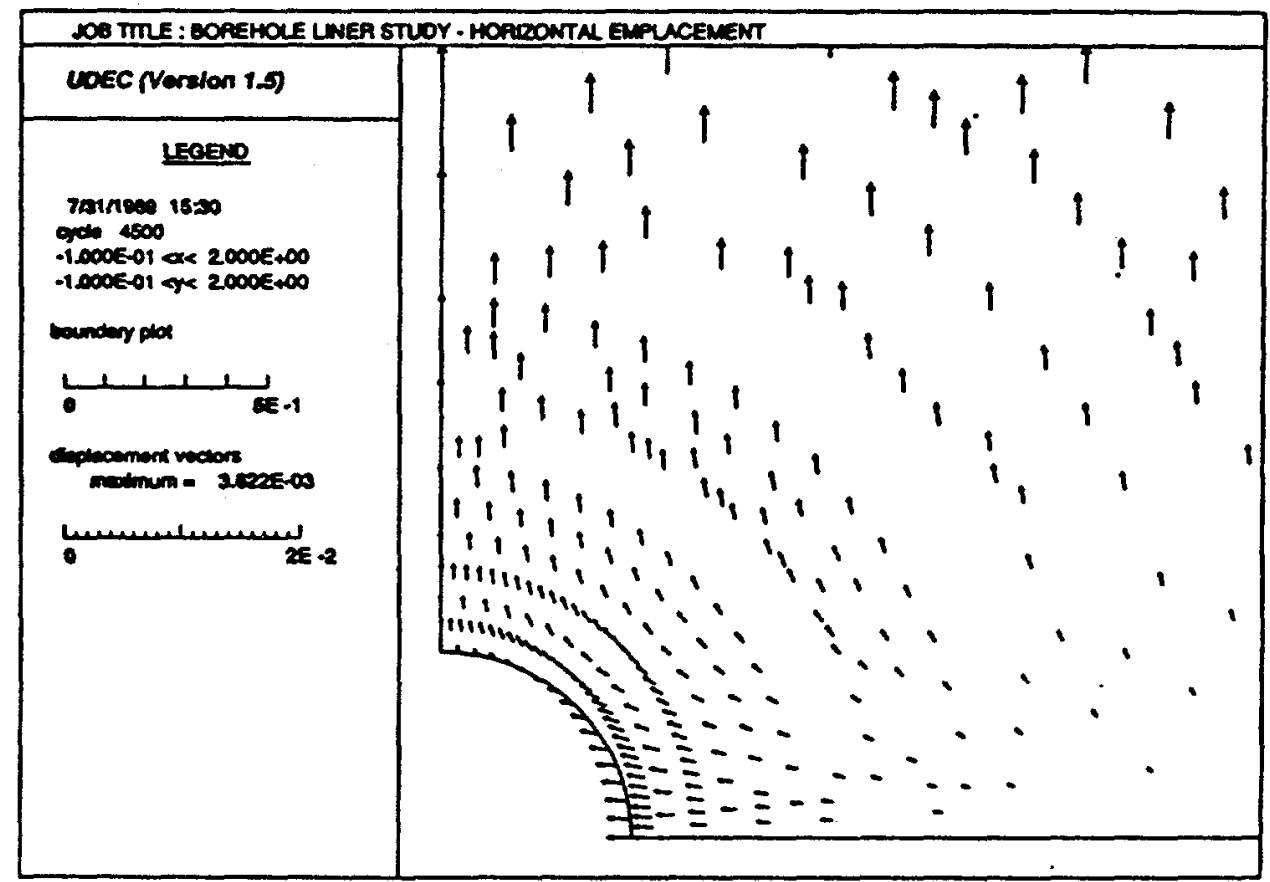

Fig. 4-7 Thermally-Induced Displacements for Continuum Model with "Recommended" Strength Values at 100 Years 


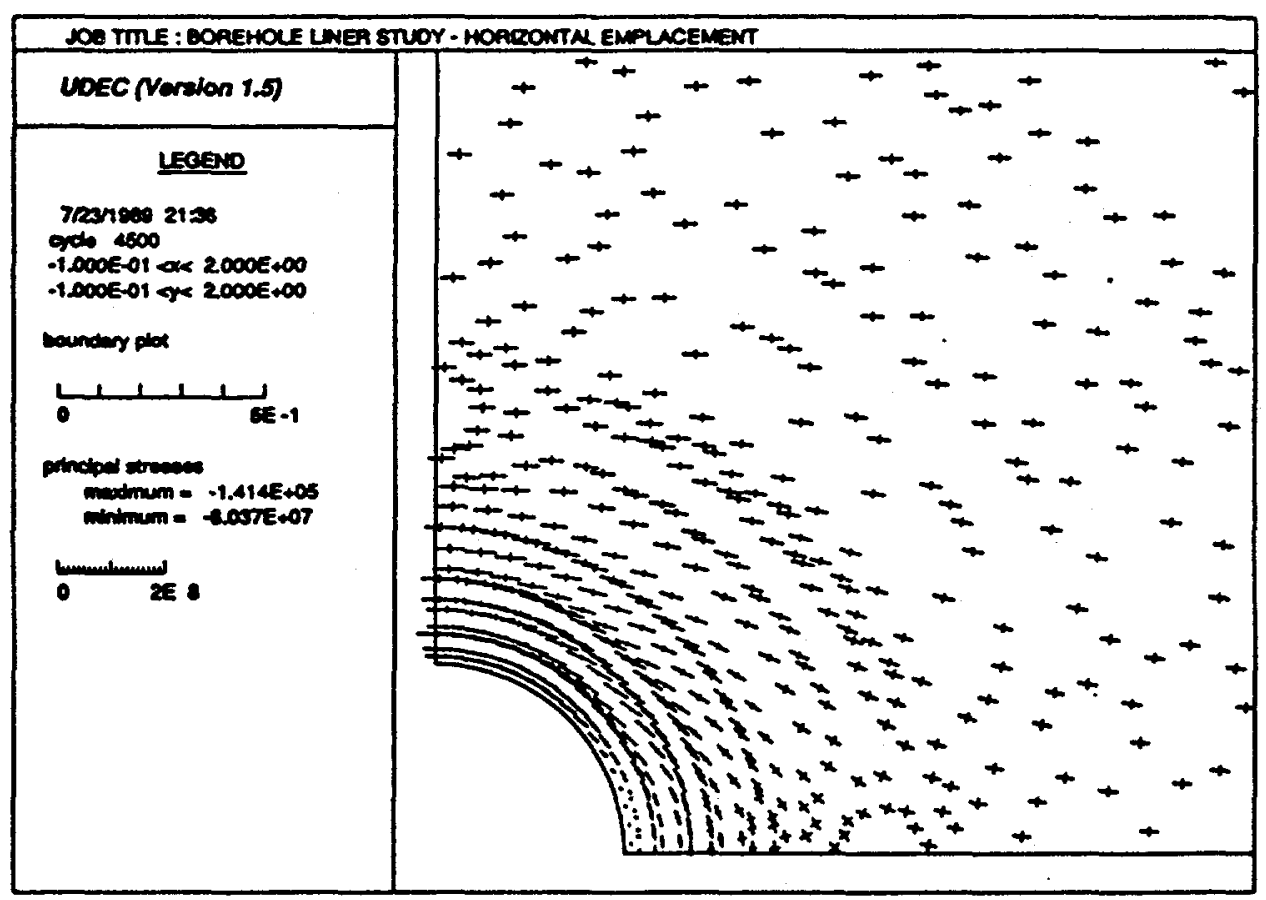

Fig. 4-8 Principal Stress Distribution for Continuum Model with "Recommended" Strength Values at 100 Years

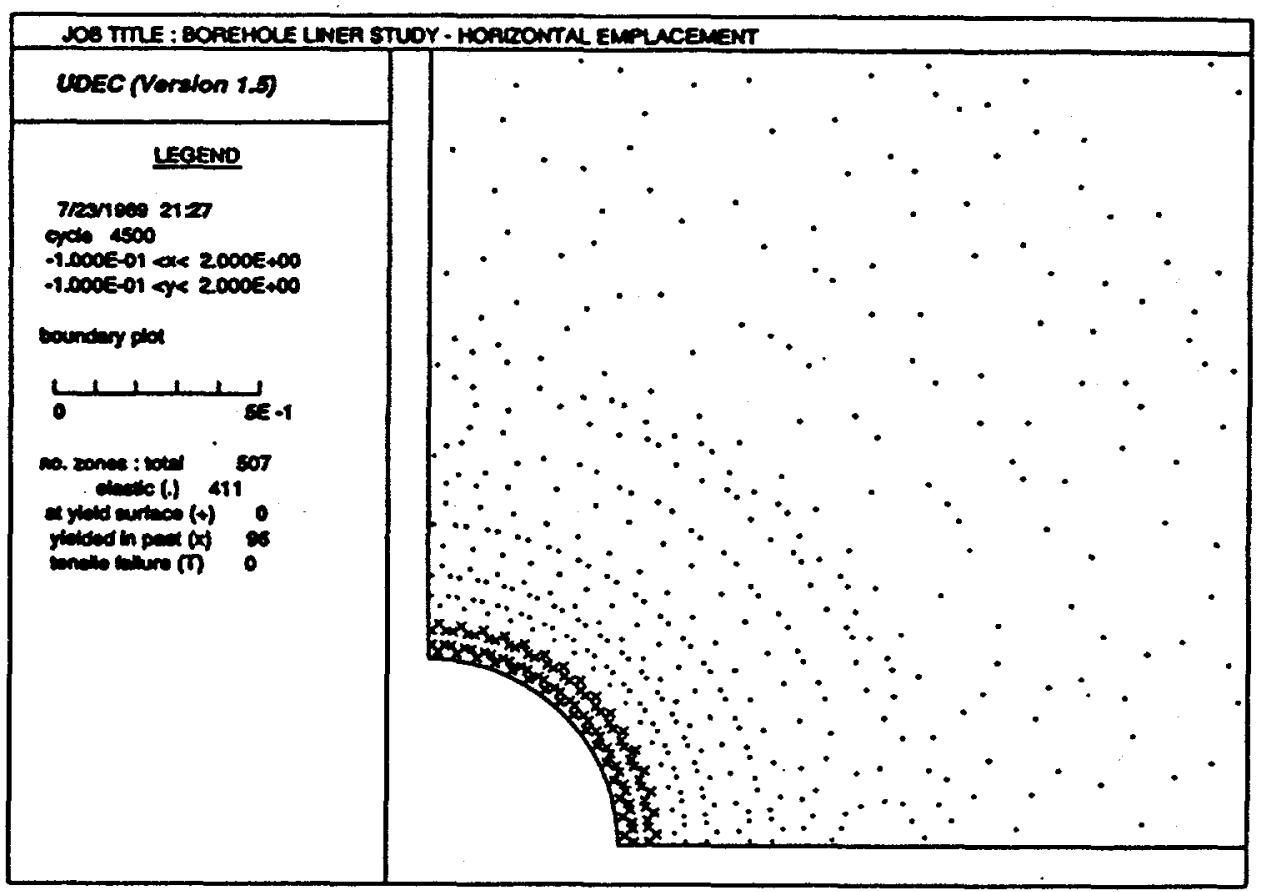

Fig. 4-9 Location of "Failed" Zones for Continuum Model with "Recommended" Strength Values at 100 Years 


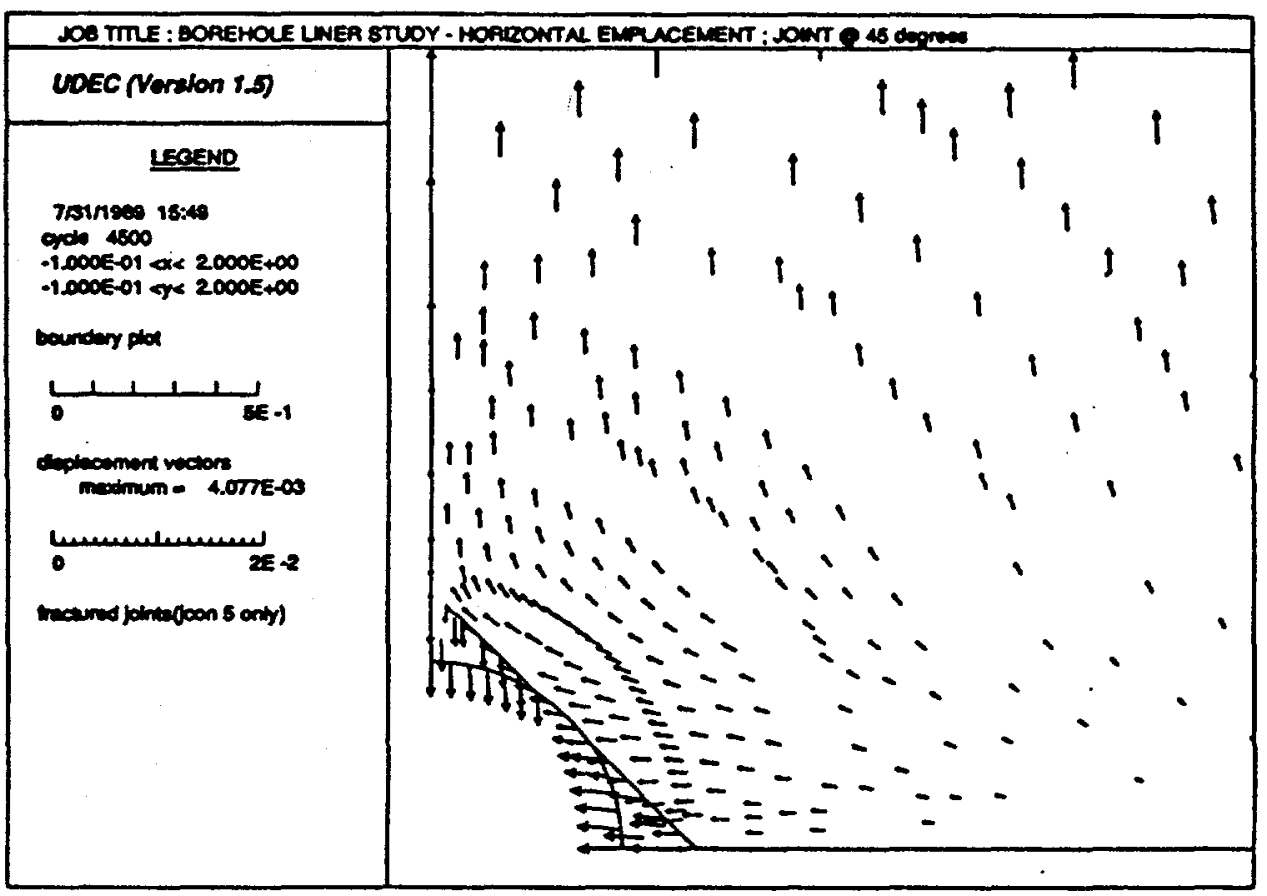

Fig. 4-10 Thermally-Induced Displacements for Wedge Model with "Recommended" Strength Values at 100 Years

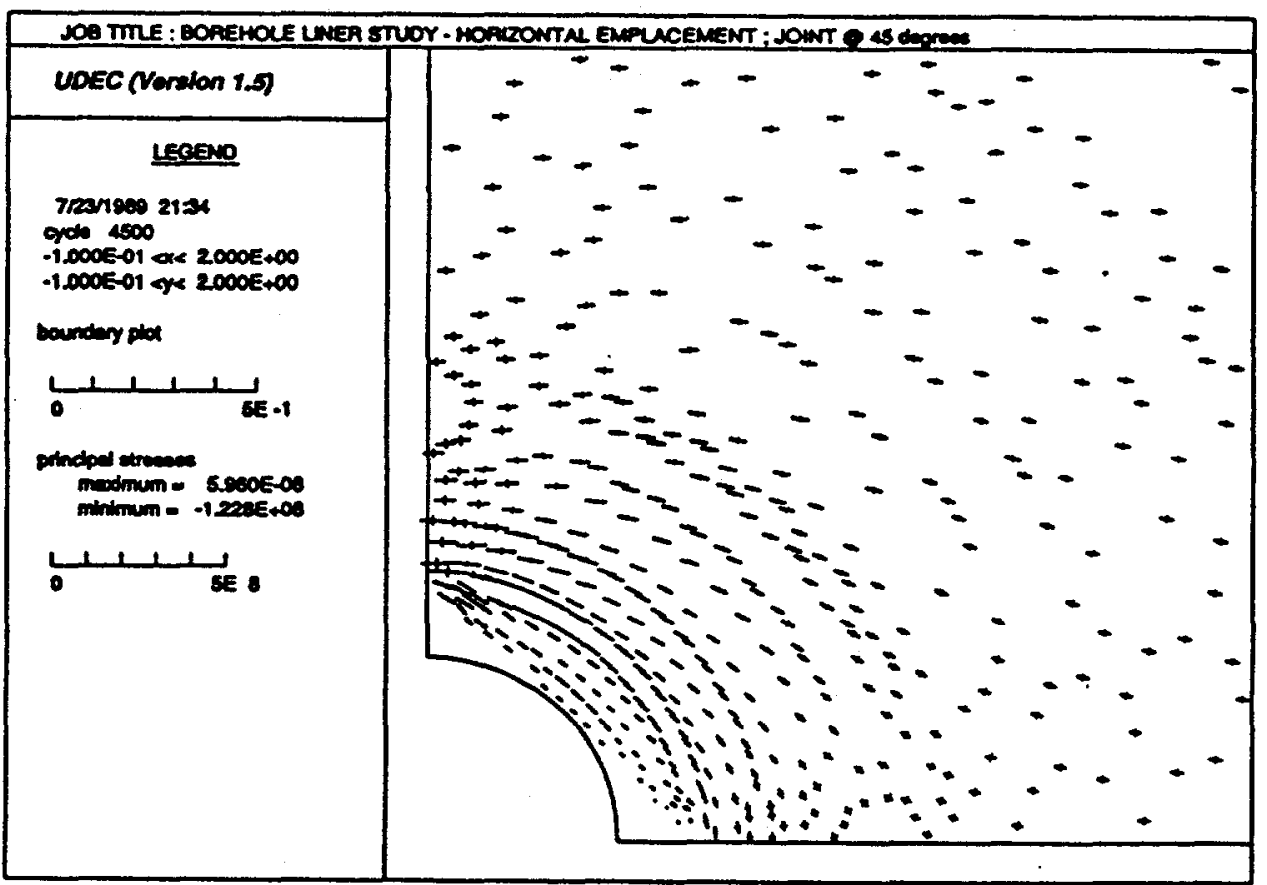

Fig. 4-11 Principal Stress Distribution for Wedge Model with "Recommended" Strength Values at 100 Years 
The induced displacement field for the parallel joint model with "recommended" strength values is shown in Fig. 4-12. This figure also shows the extent of "failed" joints. The region of "failed" joints is greater than the same region at time $=0 \mathrm{yr}$. , before heating was initiated. Figure 4-13 shows the relative shear displacement on joints. Most significant shear is restricted to a region within about two-tenths meter from the borehole periphery. The equilibrium stress state for this model is shown in Fig. 4-14. The effect of the joints is to deflect stresses away from the springline area and concentrate them in the crown region.

The borehole ground reaction curves for nine cases (i.e., three problem geometries and three strength assumptions) are shown in Figs. 4-15 through 4-23. Recall that these curves were obtained by applying internal pressures to the borehole periphery during the mechanical calculation at $t=100 \mathrm{yr}$. Because the radial displacements for all points on the borehole periphery are different, ground reaction curves for only points at the crown, springline and quarter points (i.e., $\theta=45^{\circ}$ ) are presented. In many cases the displacement at the crown is outward and no curve is presented.

Many of the ground reaction curves appear to be bilinear, with a steeply descending portions at high internal pressures and a more gradually descending portion at lower internal pressures. The usual interpretation of such curves is that the steeply descending portion represents elastic behavior, and the gradually descending portion represents inelastic behavior. 


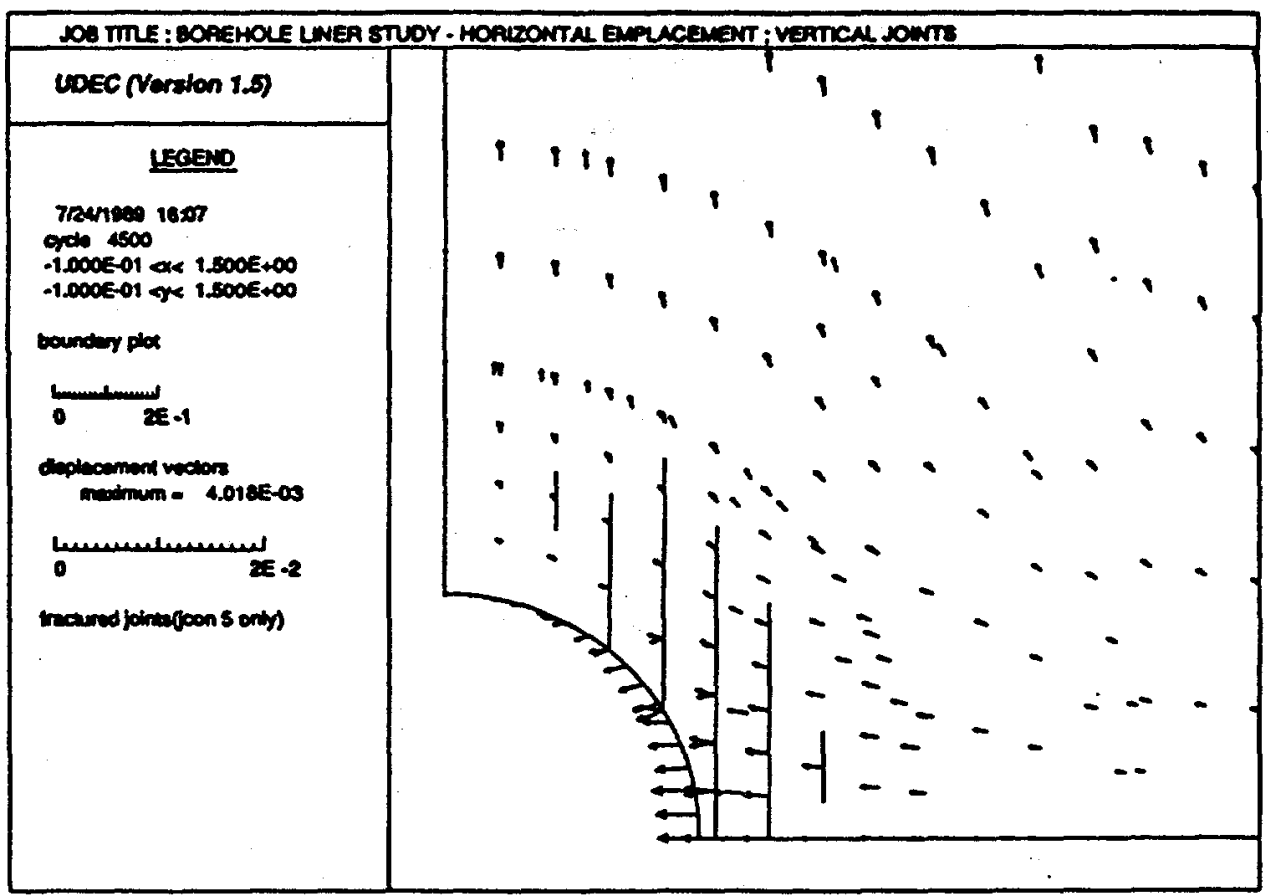

Fig. 4-12 Thermally-Induced Displacements for Parallel Joint Model with "Recommended" Strength Values at 100 Years

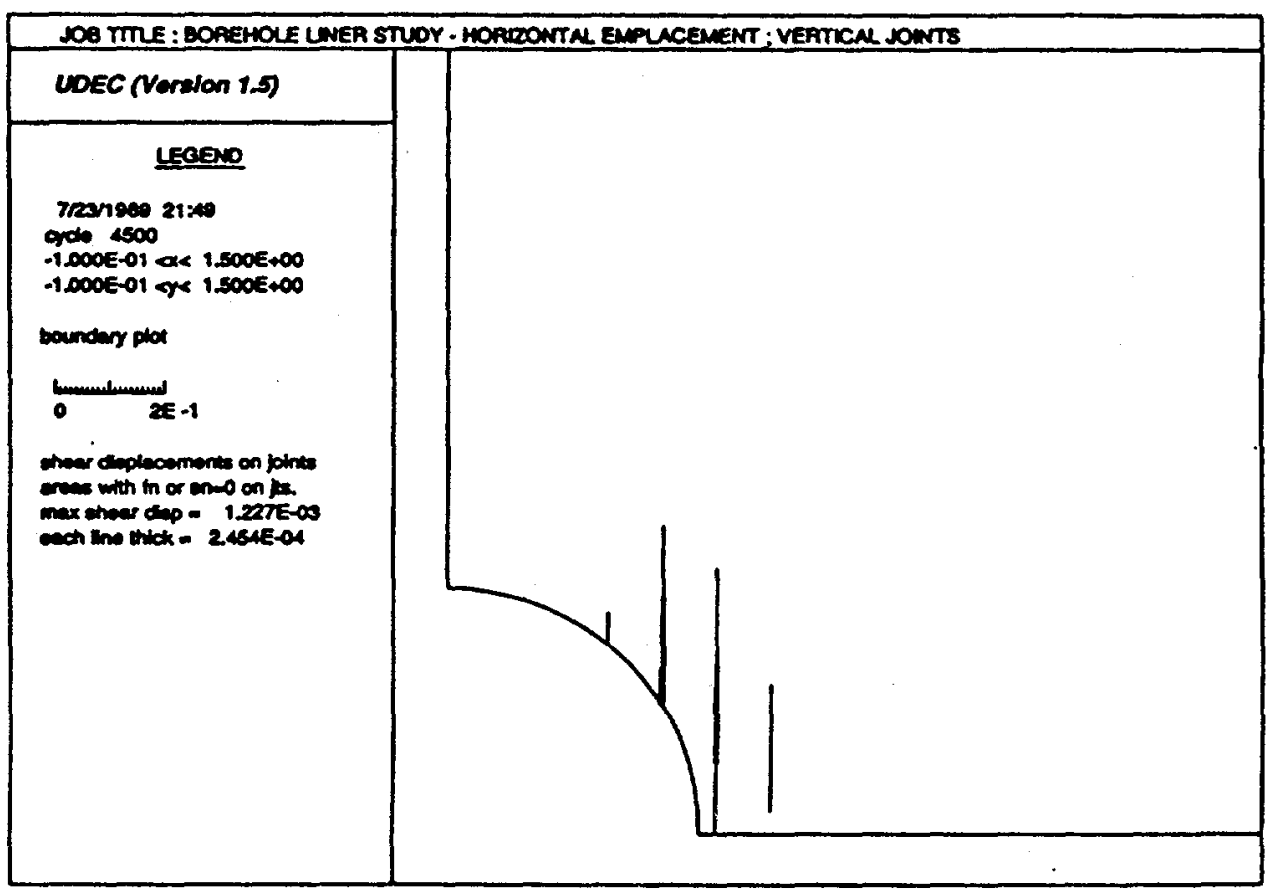

Fig. 4-13 Joint Displacements for Parallel Joint Model with "Recommended" Strength Values at 100 Years 


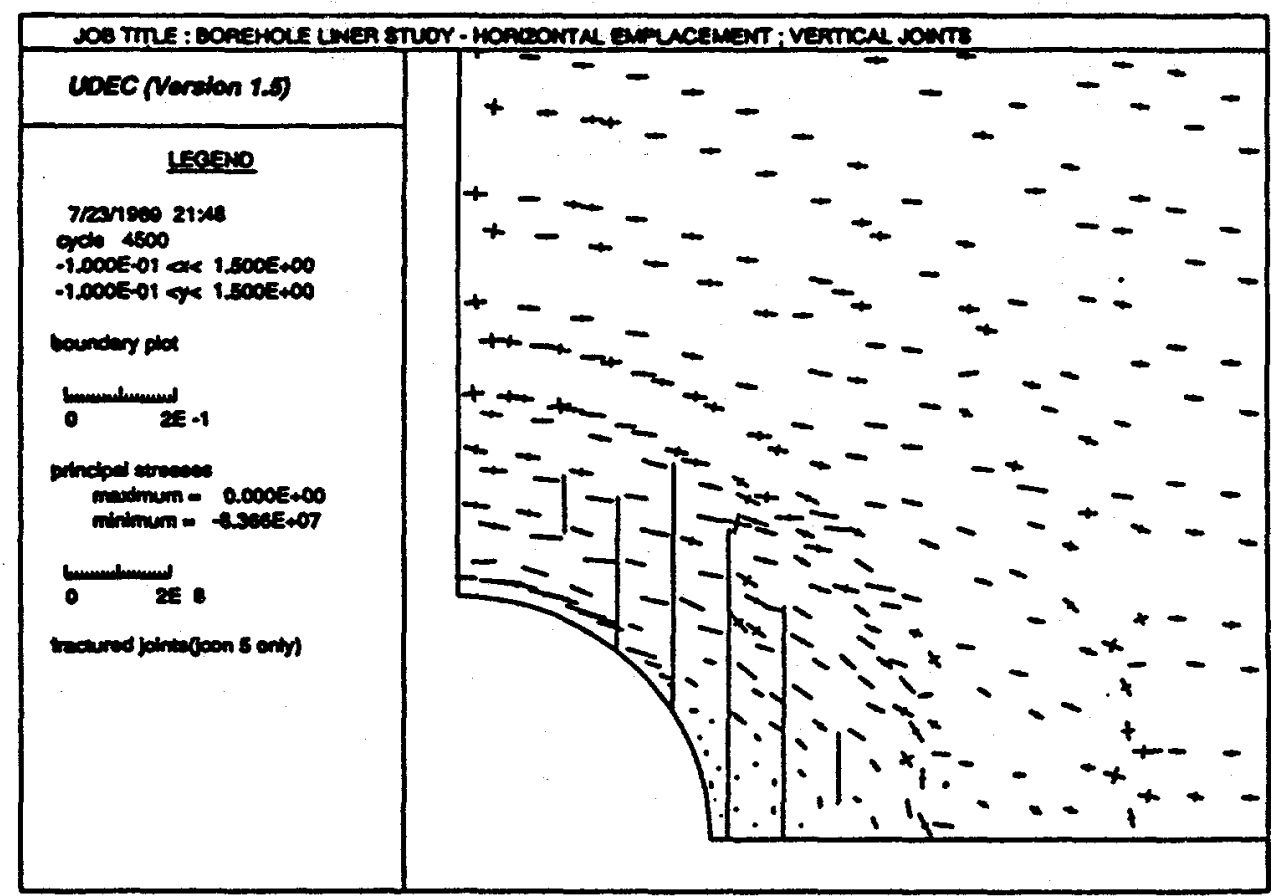

Fig. 4-14 Distribution of Principal Stresses for Parallel Joint Model with "Recommended" Strength Values at 100 Years

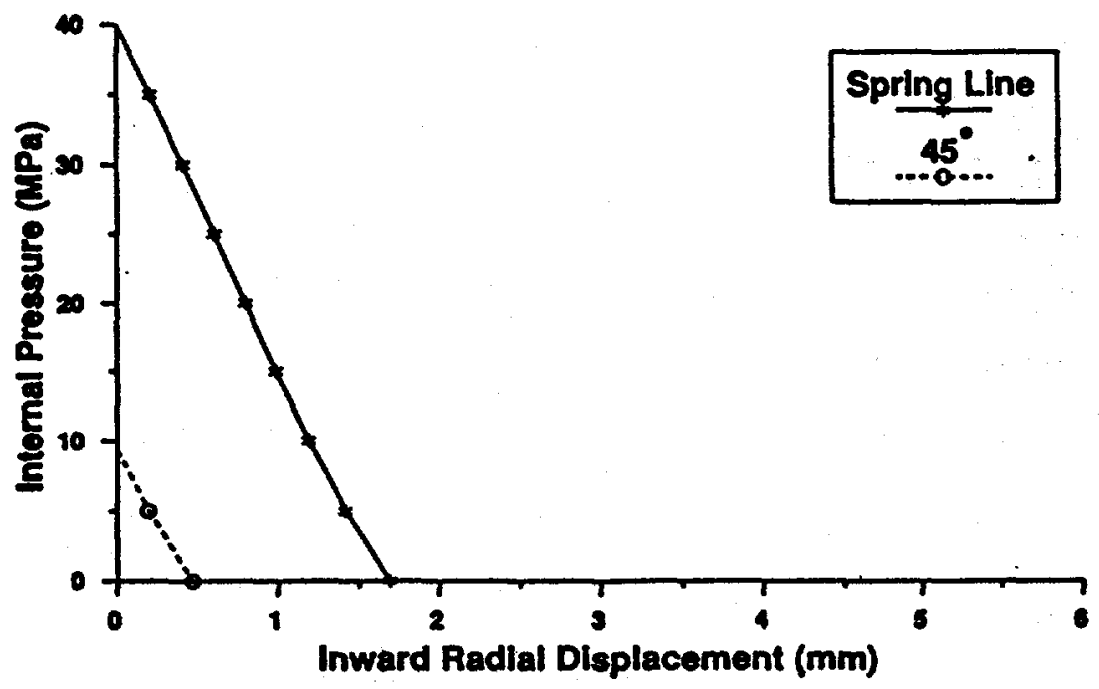

Fig. 4-15 Ground Reaction Curves for Emplacement Borehole at 100 Years (continuum model, "design" strength values) 


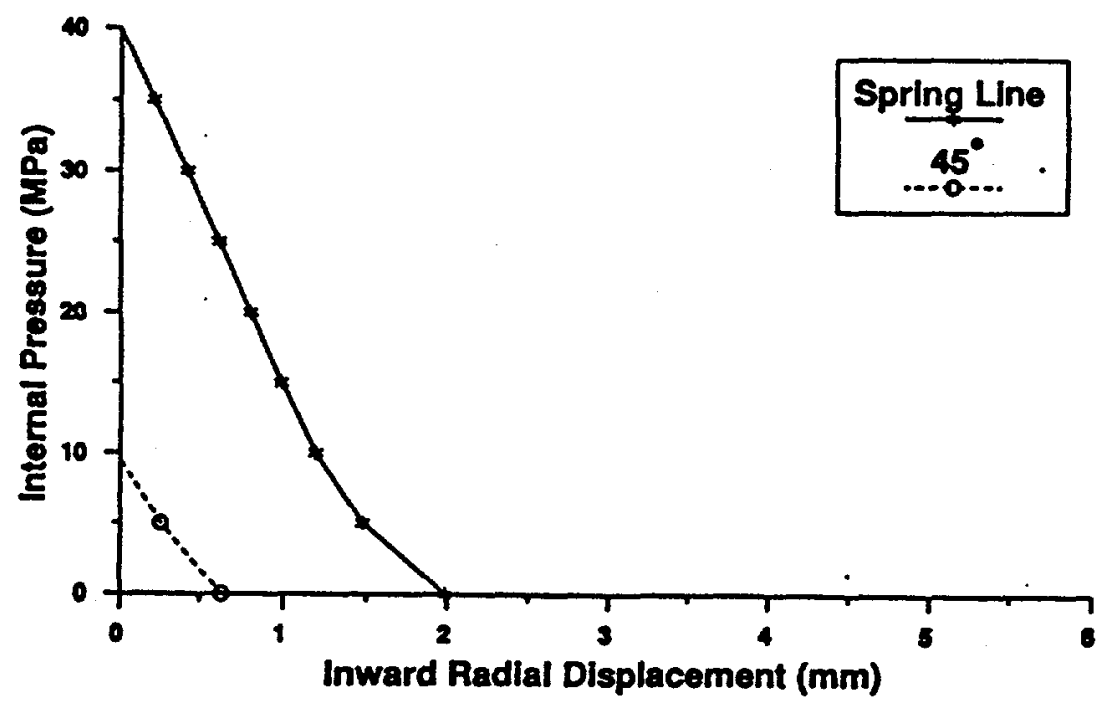

Fig. 4-16 Ground Reaction Curves for Emplacement Borehole at 100 Years (continuum model, "recommended" strength values)

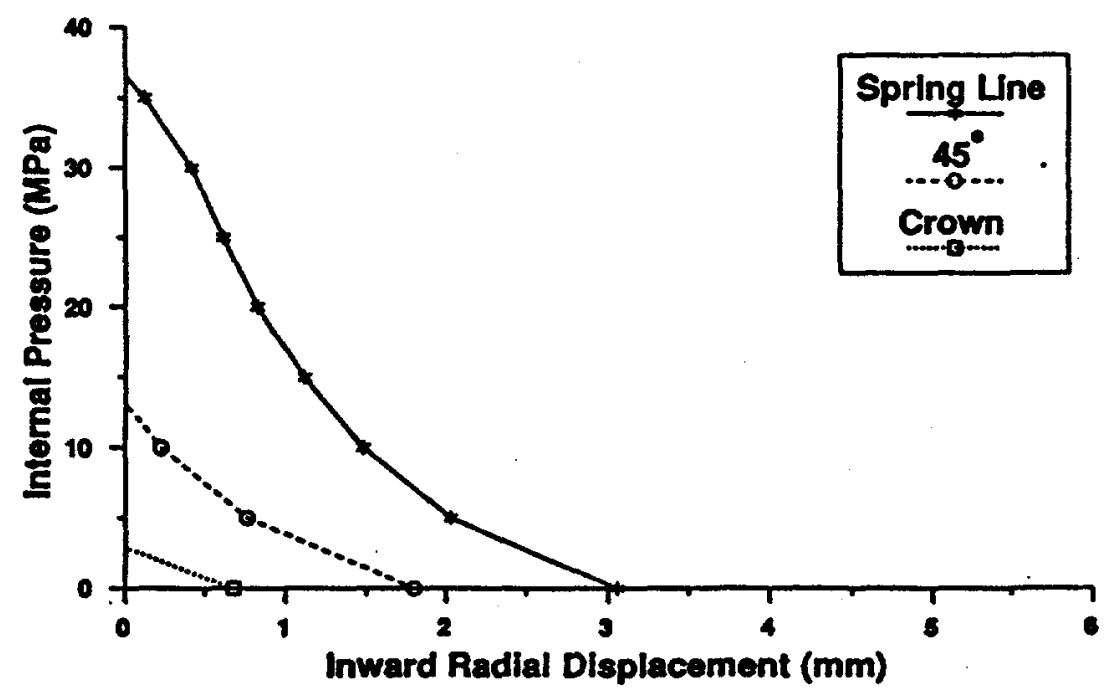

Eig. 4-17 Ground Reaction Curves for Emplacement Borehole at 100 Years (continuum model, "limit" strength values) 


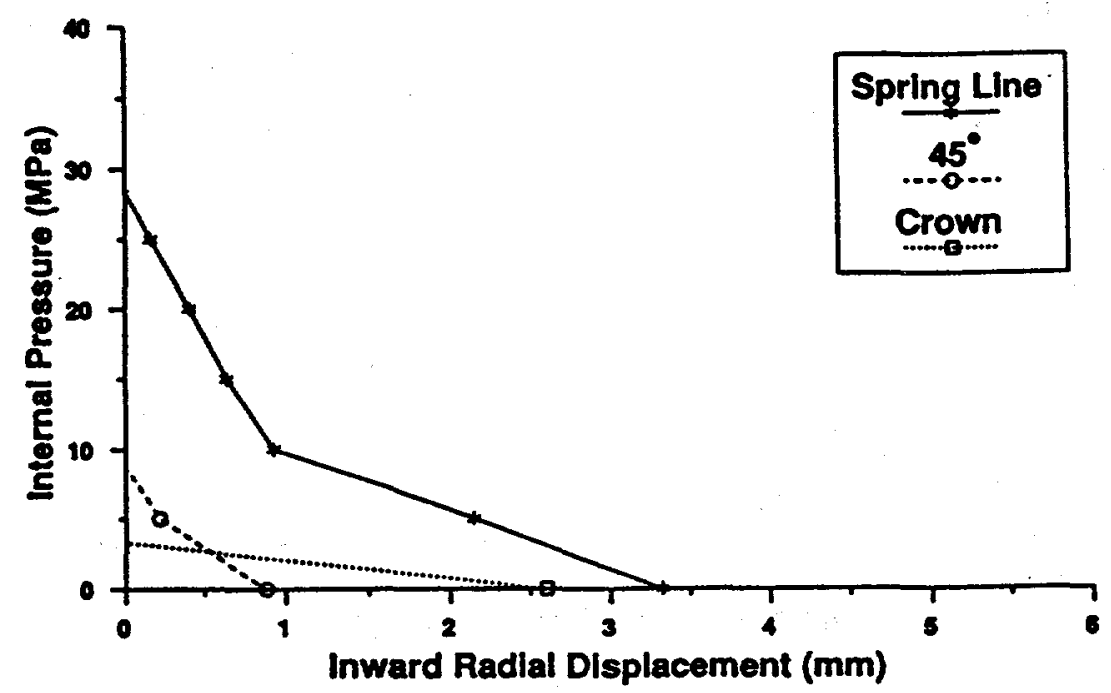
Fig. 4-18 Ground Reaction Curves for Emplacement Borehole at 100
Years (wedge model, "design" strength values)

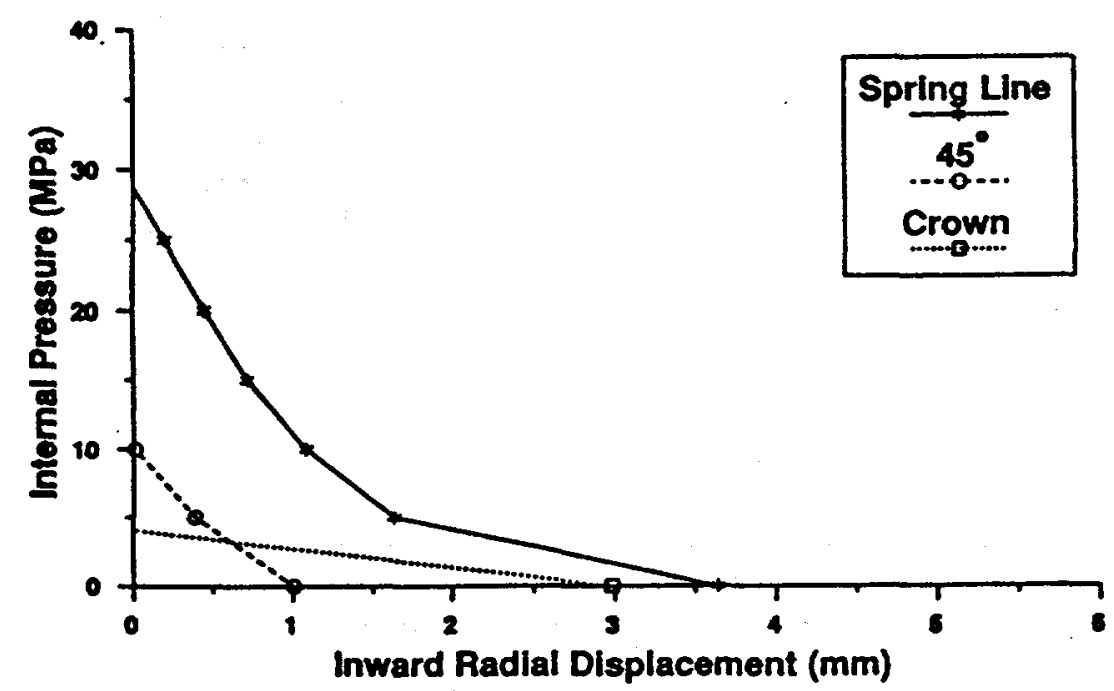

Fig. 4-19 Ground Reaction Curves for Emplacement Borehole at 100 Years (wedge model, "recommended" strength values) 


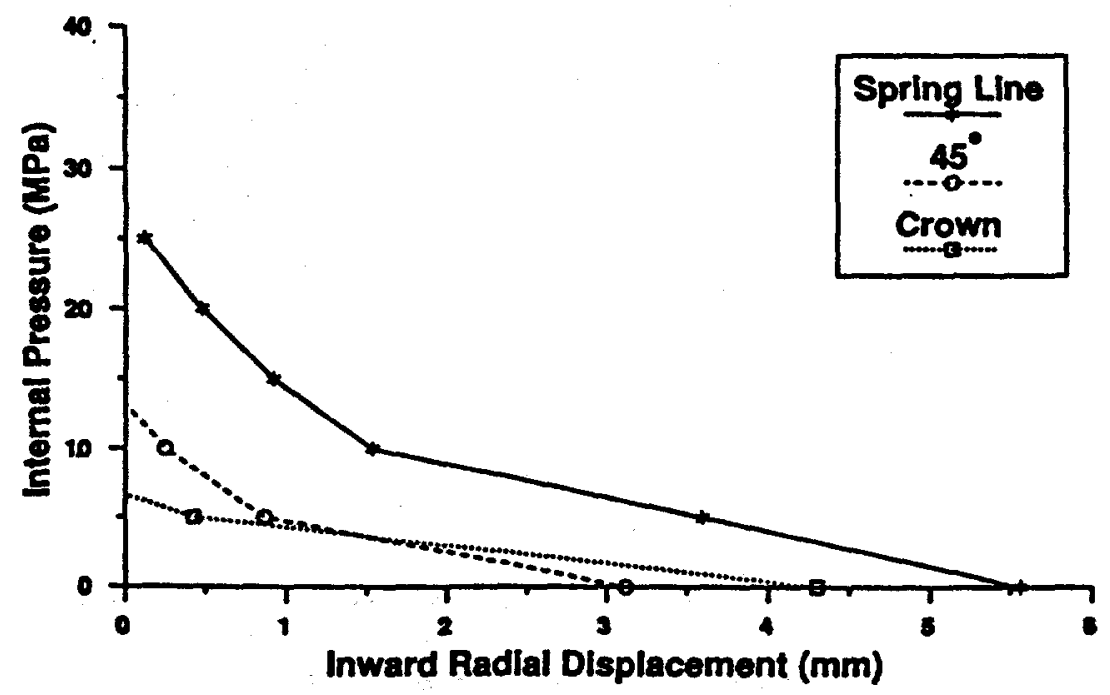

Fig. 4-20 Ground Reaction Curves for Emplacement Borehole at 100 Years (wedge model, "limit" strength values)

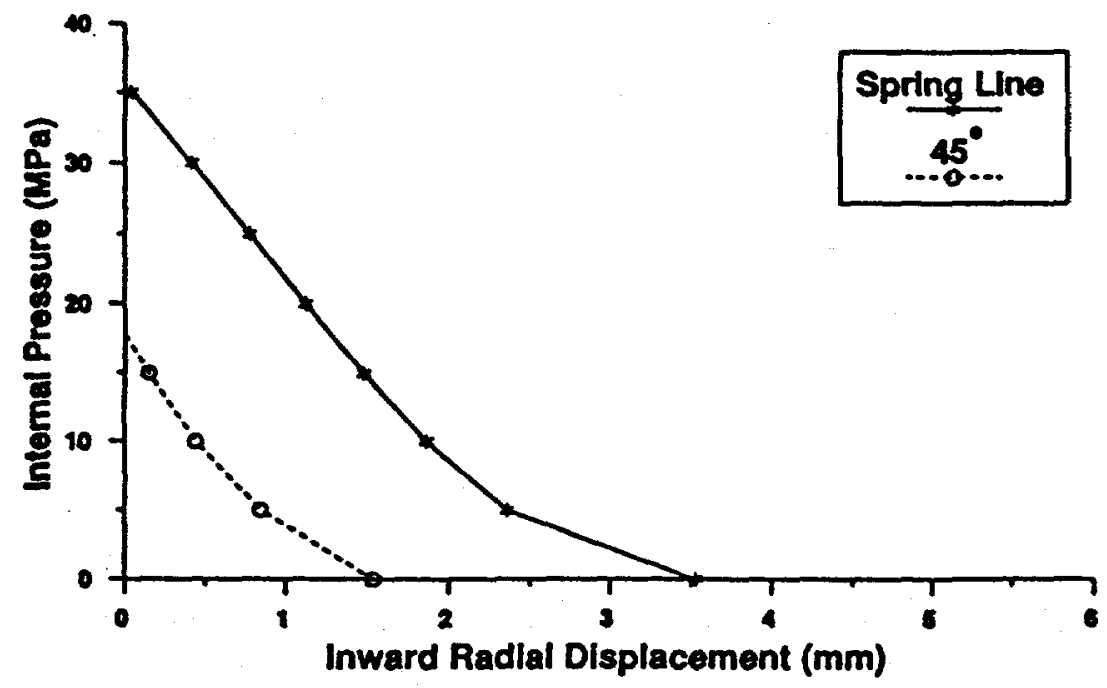

Fig. 4-21 Ground Reaction Curves for Emplacement Borehole at 100 Years (parallel joint models, "design" strength values) 


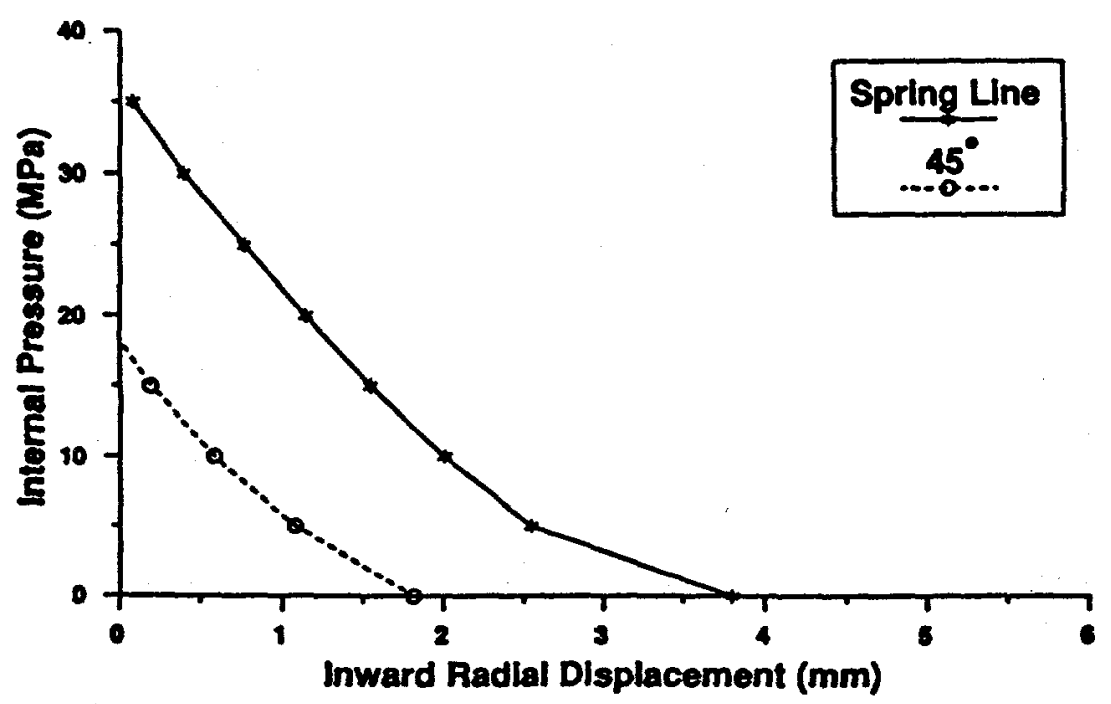

Fig. 4-22 Ground Reaction Curves for Emplacement Borehole at 100 Years (parallel joint model, "recommended" strength values)

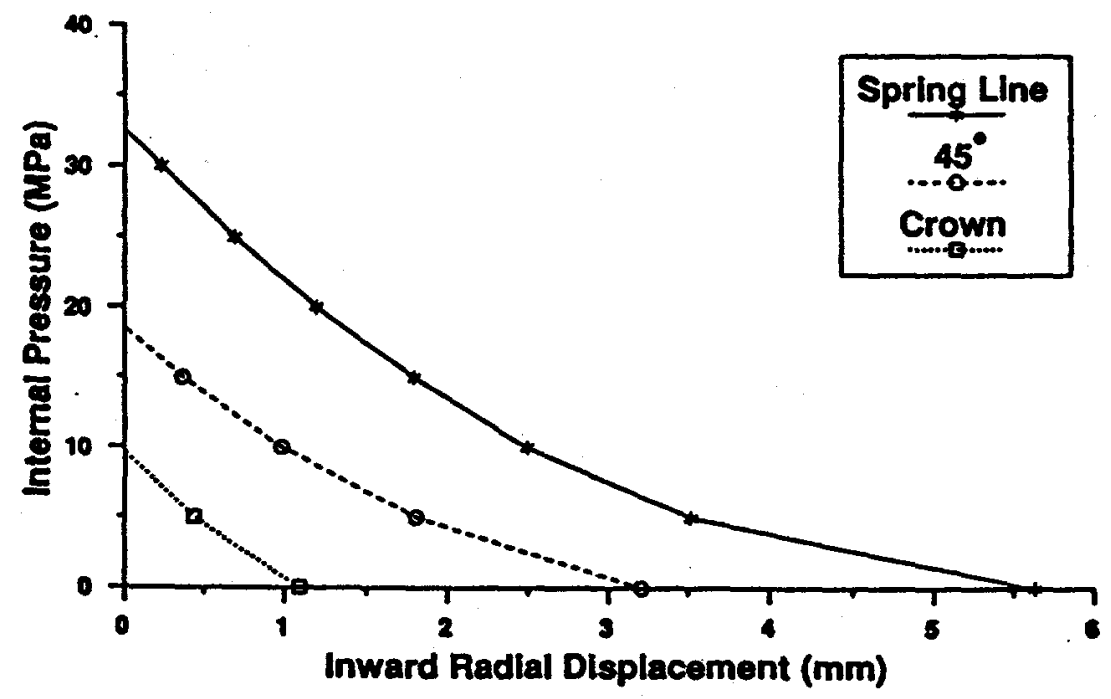

Fig. 4-23 Ground Reaction Curves for Emplacement Borehole at 100 Years (parallel joint model, "limit" strength values) 


\subsection{Results of Analytic Studies}

Computer program LINER11 (Appendix B) evaluates the bending moments, axial thrusts and radial shear forces and corresponding stresses for the two different load cases [i.e., Load Case 1 (Fig. 3-9) and Load Case 2 (Fig. 3-10).]

\subsubsection{Verification}

The computer program is verified by using following input data from Appendix B of the SCPCDR:

$\begin{array}{ll}\text { liner diameter } & 36.0 \mathrm{in.} \\ \text { liner thickness } & 0.5 \mathrm{in.} \\ \text { rock load angle } & 60^{\circ} \\ \text { base reaction angle } & 20^{\circ} \\ \text { rock load } & \mathrm{W}=20.4 \text { lb for } 1 \mathrm{in} . \\ & \end{array}$

The results for Load Case 1 at positions $x=0^{\circ}, 30^{\circ}, 90^{\circ}$ and $180^{\circ}$, obtained using the computer code and hand calculations are presented in Table 4-2. Bending moment and bending stresses along the circumference of the liner, $x=0$ to $180^{\circ}$ at intervals of $5^{\circ}$, are evaluated and compared with the results reported by MacDougall et al., (1987) and presented in Tables 4-3 and 4-4. These two tables show identical results. Table 4-5 presents the results comparing the output from the computer code and hand calculations for Load Case 2 and the numerical values are virtually identical. 
Table $4-2$
VERIFICATION OF COMPUTER CODE (IINER11) FOR LOAD CASE 1

$x$ Bending Moment (in-1b) Axial Thrust (1b) Shear Force (lb)

(deg) Calc. Computer calc. Computer calc. computer

$0^{\circ}$

75.6

75.6

$-2.46 \quad-2.46$

0.0

$0.2 e^{-5}$

$30^{\circ} \quad 32.4$

32.3

$-4.86 \quad 4.87$

$-8.98$

$-8.97$

$90^{\circ} \quad-63.6$

$-63.7$

$\begin{array}{ll}-10.2 & -10.2\end{array}$

$-0.27$

$-0.269$

$180^{\circ}$

99.12

99.0

$-1.16$

1.16

0.0

$0.3 e^{-4}$ 
Table 4-3

BENDING MOMENTS AND STRESSES COMPUTED USING IINER11 FOR LOAD CASE 1

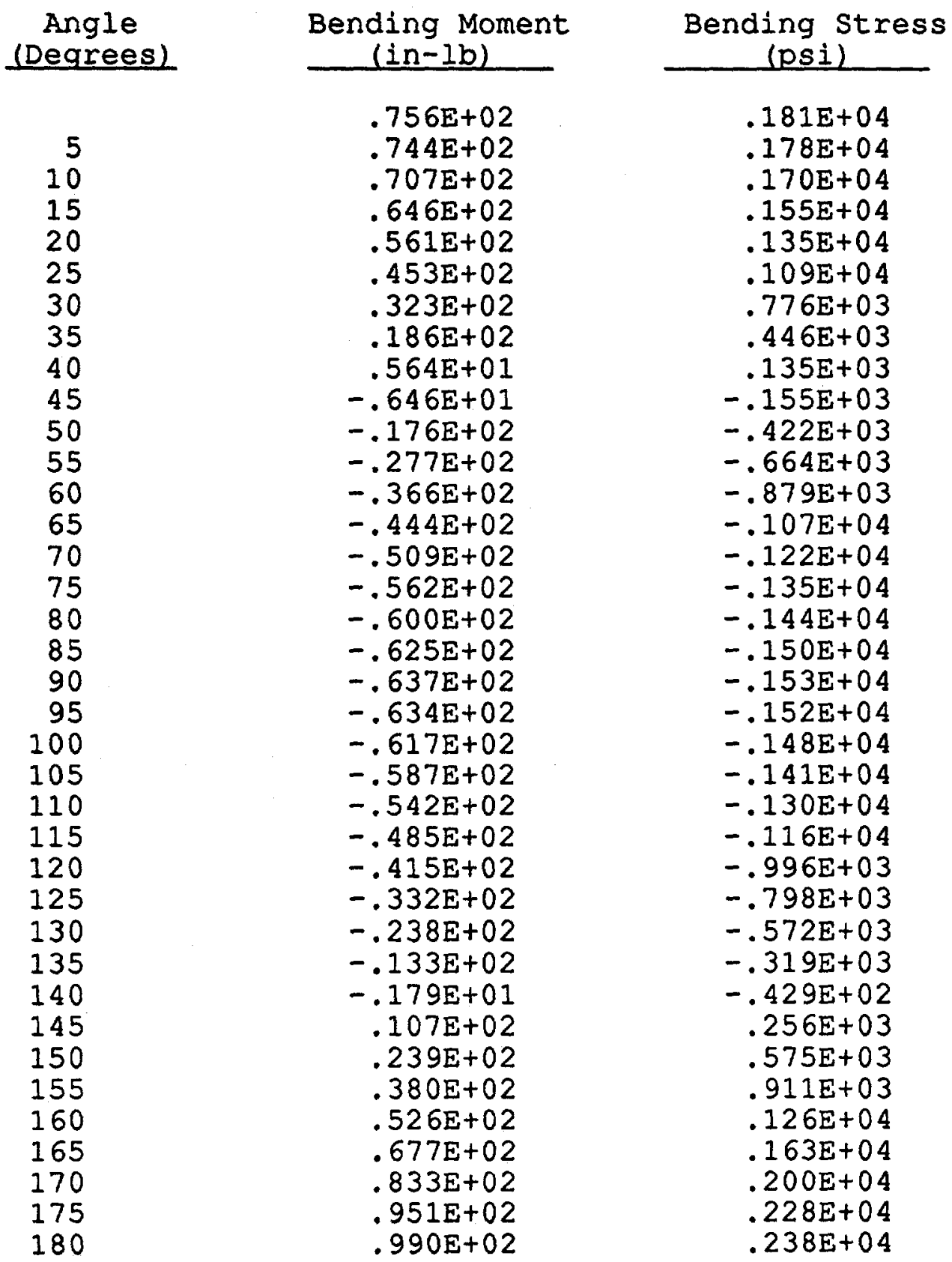


Table 4-4

BENDING MOMENTS AND STRESSES REPORTED BY MACDOUGALL ET AL. (1987) FOR LOAD CASE 1

$\begin{array}{ccc}\begin{array}{c}\text { Angle } \\ \text { (Degrees) }\end{array} & \begin{array}{c}\text { Bending Moment } \\ (\text { in-1b) }\end{array} & \begin{array}{c}\text { Bending Stress } \\ \text { (ksi) }\end{array} \\ 0 & 75.6 & 1.81 \\ 5 & 74.4 & 1.78 \\ 10 & 70.7 & 1.70 \\ 15 & 64.6 & 1.55 \\ 20 & 56.1 & 1.35 \\ 25 & 45.3 & 1.09 \\ 30 & 32.3 & 0.78 \\ 35 & 18.6 & 0.45 \\ 40 & 5.6 & 0.14 \\ 45 & -6.5 & -0.16 \\ 50 & -17.6 & -0.42 \\ 55 & -27.7 & -0.66 \\ 60 & -36.6 & -0.88 \\ 65 & -44.4 & -1.07 \\ 70 & -50.9 & -1.22 \\ 75 & -56.2 & -1.35 \\ 80 & -60.0 & -1.44 \\ 85 & -62.5 & -1.50 \\ 90 & -63.7 & -1.53 \\ 95 & -63.4 & -1.52 \\ 100 & -61.7 & -1.48 \\ 105 & -58.7 & -1.41 \\ 110 & -54.2 & -1.30 \\ 115 & -48.5 & -1.16 \\ 120 & -41.5 & -1.00 \\ 125 & -33.2 & -0.80 \\ 130 & -23.8 & -0.57 \\ 135 & -13.3 & -0.32 \\ 140 & -1.8 & -0.04 \\ 145 & 10.7 & 0.26 \\ 150 & 23.9 & 0.57 \\ 155 & 38.0 & 0.91 \\ 160 & 52.6 & 1.26 \\ 165 & 67.7 & 1.63 \\ 170 & 83.3 & 2.00 \\ 175 & 95.1 & 2.28 \\ 180 & 99.0 & 2.38 \\ & & \end{array}$


Table 4-5

VERIFICATION OF COMPUTER CODE (LINER11) FOR LOAD CASE 2

\begin{tabular}{cccccccc}
$\times$ & \multicolumn{2}{c}{ Bending Moment $(i n-1 b)$} & \multicolumn{2}{c}{ Axid Thrust (1b) } & \multicolumn{2}{c}{ Shear Force (1b) } \\
(deg) & Calc. & Computer & Calc. & Computer & Calc. & Computer \\
$0^{\circ}$ & 116.61 & 117.0 & -0.034 & -0.033 & -10.2 & -10.2 \\
$30^{\circ}$ & 24.88 & 24.7 & -5.13 & -5.13 & -8.85 & -8.82 \\
$90^{\circ}$ & -66.38 & -66.4 & -10.2 & -10.2 & 0.033 & 0.033 \\
$180^{\circ}$ & 101.81 & 102.0 & -0.86 & -0.86 & 0.0 & $0.30^{-4}$
\end{tabular}

\subsubsection{Stress Analysis}

\subsubsection{Complete Stress Analysis}

In the first segment of the analysis the bending, axial and shear stresses are computed along the circumference of a liner $(x=0$ to $180^{\circ}$ ) for the following input data:
liner diameter
$D=28$ in.
$(71 \mathrm{~cm})$
liner thickness
$=0.5$ in. $(1.27 \mathrm{~cm})$
rock load for unit length
$\mathrm{W}=20.4 \mathrm{lb}$.
$(9.25 \mathrm{~kg})$
of the liner
$(2 \alpha)=60^{\circ}$
Load Case 1 , rock load
and base reaction angle
Load Case 2,
base reaction angle
$(2 \alpha)=60^{\circ}$
base reaction

$$
\mathrm{w}=\frac{1.457 \mathrm{lb} / \mathrm{in} .2}{(0.01 \mathrm{MPa})}
$$


The bending, axial and shear stresses, for the Load Case 1 and Load Case 2 are shown in Figs. 4-24 and 4-25. It should be noted that in these figures and in all subsequent figures of this section, the stresses are presented in a dimensionless form. The dimensionless stress signifies stress per unit base reaction. The usefulness of presenting the data in this manner is that the actual stress value can be determined for any rock load $w$, by multiplying the dimensionless stress by the base reaction $w$ given as :

$$
w=\frac{w}{2 R \sin (\pi-\alpha)}
$$

The results presented in Figs, $4-24$ and $4-25$ as well as in Tables 4-6 and 4-7 indicate that the axial and shear stresses are small compared to the bending stresses and can be neglected for the present analysis. The maximum dimensionless bending stress is 1374 for Load Case 1 (Fig. 4-24, Table 4-6) and 2130 for Load Case 2 (Fig. 4-25, Table 4-7). The base reaction, $w$, for this example is $1.457 \mathrm{psi}(0.01 \mathrm{MPa})$. Thus, the actual maximum bending stress for Load Case 1 is (1.457 $\times 1376 \Rightarrow$ ) 2,000 psi $(13.8$ MPa) and for Load Case 2 is $(1.457 \times 2130 \Rightarrow 3,100$ psi $(21.4$ $\mathrm{MPa}$. The maximum stresses indicate that they are far below the yield stress for low carbon steel which is $30 \mathrm{ksi}$ (206.84 MPa). 


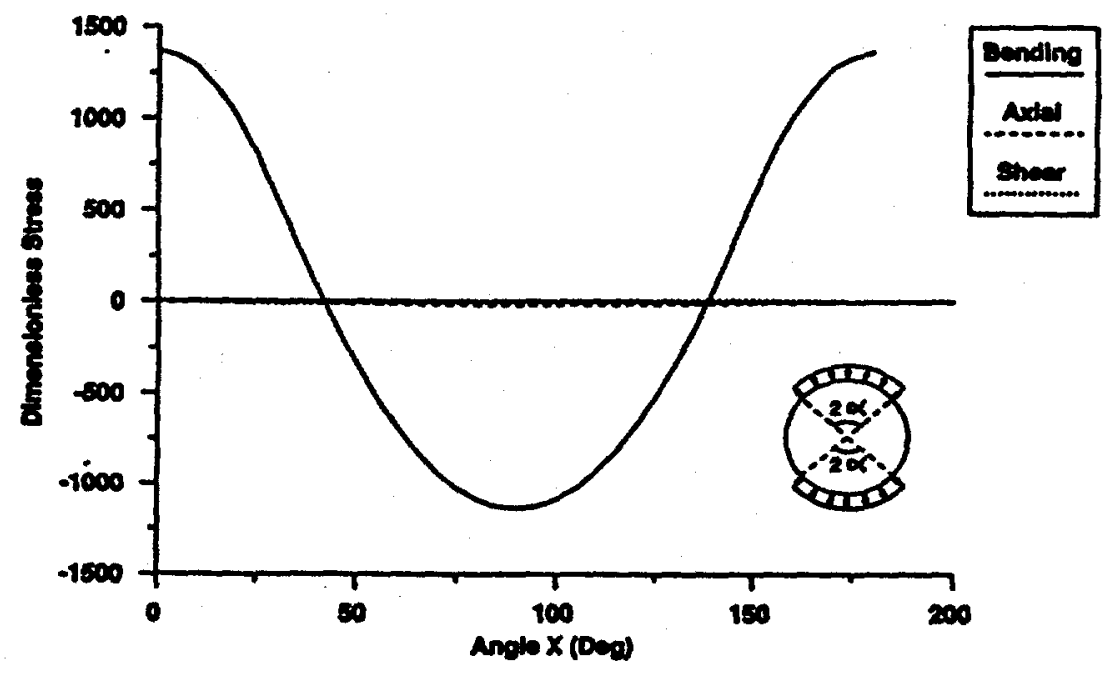

Fig. 4-24 Dimensionless Bending, Axial and Shear Stresses for 28 in. $(71 \mathrm{~cm})$ Diameter Borehole Liner for Load Case $1,2 \alpha=60^{\circ}$

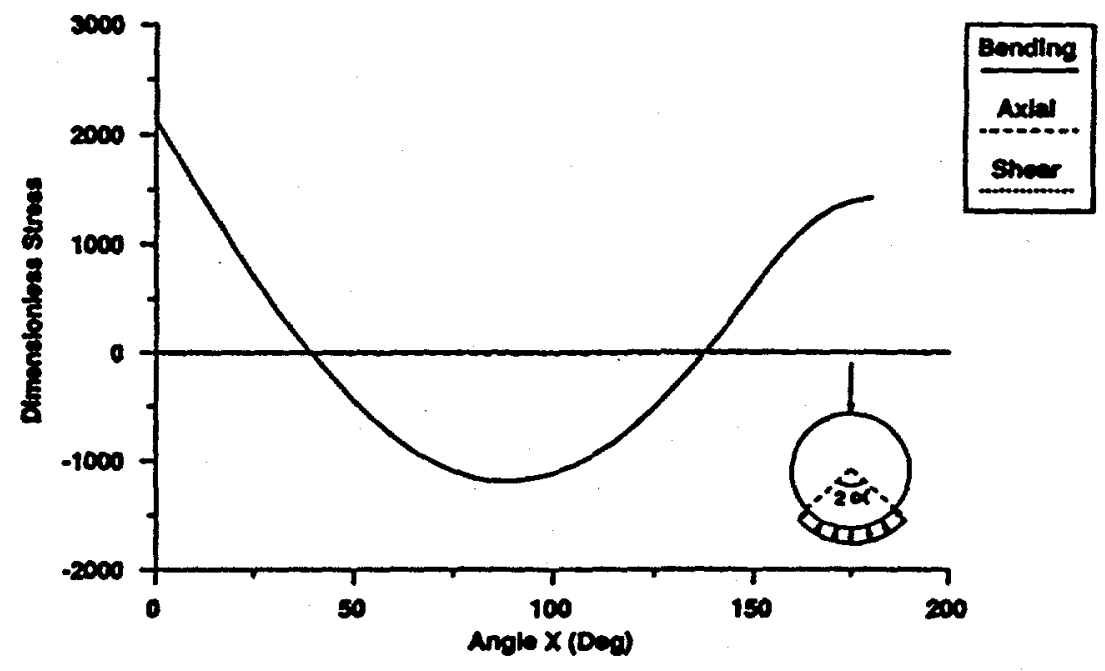

Fig. 4-25 Dimensionless Bending, Axial and Shear stress for 28 in. $(71 \mathrm{~cm})$ Diameter Borehole Liner for Load Case $2,2 \alpha=60^{\circ}$ 
Table $4-6$

DIMENSIONLESS BENDING, AXIAL AND SHEAR STRESSES FOR LOAD CASE 1 (Diameter $=28$ in., $2 \alpha=60^{\circ}$ )

Angle (Degrees)

5
10
15
20
25
30
35
40
45
50
55
60
65
70
75
80
85
90
95
100
105
110
115
120
125
130
135
140
145
150
155
160
165
170
175
180

Dimensionless Stress

$$
\begin{array}{lcc}
\hline \text { Bending } & \text { Axial } & \text { Shear } \\
.137 \mathrm{E}+04 & -.547 \mathrm{E}+01 & .191 \mathrm{E}-05 \\
.134 \mathrm{E}+04 & -.560 \mathrm{E}+01 & -.308 \mathrm{E}+01 \\
.128 \mathrm{E}+04 & -.600 \mathrm{E}+01 & -.614 \mathrm{E}+01 \\
.116 \mathrm{E}+04 & -.667 \mathrm{E}+01 & -.915 \mathrm{E}+01 \\
.101 \mathrm{E}+04 & -.760 \mathrm{E}+01 & -.121 \mathrm{E}+02 \\
.810 \mathrm{E}+03 & -. .878 \mathrm{E}+01 & -.149 \mathrm{E}+02 \\
.571 \mathrm{E}+03 & -.102 \mathrm{E}+02 & -.177 \mathrm{E}+02 \\
.319 \mathrm{E}+03 & -.117 \mathrm{E}+02 & -.167 \mathrm{E}+02 \\
.818 \mathrm{E}+02 & -.131 \mathrm{E}+02 & -.156 \mathrm{E}+02 \\
-.139 \mathrm{E}+03 & -.144 \mathrm{E}+02 & -.144 \mathrm{E}+02 \\
-.341 \mathrm{E}+03 & -.156 \mathrm{E}+02 & -.131 \mathrm{E}+02 \\
-.523 \mathrm{E}+03 & -.167 \mathrm{E}+02 & -.117 \mathrm{E}+02 \\
-.683 \mathrm{E}+03 & -.177 \mathrm{E}+02 & -.102 \mathrm{E}+02 \\
-.821 \mathrm{E}+03 & -.185 \mathrm{E}+02 & -.862 \mathrm{E}+01 \\
-.936 \mathrm{E}+03 & -.192 \mathrm{E}+02 & -.698 \mathrm{E}+01 \\
-.103 \mathrm{E}+04 & -.197 \mathrm{E}+02 & -.528 \mathrm{E}+01 \\
-.109 \mathrm{E}+04 & -.201 \mathrm{E}+02 & -.354 \mathrm{E}+01 \\
-.113 \mathrm{E}+04 & -.203 \mathrm{E}+02 & -.178 \mathrm{E}+01 \\
-.114 \mathrm{E}+04 & -.204 \mathrm{E}+02 & -.399 \mathrm{E}-05 \\
-.113 \mathrm{E}+04 & -.203 \mathrm{E}+02 & .178 \mathrm{E}+01 \\
-.109 \mathrm{E}+04 & -.201 \mathrm{E}+02 & .354 \mathrm{E}+01 \\
-.103 \mathrm{E}+04 & -.197 \mathrm{E}+02 & .528 \mathrm{E}+01 \\
-.936 \mathrm{E}+03 & -.192 \mathrm{E}+02 & .698 \mathrm{E}+01 \\
-.821 \mathrm{E}+03 & -.185 \mathrm{E}+02 & .862 \mathrm{E}+01 \\
-.683 \mathrm{E}+03 & -.177 \mathrm{E}+02 & .102 \mathrm{E}+02 \\
-.523 \mathrm{E}+03 & -.167 \mathrm{E}+02 & .117 \mathrm{E}+02 \\
-.341 \mathrm{E}+03 & -.156 \mathrm{E}+02 & .131 \mathrm{E}+02 \\
-.139 \mathrm{E}+03 & -.144 \mathrm{E}+02 & .144 \mathrm{E}+02 \\
.818 \mathrm{E}+02 & -.131 \mathrm{E}+02 & .156 \mathrm{E}+02 \\
.319 \mathrm{E}+03 & -.117 \mathrm{E}+02 & .167 \mathrm{E}+02 \\
. .571 \mathrm{E}+03 & -.102 \mathrm{E}+02 & .177 \mathrm{E}+02 \\
.810 \mathrm{E}+03 & -.878 \mathrm{E}+01 & .149 \mathrm{E}+02 \\
.101 \mathrm{E}+04 & -.760 \mathrm{E}+01 & .121 \mathrm{E}+02 \\
.116 \mathrm{E}+04 & -.667 \mathrm{E}+01 & .915 \mathrm{E}+01 \\
.128 \mathrm{E}+04 & -.600 \mathrm{E}+01 & .614 \mathrm{E}+01 \\
.134 \mathrm{E}+04 & -.560 \mathrm{E}+01 & .308 \mathrm{E}+01 \\
.137 \mathrm{E}+04 & -.547 \mathrm{E}+01 & .149 \mathrm{E}-04 \\
& &
\end{array}
$$


Table 4-7

DIMENSIONLESS BENDING, AXIAL AND SHEAR STRESSES FOR LOAD CASE 2 (Diameter $=28$ in., $2 \alpha=60^{\circ}$ )

Angle (Degrees)

5

10

15

20

25

30

35

40

45

50

55

60

65

70

75

80

85

90

95

100

105

110

115

120

125

130

135

140

145

150

155

160

165

170

175

180
Dimensionless Stress

Bending Axial Shear

$213 E+04$
$183 E+04$

$-.605 E+00$

$-.204 \mathrm{E}+02$

$-.238 \mathrm{E}+01$

$-.414 E+01$

$.154 \mathrm{E}+04$

$.125 \mathrm{E}+04$

$.966 \mathrm{E}+03$

$.693 E+03$

$.432 E+03$

$.184 \mathrm{E}+03$

$-.475 \mathrm{E}+02$

$-.262 E+03$

$-.457 \mathrm{E}+03$

$-.632 E+03$

$-.786 \mathrm{E}+03$

$-.916 \mathrm{E}+03$

$-.102 E+04$

$-.110 \mathrm{E}+04$

$-.116 E+04$

$-.119 \mathrm{E}+04$

$-.119 E+04$

$-.117 E+04$

$-.112 \mathrm{E}+04$

$-.105 E+04$

$-.952 E+03$

$-.830 E+03$

$-.684 \mathrm{E}+03$

$-.516 \mathrm{E}+03$

$-.327 \mathrm{E}+03$

$-.118 \mathrm{E}+03$

$.108 \mathrm{E}+03$

$.351 E+03$

$.608 \mathrm{E}+03$

$.851 E+03$

$.105 \mathrm{E}+04$

$.121 \mathrm{E}+04$

$.132 \mathrm{E}+04$

$.139 \mathrm{E}+04$

$.142 \mathrm{E}+04$
$-.586 E+01$

$-.755 E+01$

$-.917 \mathrm{E}+01$

$-.107 E+02$

$-.122 \mathrm{E}+02$

$-.136 \mathrm{E}+02$

$-.149 \mathrm{E}+02$

$-.160 \mathrm{E}+02$

$-.171 \mathrm{E}+02$

$-.180 \mathrm{E}+02$

$-.187 \mathrm{E}+02$

$-.194 \mathrm{E}+02$

$-.199 \mathrm{E}+02$

$-.202 E+02$

$-.204 \mathrm{E}+02$

$-.204 \mathrm{E}+02$

$-.203 E+02$

$-.200 E+02$

$-.195 \mathrm{E}+02$

$-.190 \mathrm{E}+02$

$-.182 \mathrm{E}+02$

$-.174 \mathrm{E}+02$

$-.164 E+02$

$-.152 E+02$

$-.140 \mathrm{E}+02$

$-.126 E+02$

$-.112 E+02$

$-.968 \mathrm{E}+01$

$-.823 E+01$

$-.703 E+01$

$-.609 E+01$

$-.541 E+01$

$-.500 E+01$

$-.486 E+01$
$-.203 \mathrm{E}+02$

$-.200 \mathrm{E}+02$

$-.195 \mathrm{E}+02$

$-.190 \mathrm{E}+02$

-.182E+02

$-.174 \mathrm{E}+02$

$-.164 \mathrm{E}+02$

$-.152 \mathrm{E}+02$

$-.140 \mathrm{E}+02$

$-.126 \mathrm{E}+02$

$-.112 \mathrm{E}+02$

$-.968 \mathrm{E}+01$

$-.807 \mathrm{E}+01$

$-.641 E+01$

$-.470 \mathrm{E}+01$

$-.295 E+01$

$-.118 \mathrm{E}+01$

$.605 \mathrm{E}+00$

$.238 \mathrm{E}+01$

$.414 \mathrm{E}+01$

$.586 \mathrm{E}+01$

$.755 \mathrm{E}+01$

$.107 \mathrm{E}+02$

$.122 \mathrm{E}+02$

$.136 \mathrm{E}+02$

$.149 E+02$

$.160 \mathrm{E}+02$

$.171 E+02$

$.180 E+02$

$.152 \mathrm{E}+02$

$.123 E+02$

$.930 E+01$

$.624 E+01$

$.313 \mathrm{E}+01$

$.153 \mathrm{E}-04$
$.917 E+01$ 


\subsubsection{Maximum Stress Analysis}

Several computer runs were made for Load Case 1 and Load Case 2. The bending stresses were evaluated from maximum bending moments for a range of liner thicknesses. Curves showing dimensionless stress versus flexibility ratio for a set of base reaction load angles $(2 \alpha)$ are shown in Figs. $4-26$ to $4-29$. Flexibility ratio is given by $R^{3} / 6 I$ where $I$ is the second moment of area of the liner cross section over a unit width. Flexibility ratio increases with decreasing liner thickness. The thickness of the liner was varied from 1.0 in. $(2.54 \mathrm{~cm})$ to 0.2 in. $(0.51 \mathrm{~cm})$.

The set of curves in Figs. 4-26 to 4-29 show that dimensionless stress increases with increasing flexibility ratio. Dimensionless stress also increases with increasing base reaction angle $2 \alpha$. The maximum bending stress for Load Case 1 approaches a limiting value at $2 \alpha=80^{\circ}$ and then decreases with further increase of $2 \alpha$. The bending stress for Load Case 2, however, increases with increasing $2 \alpha$.

Bending stress values presented in Tables 4-8 and 4-9 were obtained from Figs. 4-26 to 4-29 and correspond to a base reaction $w=1$ psi. Table 4-8 presents the maximum and minimum bending stresses for the range of $2 \alpha$ from $30^{\circ}$ to $80^{\circ}$ for Load Cases 1 and 2 and for liner thicknesses 0.5 in. $(1.27 \mathrm{~cm})$ and 0.2 in $(0.51$ $\mathrm{cm})$. Flexibility ratio for a $28 \mathrm{in}$. diameter liner with liner thickness $0.5 \mathrm{in} .(1.27 \mathrm{~cm})$ is $43.9 \times 10^{3}$ and for 0.2 in. 10.51 $\mathrm{cm})$ is $686 \times 10^{3}$. Table $4-9$ presents the results for a 36 in. diameter liner at flexibility ratios corresponding to $0.5 \mathrm{in.}$ $(1.27 \mathrm{~cm})$ and $0.2 \mathrm{in} .(0.51 \mathrm{~cm})$ thick liner.

\section{Table $4-8$}

BENDING STRESS FOR 28 IN. DIAMETER LINER

[Bending stresses are in ksi (MPa)]

\begin{tabular}{|c|c|c|c|c|}
\hline \multirow{2}{*}{$\begin{array}{l}\text { Elexibility } \\
\text { Ratio } \times 10^{3}\end{array}$} & \multicolumn{2}{|c|}{ Load Case 1} & \multicolumn{2}{|c|}{ Load Case 2} \\
\hline & $\begin{array}{l}\text { Maximum } \\
\left(2 \alpha=80^{\circ}\right)\end{array}$ & $\begin{array}{l}\text { Minimum } \\
\left(2 \alpha=30^{\circ}\right)\end{array}$ & $\begin{array}{l}\text { Maximum } \\
\left(2 \alpha=90^{\circ}\right)\end{array}$ & $\begin{array}{l}\text { Minimum } \\
\left(2 \alpha=30^{\circ}\right)\end{array}$ \\
\hline 43.9 & $\begin{array}{l}0.884 \\
(6.1)\end{array}$ & $\begin{array}{l}0.802 \\
(5.5)\end{array}$ & $\begin{array}{l}0.991 \\
(6.8)\end{array}$ & $\begin{array}{c}2.58 \\
(17.8)\end{array}$ \\
\hline 686 & $\begin{array}{c}7.96 \\
(54.9)\end{array}$ & $\begin{array}{c}5.01 \\
(34.6)\end{array}$ & $\begin{array}{c}6.19 \\
(42.7)\end{array}$ & $\begin{array}{c}16.1 \\
(111.0)\end{array}$ \\
\hline
\end{tabular}


Table $4-9$

BENDING STRESS FOR 36 IN. DIAMETER IINER

[Bending stresses are in ksi (MPa)]

\begin{tabular}{cccccc}
$\begin{array}{l}\text { Flexibility } \\
\text { Ratio } \times 10^{3}\end{array}$ & $\begin{array}{c}\text { Laximum } \\
\left(2 \alpha=80^{\circ}\right)\end{array}$ & $\begin{array}{c}\text { Minimum } \\
\left(2 \alpha=30^{\circ}\right)\end{array}$ & $\begin{array}{c}\text { Maximum } \\
\left(2 \alpha=90^{\circ}\right)\end{array}$ & $\begin{array}{c}\text { Minimum } \\
\left(2 \alpha=30^{\circ}\right)\end{array}$ \\
\hline \multirow{2}{*}{93.3} & 1.61 & 1.03 & 3.32 & 1.27 \\
& $(11.1)$ & $(7.1)$ & $(22.9)$ & $(8.8)$ \\
1460 & 10.2 & 6.46 & 20.7 & 7.96 \\
& $(70.3)$ & $(44.5)$ & $(142.8)$ & $(54.9)$ \\
\hline
\end{tabular}

It is clear from Tables $4-8$ and $4-9$ that bending stresses for a 0.5 in. (1.27 cm) thick liner with 28 in. $(71 \mathrm{~cm})$ diameter and 36 in. $(91 \mathrm{~cm})$ diameter and for Load Cases 1 and 2 vary between $0.802 \mathrm{ksi}(5.5 \mathrm{MPa})$ and $3.32 \mathrm{ksi}(23.9 \mathrm{MPa})$. These stress values are below $30 \mathrm{ksi}$ yield stress for low carbon steel. The stresses for 0.2 in. $(0.51 \mathrm{~cm})$ thick liner are higher. For Load Case 2 and $36 \mathrm{in}$. diameter the stress is as high as $20.7 \mathrm{ksi}(142.8$ MPa), which is still below the yield stress.

The analysis presented here can provide a design guide for 28 in. and 36 in. diameter liners and for two cases of loading. The design procedure involves estimation of the applied angle of base reaction $(2 \alpha)$ and evaluation of base reaction load $w$. The next step is to determine the dimensionless bending stress from Figs. 4-26 to 4-29 for a flexibility ratio corresponding to the liner thickness. The dimensionless bending stress is then multiplied by $w$ to obtain the actual bending stress which can be compared to the allowable limits of yield stress of the liner material. 


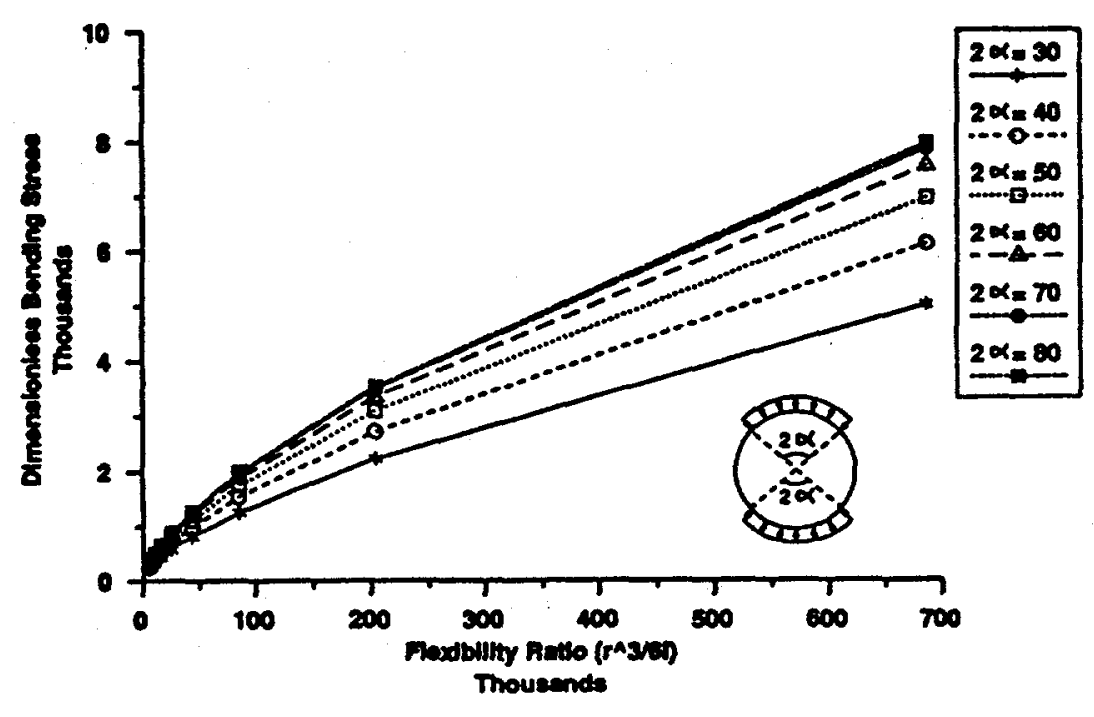

Fig. 4-26 Dimensionless Maximum Bending Stress for 28 in. $(71 \mathrm{~cm})$ Diameter Borehole Liner for Load Case 1

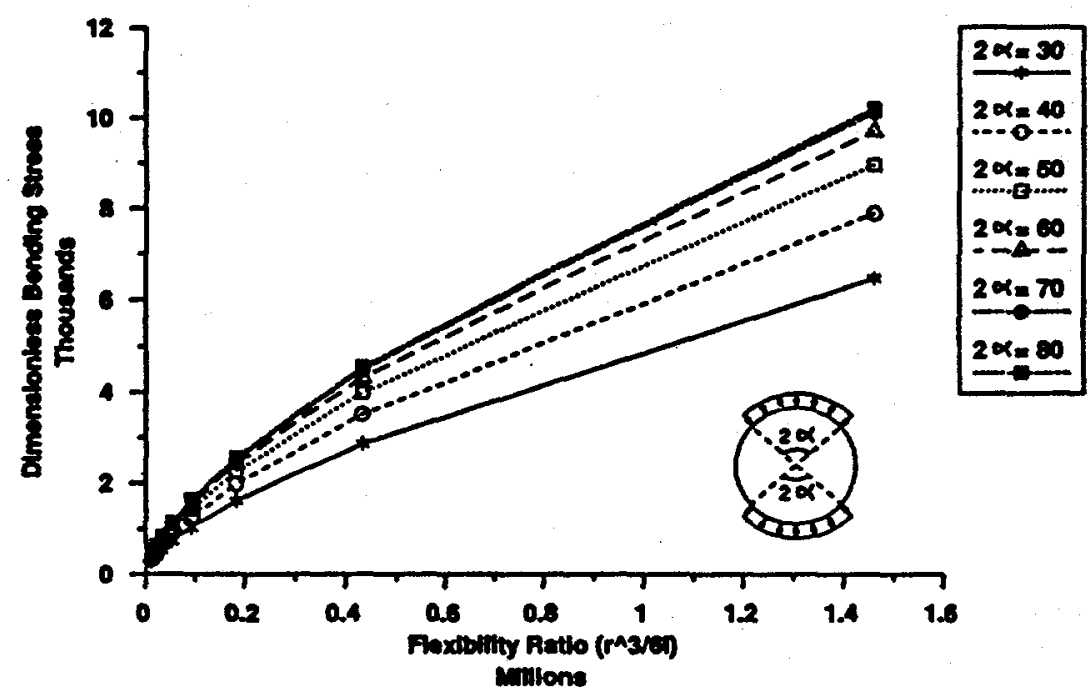

Fig. 4-27 Dimensionless Maximum Bending stress for 36 in. (91 cm) Diameter Borehole Liner for Load Case 1 


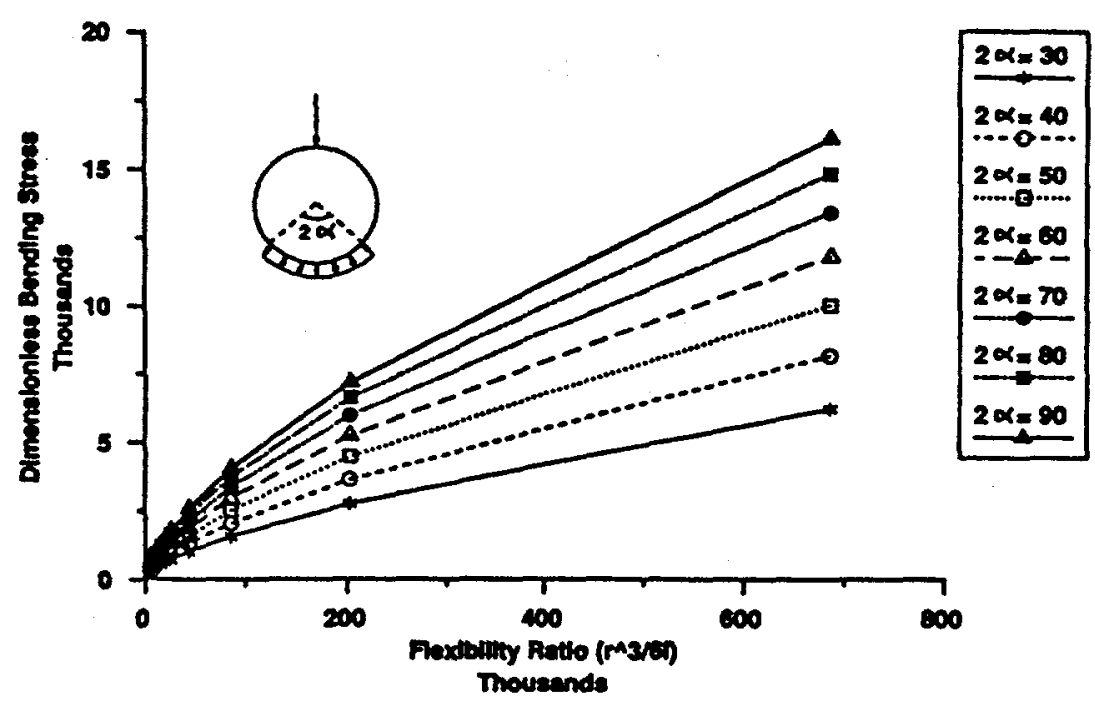

Fig. 4-28 Dimensionless Maximum Bending Stress for 28 in. $(71 \mathrm{~cm})$ Diameter Borehole Liner for Load Case 2

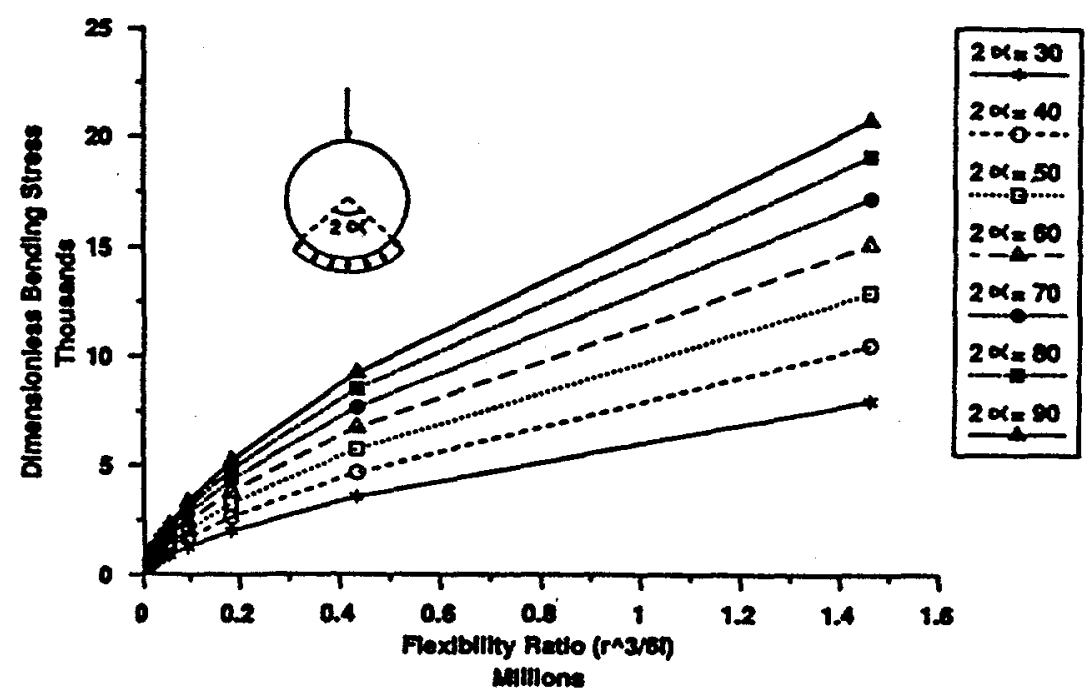

Fig. 4-29 Dimensionless Maximum Bending Stress for 36 in. $(91 \mathrm{~cm})$ Diameter Borehole Liner for Load Case 2 


\subsection{DISCUSSION}

\subsection{Installation Tolerance and Borehole Closure}

The borehole closures predicted here are all less than onequarter inch $(6 \mathrm{~mm})$. The clearance space or installation tolerance between the borehole wall and any liner is likely to be onequarter inch or larger. Therefore, it is unlikely that borehole closure will significantly load any lining.

It should be noted that the results presented thus far do not address the issue of borehole liner thermal expansion. It is reasonable to ignore borehole liner thermal expansion based on the following.

Radial expansion, $u_{r}$, of a thin-walled cylinder with radius, $r$, heated uniformly is given by

$$
u_{r}=r \beta \Delta T
$$

where $\beta=$ coefficient of linear thermal expansion, and

$$
\Delta \mathrm{T}=\text { temperature change. }
$$

For steel with $\beta=11.7 \mathrm{e}^{-6 /{ }^{\circ} \mathrm{C}}$ [see, for example, AISC (1970), p. 6-12], and $\Delta \mathrm{T}=250^{\circ} \mathrm{C}$, the radial expansion of a 36 in. diameter cylinder is $0.053 \mathrm{in.}(1.35 \mathrm{~mm})$. For a cylinder with a 28 in. diameter, the calculated radial expansion is 0.041 in. (1.04 mm). Note that radial expansion is independent of liner thickness. 


\subsection{Gravity Loading of Borehole Liner}

Blocks which are kinematically capable of potentially falling onto the lining can be identified by superimposing assumed joint patterns onto the borehole geometry and either inspecting visualIy or using topologic methods such as given by Yow (1985). Stability of potential wedges depends primarily on the joint friction angle and wedge geometry as shown in Fig. 5-1.

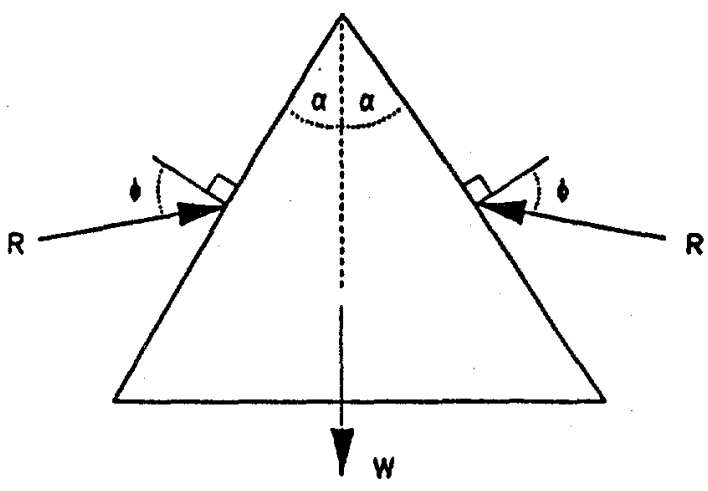

favorable: $\phi>\alpha$

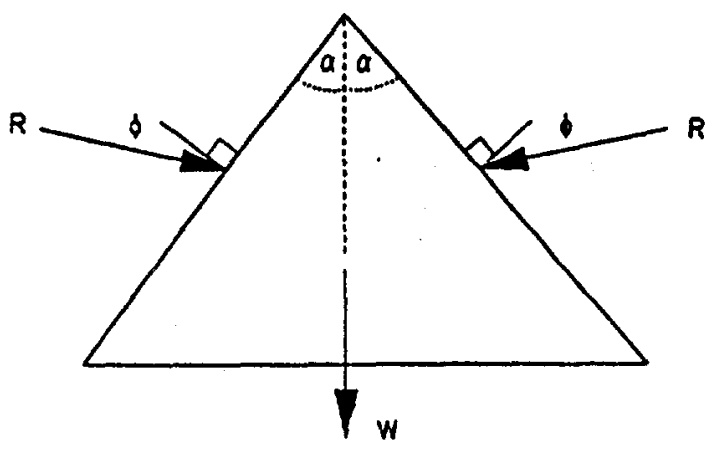

unfavorable: $\phi<a$

Fig. 5-1 Conditions Favorable and Unfavorable for Wedge Stability, Based on Closed Form Solutions 
The force required to support individual unstable wedges can be estimated analytically. The analytic solution for the static equilibrium of a two-dimensional symmetric wedge, such as shown in Fig. 5-2, bounded by non-dilatant cohesionless joints with $\Phi$ greater than $\alpha$ is given by Brady and Brown (1985) as:

for $K_{n} \gg K_{s}$

$$
A=W-2 H_{0} \sin \alpha \sin (\Phi-\alpha) / \sin \Phi
$$

for $K_{n}=K_{s}$

$$
A=W-2 H_{0} \tan (\Phi-\alpha)
$$

where $A$ = required support force,

$\mathrm{w}$ = weight of wedge,

$\mathrm{H}_{0}=$ horizontal force representing tangential stress flow around the hole,

$K_{n}=$ joint normal stiffness, and

$K_{s}=$ joint shear stiffness.

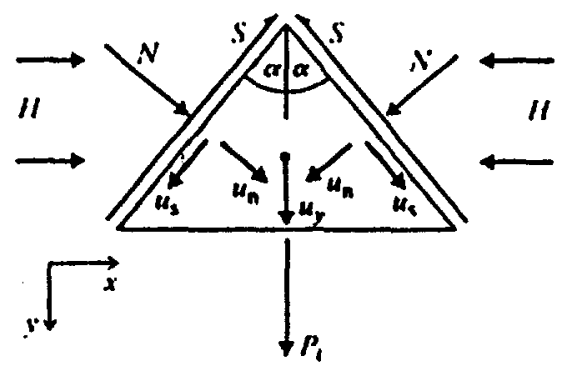

Fig. 5-2 Problem Geometry and Parameters Used in Deriving Formulae for Determining Force Required to support an Isolated Wedge 
Results shown in Section 4 confirm the notion given in Appendix $B$ of the SCPCDR that gravity loading by isolated wedges does not significantly stress borehole liners.

\subsection{Intersection of Borehole Liners and Emplacement Drifts}

This report considered the 2-D plain strain behavior of a borehole. The assumption inherent in these analyses is that the borehole is infinitely long and does not intersect any drifts, etc. Christianson and Brady (1989) examined horizontal borehole stability near intersections with drifts by assuming an insitu stress ratio of 13 vertical to 1 horizontal. These authors noted that the vertical tangential stress is initially high compared with the horizontal tangential stress directed parallel to the drift axis. As heating proceeds, the vertical tangential stress at the drift wall for a period becomes tensile and then returns to a compressive state. The authors state that this stress path could conceivably lead to initial rock mass failure at the borehole collar, followed by loosening and detachment of broken material, and then reloading, resulting in appreciable transfer of load to the borehole liner.

5.4 Long-Term Exposure of Tuff to Elevated Temperatures, Stress and Radiation Levels

Implicit in the analyses presented here is the assumption that the tuff thermomechanical properties do not change with time or elevated temperature and stress levels. Initial studies of these long-term effects are reported by Blacic et al. (1986). These authors observed "relatively large differences in tensile strength, compressive strength, and permeability between control and altered samples" (p. 26). They noted that thermal properties were unaffected by hydrothermal exposure, and concluded "that large charges in tuff mechanical properties may result from hydrothermal alteration, without correlated large changes in mineralogy or thermal properties," (p. 27). If tuff mechanical properties were to degrade with time and exposure, then the results of this study could be significantly changed.

Exposure of tuff to radiation is not discussed here. DOE has not developed a specific plan to investigate radiation effects on thermal and mechanical rock properties. SCP section 8.3.4.3.4.1.5 describes an activity to establish effects of radiation on water chemistry. Radiation-field effects are also described in SCP Section 7.4 .1 .4 . 


\subsection{Redundancy of Circular Rings}

All of the lining analyses presented in the study have involved elastic analyses of representative ring structures. Nothing has been discussed about the ultimate capacity of the rings. Capacity greater than that predicted by initial yield may result from passive reactions which the lining develops against the rock, preventing unrestricted deformation. The level of ultimate capacity achieved is therefore a function of the loading conditions and problem geometry (i.e., deformation required to develop passive reactions).

\subsection{Boreholes Intersected by Fault or Shear zone}

It is likely impossible to attempt to design a borehole lining to resist a potential offset of a fault or shear zone. DOE recognizes this and states that "boreholes will be inspected for fault and shear zone, and waste packages will not be emplaced across such regions," (SCP, p. 8.3.4.2-28). Analyses presented in this study do not consider the direct effect of possible transverse fault displacement across the borehole axis, nor to they consider any seismic effects. Stress analyses of linings which are deformed by displacements transverse to the borehole axis are complex because of the possible deformation modes involved as shown in Fig. 5-3. Case (a) represents the case where the liner is in intimate contact with the borehole, and displaces with it. Case (b) represents the case of lining in an oversized borehole, such that the lining only tilts to accommodate the displacement.

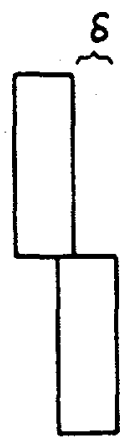

a

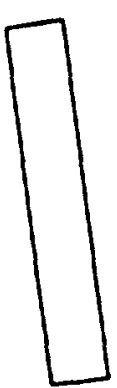

b

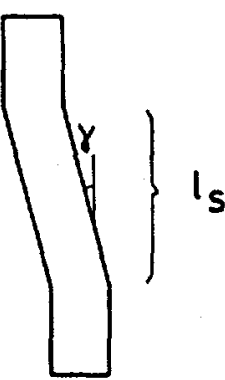

C

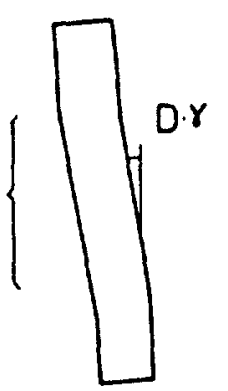

d

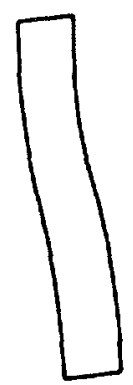

e

Fig. 5-3 Possible Liner Deformations Due to Rock Displacements in an Emplacement Hole (after Borgesson, 1986) 
In case (c), the liner is assumed to be fixed at both ends without lifting and sheared over a certain length $l_{s}$ and shear strain $\gamma$. Case (d) is similar to (c) with the exception that some tilting has occurred, reducing the shear strain in the liner by a factor D. The most probable case is case (e) which involves some bending.

\subsection{Borehole Liner Thermal Stress}

Circumferential and longitudinal stresses develop in long hollow cylinders with thin walls only if a temperature gradient exists through the thickness of the wall (see, for example, Roark and Young, 1975, p. 585). Assuming the outer surface is at a uniform temperature $T$, the inner surface is at a uniform temperature $T+$ $\Delta T$, and the temperature gradient through the thickness is linear, then, at points remote from the ends, the maximum circumferential stress is $1 / 2 \Delta \mathrm{T} \beta \mathrm{E} /(1-\mathrm{V})$, and the maximum longitudinal stress is also $1 / 2 \Delta T \beta E /(1-V)$, where $\beta=$ coefficient of linear thermal expansion, $\mathrm{E}=$ modulus of elasticity, and $\boldsymbol{v}=$ Poisson's ratio. Since it is unlikely that significant thermal gradients will exist across the borehole liner, borehole liner thermal stresses may reasonably be ignored. 


\subsection{RECOMMENDATION FOR FUTURE STUDIES}

Studies of borehole behavior presented here are restricted to 2-D plain strain analyses. These studies therefore do not provide vigorous analyses for the vertical emplacement option. Additionally, previous studies by Christianson and Brady (1989) have indicated that the most serious problems associated with borehole behavior may involve their intersection with emplacement drifts. Future studies therefore, should include three-dimensional analyses.

In this study, only rock strength values were systematically varied. Future studies shown investigate other problem variables, including in-situ stress state.

The results of in-situ testing at Yucca Mountain should be closely monitored. In particular, results of canister-scale heater tests should be compared to analyses similar to those presented here. This study should then be updated at a later date to reflect an improved understanding of conditions and behavior at repository depth. 


\subsection{REEERENCES}

AISC (American Institute of Steel Construction, Inc.). Manual of Steel Construction, 7th Ed. New York: AISC, 1970.

Arulmoli, K., and C. M. St. John. Analysis of Horizontal Waste Emplacement Boreholes of a Nuclear Waste Repository in Tuff. Sandia National Laboratories, SAND86-7133, March 1987.

Barton, Nick. "Modelling Rock Joint Behavior from In Situ Block Tests: Implications for Nuclear Waste Repository Design," TerraTek Report to ONWI, ONWI-308, 1982.

Blacic, J. D., D. T. Vaniman, D. L. Bish, C. J. Duffy and R. C. Gooley. "Effects of Long-Term Exposure of Tuffs to High-Level Nuclear Waste Repository Conditions: Final Report," Los Alamos National Laboratory, LA-9330-MS, August 1986.

Board, Mark. "Near-Field Thermal Analysis of SCP-CDR Waste Emplacement Schemes at NNWSI," Itasca Consulting Group Inc. Report, U.S. NRC, Contract NRC-02-85-002, July 1988.

Borgesson, Lennart. "Model Shear Tests of Canisters with Smectite Clay Envelopes in Deposition Holes," SKB (Swedish Nuclear Fuel and Waste Management Co.) Technical Report 86-26, December 1986.

Brady, B.H.G., and E. T. Brown. Rock Mechanics for Underground Mining. London: George Allen and Unwin, 1985.

Christianson, M. C., and B. Brady. Analysis of Alternative Waste Isolation Concepts. U.S. Nuclear Regulatory Commission, NUREG/ CR-5389, June 1989.

Cundall, P.A., and J. V. Lemos. "Numerical Simulation of Fault Instabilities with the Continuously-Yielding Joint Model, " in Proc. 2nd Int. Symp. on Rockbursts and Seismicity in Mines (University of Minnesota, June 1988).

Flores, Richard J. "Retrievability: Strategy for Compliance Demonstration," Sandia National Laboratories, SAND84-2242, January 1986. 
Itasca Consulting Group, Inc. UDEC (Universal Distinct Element Code), Version ICGI.5 User's Manual. Minneapolis, Minnesota: ICG, 1989.

Johnstone, J. Keith, Ralph R. Peters and Paul E. Gnirk. Unit Evaluation at Yucca Mountain, Nevada Test Site: Summary Report and Evaluation. Sandia National Laboratories, SAND83-0372, June 1984 .

Keyser, Carl A. Materials Science in Engineering, 3rd Ed. Columbus, Ohio: Charles E. Merrill Publishing Co., 1980.

MacDougall, Hugh R., Leo W. Scully and Joe R. Tillerson (Compilers). Site Characterization Plan Conceptual Design Report. Sandia National Laboratories, SAND84-2641, September 1987.

Mansure, A. J. "Expected Temperatures for Spent Fuel Borehole Walls and Drifts," Memo to R. J. Flores, Sandia Keystone Memo 6310-85-8, April 15, 1985.

Nimick, Francis B., and Barry M. Schwartz. Bulk, Thermal, and Mechanical Properties of the Topopah Spring Member of the Paintbrush Tuff, Yucca Mountain, Nevada. Sandia National Laboratories, SAND85-0762. September 1987.

Nuclear Waste Policy Act of 1982. Public Law 97-425, 96 stat. 2201, 42 USC 10101, Washington, D.C., January 1983.

Peters, Ralph R. "Thermal Response to Emplacement of Nuclear Waste in Long, Horizontal Boreholes, "Sandia National Laboratories, SAND82-2497, April 1983.

Roark, R. J., and W. E. Young. Formulas for Stress and Strain. New York: MCGraw-Hill Book Co., 1975.

St. John, Christopher, and Mark Christianson. "STRES3D: A Computer Program for Determining Temperatures, Stresses, and Displacements Around Single or Arrays of Constant or Decaying Heat Sources - User's Guide and Manual," University of Minnesota Report to Rockwell Hanford Operations, RHO-BWI-C-78, September 1980 .

U.S. Department of Energy. Consultation Draft Site Characterization Plan, Yucca Mountain Site, Nevada Research and Development Area, Nevada (CDSCP). Nuclear Waste Policy Act, Section 113. January 1988 b. 
U.S. Department of Energy (DOE). "Generic Requirements for a Mined Geologic Disposal System, Appendix D, 'Department of Energy Position on Retrievability and Retrieval for a Geologic Repository," OGR/B-2, DOE/RW-0090, Office of Civilian Radioactive Waste Management, Washington, D.C., September 1986.

U.S. Department of Energy. Site Characterization Plan, Yucca Mountain Site, Nevada Research and Development Area, Nevada, Nuclear Waste Policy Act (Section 113). DOE/RW-0198. December 1988a.

Yow, J. L. "Field Investigation of Keyblock Stability," Lawrence Livermore National Laboratory, UCRL-53632, April 1985.

Zimmerman, Roger M., Robert L. Schuch, Donald S. Mason, Michael L. Wilson, Michael E. Hall, Mark P. Board, Robert P. Bellman and Mark I. Blanford. Einal Report: G-Tunnel Heated Block Experiment. Sandia National Laboratories, SAND84-2620. May 1986. 
APPENDIX A

UDEC INPUT COMMANDS

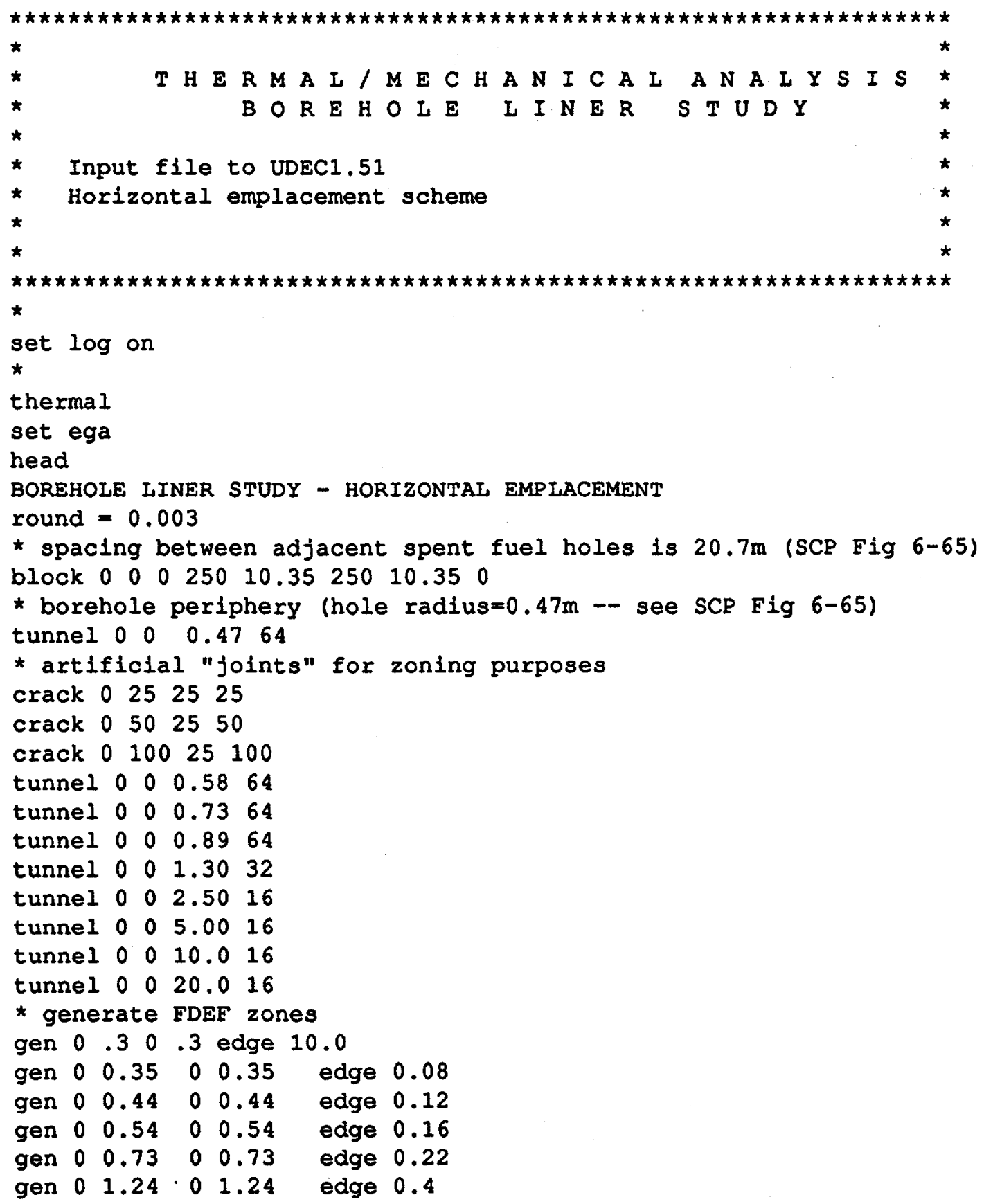




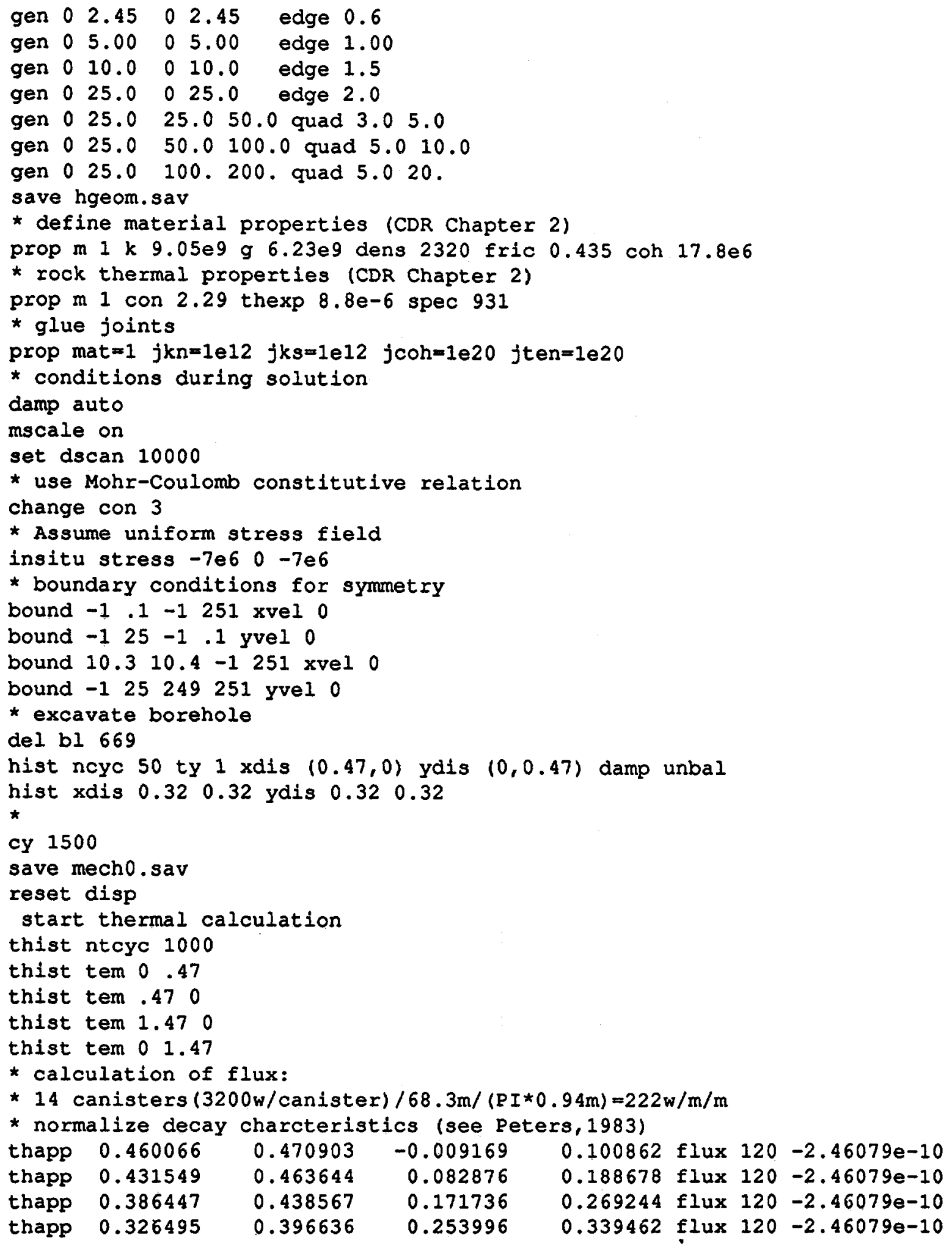




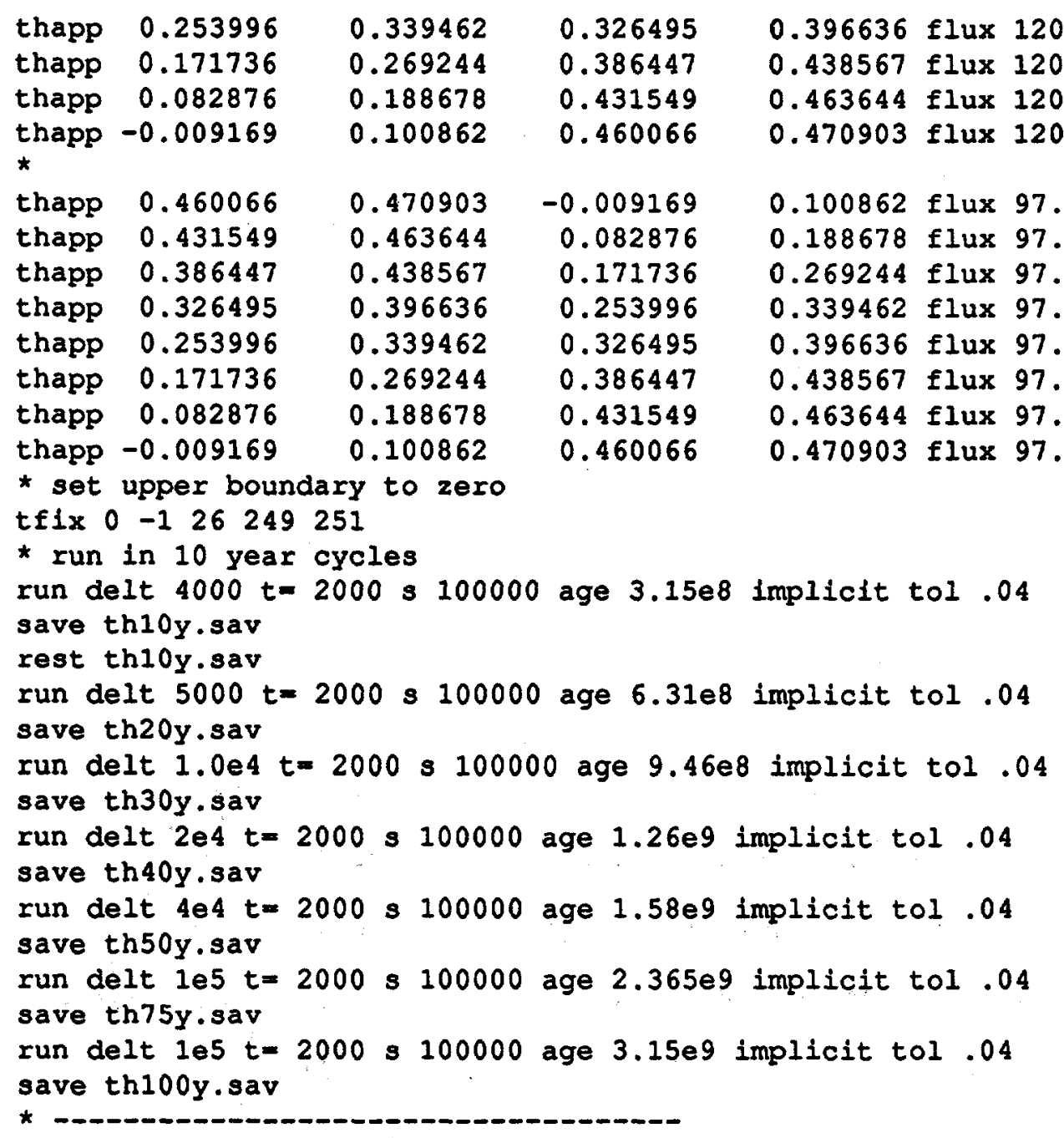




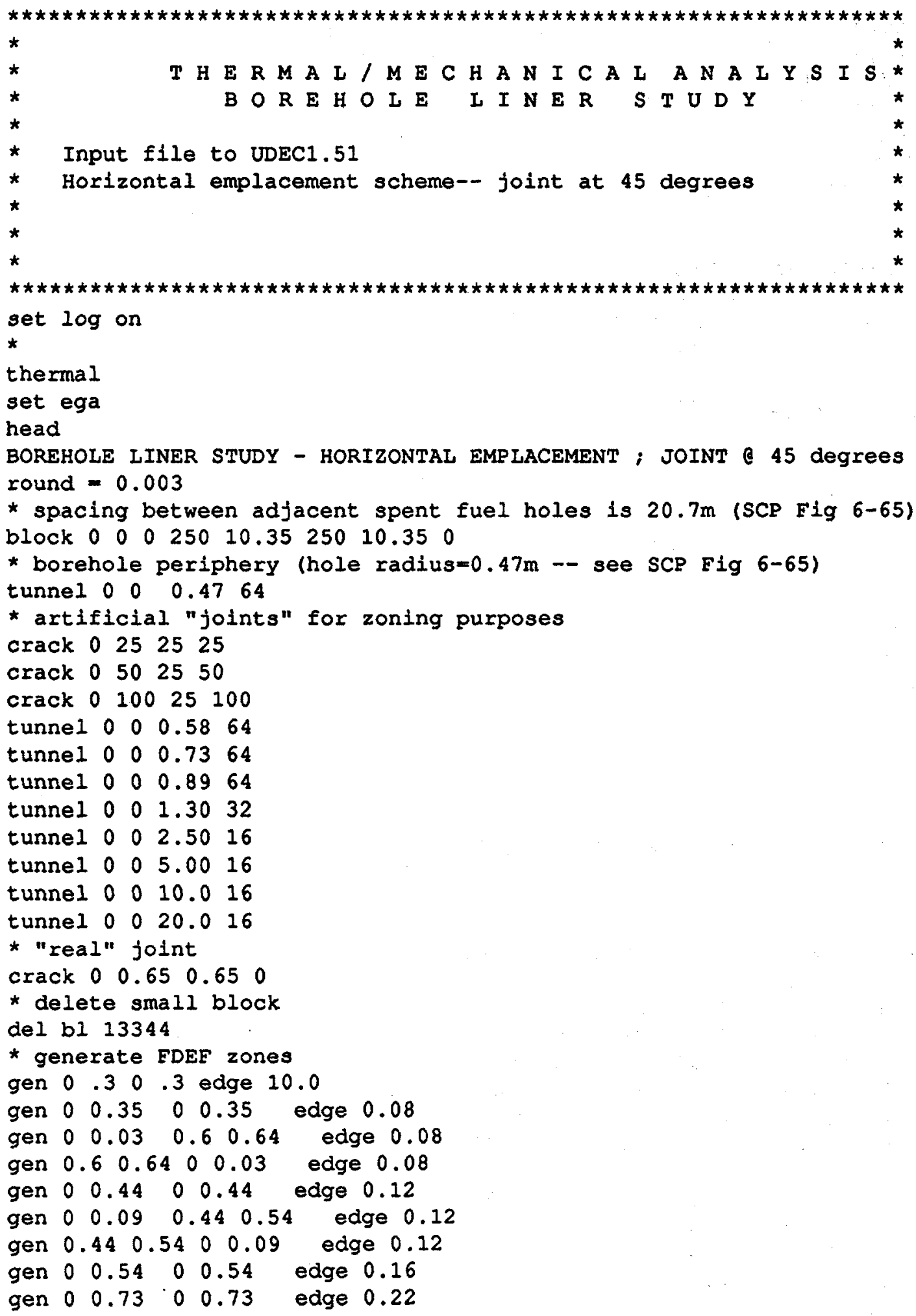




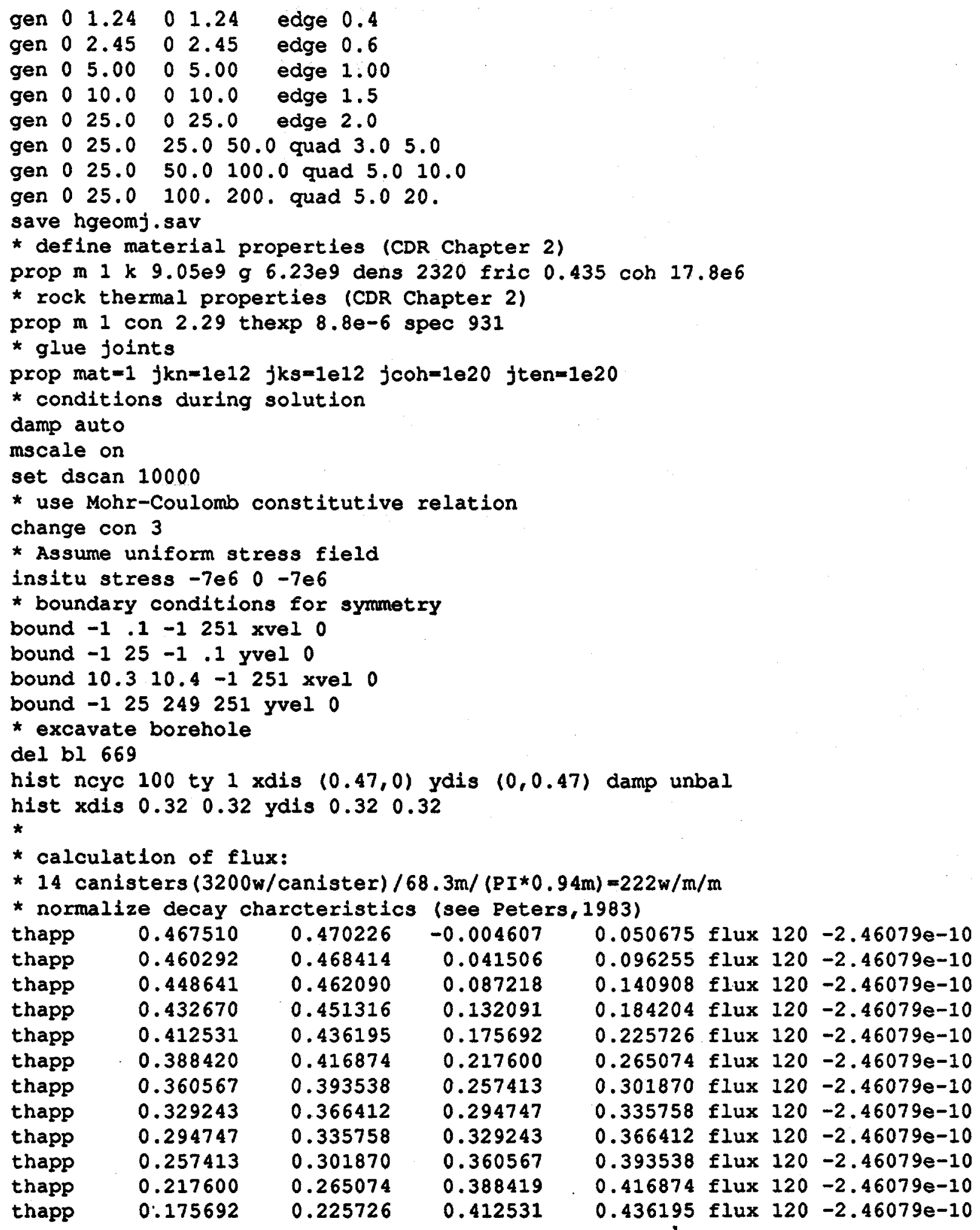




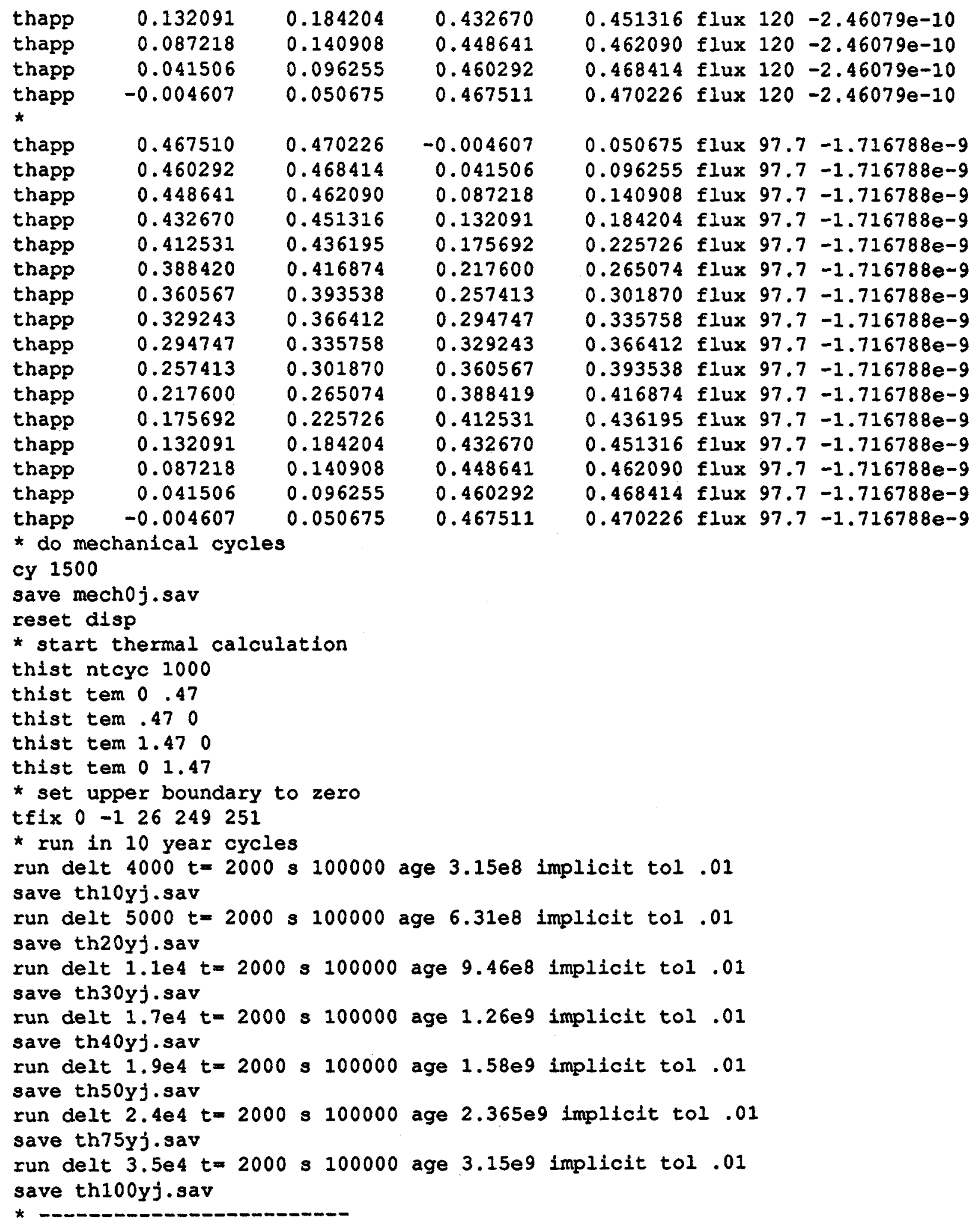




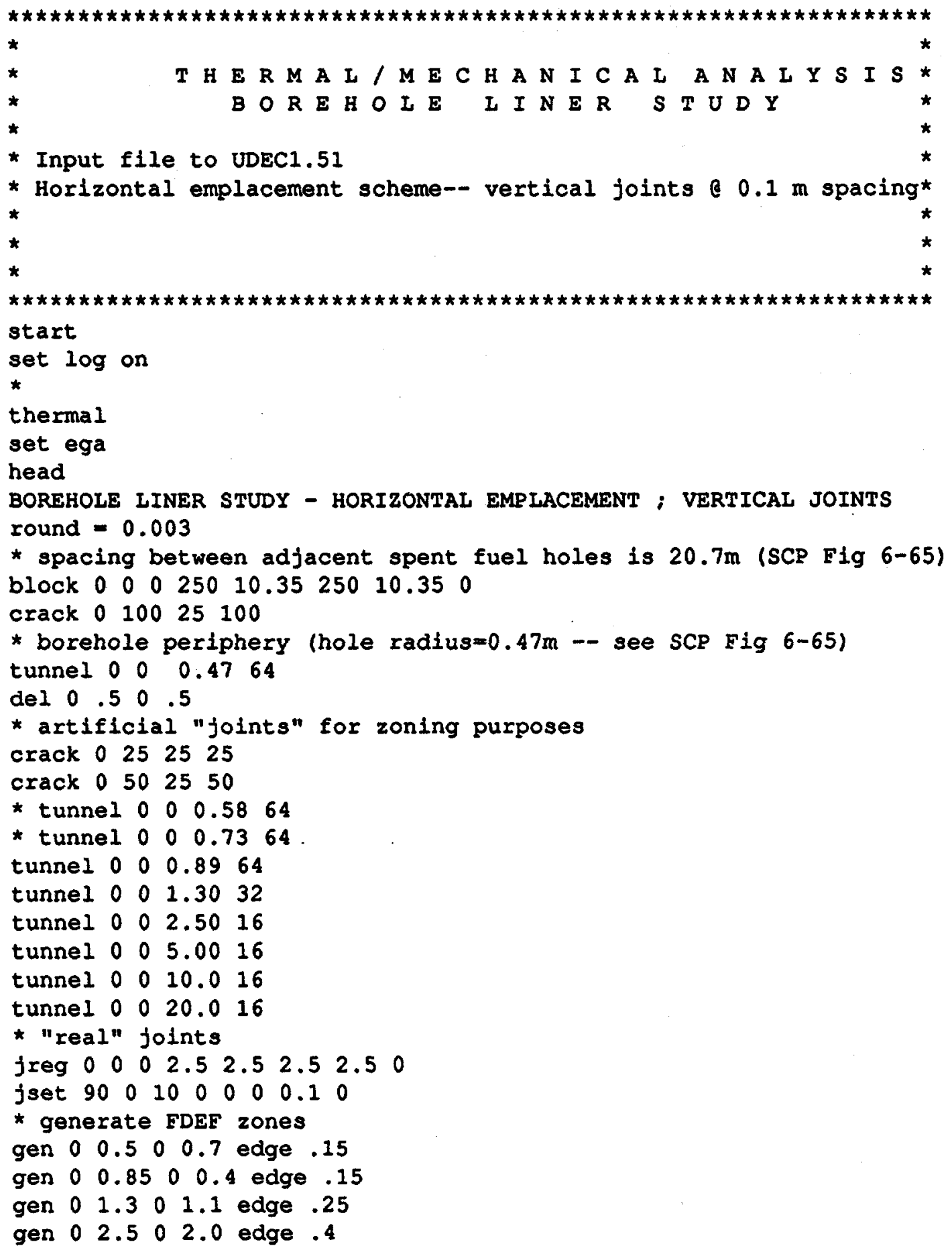


* gen 0.30 .3 edge 10.0

* gen $0 \quad 0.35 \quad 0 \quad 0.35$ edge 0.08

* gen $0 \quad 0.03 \quad 0.6 \quad 0.64$ edge 0.08

* gen $0.6 \quad 0.6400 .03$ edge 0.08

* gen $00.44 \quad 0 \quad 0.44$ edge 0.12

* gen $00.09 \quad 0.44 \quad 0.54$ edge 0.12

* gen 0.440 .5400 .09 edge 0.12

* gen $0 \quad 0.54 \quad 0 \quad 0.54$ edge 0.16

* gen $00.73 \quad 0 \quad 0.73$ edge 0.22

* gen 01.2401 .24 edge 0.4

gen $022.45 \quad 02.45$ edge 0.6

gen $0 \quad 5.00 \quad 0 \quad 5.00$ edge 1.00

gen $0 \quad 10.0 \quad 0 \quad 10.0 \quad$ edge 1.5

gen $\begin{array}{lllll}0 & 25.0 & 0 & 25.0 & \text { edge } 2.0\end{array}$

gen $025.0 \quad 25.0 \quad 50.0$ quad 3.05 .0

gen $025.0 \quad 50.0 \quad 100.0$ quad $5.0 \quad 10.0$

gen 025.0 100. 200. quad 5.020 .

save hgeomv.sav

* define rock mass material properties (CDR Chapter 2)

prop $\mathrm{m} 1 \mathrm{k} 9.05 \mathrm{e} 9 \mathrm{~g} 6.23 \mathrm{eg}$ dens 2320 fric $0.435 \mathrm{coh} 17.8 \mathrm{e} 6$

* rock thermal properties (CDR Chapter 2)

prop $\mathrm{m} 1$ con 2.29 thexp $8.8 \mathrm{e}-6$ spec 931

* glue joints

prop mat $=1 j k n=1$ el2 jks=1e12 jcoh=1e20 jten=1e20

* define intact rock mass properties (CDR Chapter 2)

prop $\mathrm{m} 2 \mathrm{k} 18.1 \mathrm{e} 9 \mathrm{~g} 12.46 \mathrm{e} 9$ dens 2320 fric 0.56 coh $50 \mathrm{e} 6$

* rock thermal properties (CDR Chapter 2)

prop m 2 con 2.29 thexp $8.8 e-6$ spec 931

* joints

prop mat $=2 j k n=1 e 11 j k s=1 e 11$ jcoh $=1 e 6$ jfric $=0.8$

* conditions during solution

damp auto

mscale on

set dscan 10000

* use Mohr-Coulomb constitutive relation

change con 3 mat $=1$ jcon $=2$ jmat $=1$

* assign properties to near field

change $02.5 \quad 02.4$ mat $=2$

change angle 8991 jmat $=2$ jcon $=5$

* Assume uniform stress field

insitu stress $-7 e 6 \quad 0-7 e 6$ nodis

* boundary conditions for symmetry

bound $-1.12-1251$ xvel 0

bound $-1 \quad 25-1 \quad .1$ yvel 0

bound $10.3 \quad 10.4-1251$ xvel 0

bound -1 25249251 yvel 0

hist ncyc 100 ty 1 xdis $(0.47,0)$ ydis $(0,0.47)$ damp unbal

$\begin{array}{llllll}\text { hist } x d i s & 0.32 & 0.32 & y d i s & 0.32 & 0.32\end{array}$ 


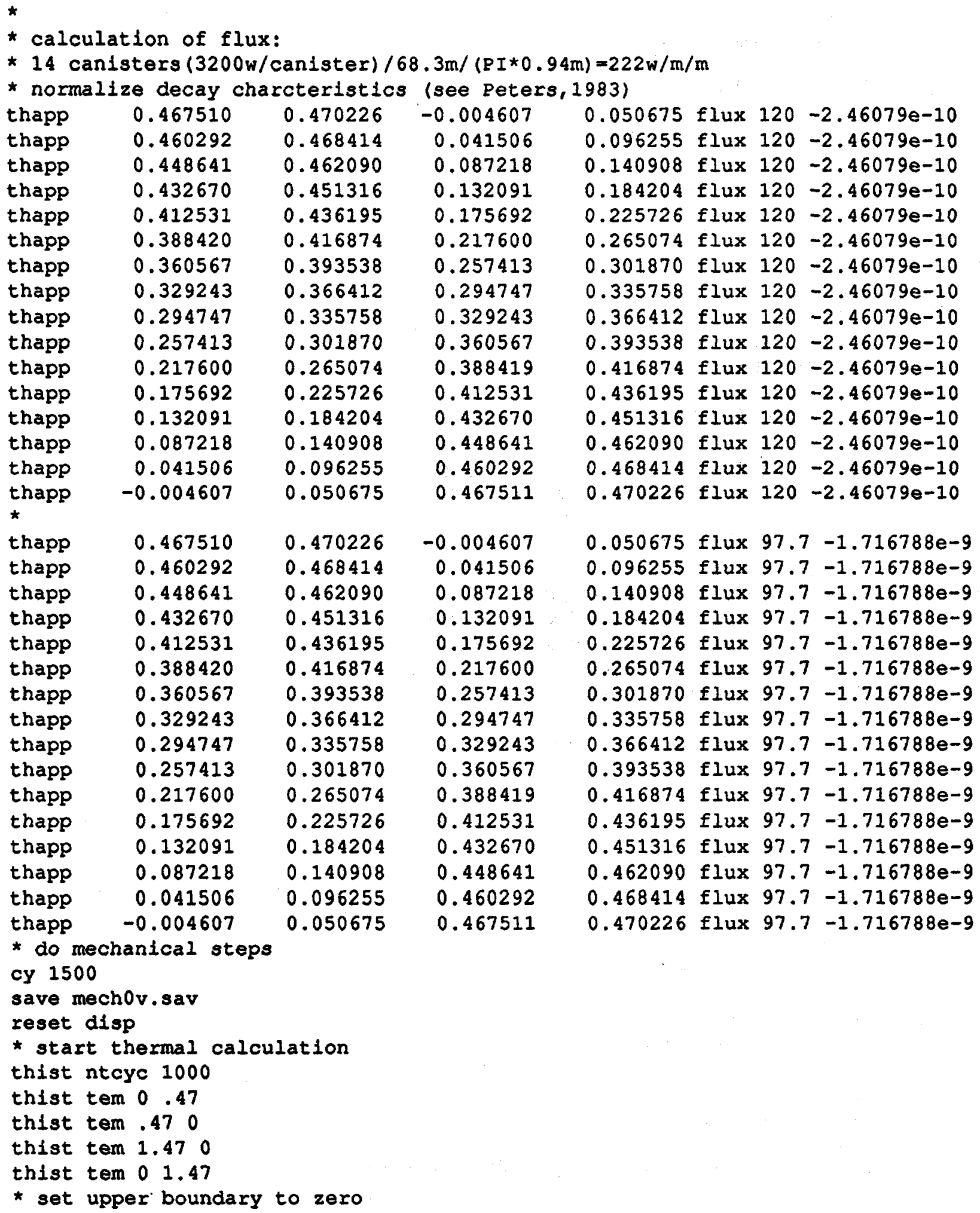


tfix $0 \quad-126249251$

* run in 10 year cycles

run delt $4000 t=2000$ s 100000 age $3.15 e 8$ implicit tol .01 save thloyv.sav run delt $0.7 e 4 t=2000$ s 100000 age $6.31 e 8$ implicit tol .01 save th20yv.sav run delt $0.9 e 4 t=2000 \mathrm{~s} 100000$ age $9.46 \mathrm{e} 8$ implicit tol .01 save th30yv.sav run delt $1.0 \mathrm{e} 4 \mathrm{t}=2000 \mathrm{~s} 100000$ age $1.26 \mathrm{e} 9 \mathrm{implicit}$ tol .01 save th40yv.sav run delt 1.1 e4 $t=2000$ s 100000 age $1.58 \mathrm{e} 9$ implicit tol .01 save th50yv.sav run delt $1.25 e 4 t=2000$ s 100000 age $2.365 e 9$ implicit tol .01 save th75yv.sav run delt $1.30 e 4 t=2000 \mathrm{~s} 100000$ age $3.15 \mathrm{e}$ implicit tol .01 save thlooyv.sav

ret 


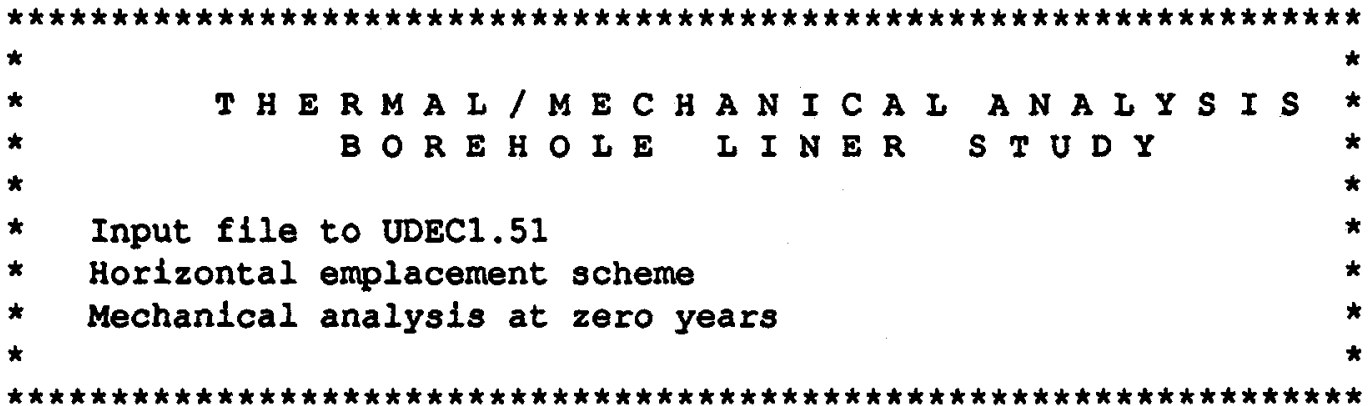

set $\log$ on

* -..- continuum model _-.. "recommended " values

rest hgeom.sav

* define material properties (CDR Chapter 2)

prop m $1 \mathrm{k} 9.05 \mathrm{eg} \mathrm{g} 6.23 \mathrm{e} 9$ dens 2320 fric $0.435 \mathrm{coh} 17.8 \mathrm{e} 6$

* rock thermal properties (CDR Chapter 2)

prop m 1 con 2.29 thexp 8.8 e-6 spec 931

* glue joints

prop mat $=1$ jkn=1e12 jks=1e12 jcoh=1e20 jten=1e20

* conditions during solution

damp auto

mscale on

set dscan 10000

* use Mohr-Coulomb constitutive relation

change con 3

* Assume uniform stress field

Insitu stress $-7 e 6 \quad 0 \quad-7 e 6$

* boundary conditions for symmetry

bound $-1.1 \quad 1 \quad-1251$ xvel 0

$\begin{array}{lllllll}\text { bound } & -1 & 25 & -1 & .1 & \text { yvel } & 0\end{array}$

bound $10.310 .4-1251$ xvel 0

bound -125249251 yvel 0

* excavate borehole

del bl 669

hist ncyc 50 ty 1 xdis $(0.47,0)$ ydis $(0,0.47)$ damp unbal

hist xdis 0.320 .32 ydis 0.320 .32

*

cy 2500

save mechor.sav

pr h 1256

* -

* -- continuum model _... "design " values

rest hgeom.sav

* define material properties (CDR Chapter 2)

prop m 1 k $9.05 e 9$ g $6.23 e 9$ dens 2320

prop m 1 fric 0.56 coh 22.1 e 6

* rock thermal properties (CDR Chapter 2)

prop $\mathrm{m} 1$ con 2.29 thexp $8.8 \mathrm{e}-6$ spec 931 
* glue joints

prop mat $=1 j k n=1$ e12 jks=1e12 jcoh $=1$ e20 jten $=1$ e20

* conditions during solution

damp auto

mscale on

set dscan 10000

* use Mohr-Coulomb constitutive relation

change con 3

* Assume uniform stress field

insitu stress $-7 e 6 \quad 0 \quad-7 e 6$

* boundary conditions for symmetry

bound -1.1 . 1251 xvel 0

$\begin{array}{lllllll}\text { bound } & -1 & 25 & -1 & .1 & \text { yvel } & 0\end{array}$

bound $10.3 \quad 10.4 \quad-1251$ xvel 0

bound -125249251 yvel 0

* excavate borehole

del bl 669

hist neyc 50 ty 1 xdis $(0,47,0)$ ydis $(0,0.47)$ damp unbal

hist xdis 0.320 .32 ydis $0.32 \quad 0.32$

*

cy 2500

save mechod.sav

prh 12556

*

* -..- continuum model -..- "limit " values

rest hgeom.sav

* define material properties (CDR Chapter 2)

prop $\mathrm{m} 1 \mathrm{k} 9.05 \mathrm{e} 9 \mathrm{~g} 6.23 \mathrm{e} 9$ dens 2320

prop m 1 fric 0.285 coh $12.1 \mathrm{e} 6$

* rock thermal properties (CDR Chapter 2)

prop $\mathrm{m} 1$ con 2.29 thexp $8.8 e-6$ spec 931

* glue joints

prop mat $=1 j k n=1 e 12 j k s=1 e 12 j c o h=1 e 20 j$ jen $=1$ e20

* conditions during solution

damp auto

mscale on

set dscan 10000

* use Mohr-Coulomb constitutive relation

change con 3

* Assume uniform stress field

insitu stress $-7 e 6 \quad 0 \quad-7 e 6$

* boundary conditions for symmetry

bound $-1.1 \quad 1 \quad-1251$ xvel 0

bound $-1 \quad 25 \quad-1.1$ yvel 0

bound $10.3 \quad 10.4 \quad-1251$ xvel 0

bound -125249251 yvel 0

* excavate borehole

del bl 669 . 
hist ncyc 50 ty 1 xdis $(0.47,0)$ ydis $(0,0.47)$ damp unbal hist xdis 0.320 .32 ydis $0.32 \quad 0.32$

*

cy 2500

save mech01.sav

pr h 1256

*

* 45 degree foints "recommended" values

rest hgeomf.sav

* define material properties (CDR Chapter 2)

prop $\mathrm{m} 1 \mathrm{k} 9.05 \mathrm{e} 9 \mathrm{~g} 6.23 \mathrm{e} 9$ dens 2320 frlc $0.435 \mathrm{coh} 17.8 \mathrm{e} 6$

* rock thermal properties (CDR Chapter 2)

prop $\mathrm{m} 1$ con 2.29 thexp $8.8 \mathrm{e}-6$ spec 931

* glue joints

prop mat=1 jkn=1e12 jks=1e12 jcoh=1e20 jten=1e20

* 45 degree joints

change $0 \quad 0.65 \quad 0 \quad 0.65$ angle $-46 \quad-44$ jmat 2 jcon=5

prop $\mathrm{m} 2 \mathrm{jkn}$ lell jks lell jfric 0.54 jcoh $=0.1 \mathrm{e} 6$

* conditions during solution

damp auto

mscale on

set dscan 10000

* use Mohr-Coulomb constitutive relation

change con 3

* Assume uniform stress field

insitu stress $-7 e 6 \quad 0 \quad-7 e 6$

* boundary conditions for symmetry

bound $-1.12-1251$ xvel 0

bound $-1 \quad 25 \quad-1 \quad .1$ yvel 0

bound $10.310 .4-1251$ xvel 0

bound -125249251 yvel 0

* excavate borehole

del bl 669

hist ncyc 100 ty 1 xdis $(0.47,0)$ ydis $(0,0.47)$ damp unbal

hist xdis 0.320 .32 ydis $0.32 \quad 0.32$

$\star$

cy 2500

save mechojr.sav

pr h 1256

* 45 degree foints "design" values

rest hgeomj.sav

* define material properties (CDR Chapter 2)

prop m 1 k $9.05 e 9 \mathrm{~g} 6.23 \mathrm{e} 9$ dens 2320

prop $m 1$ fric 0.56 coh 22.1 e 6

* rock thermal properties (CDR Chapter 2)

prop $\mathrm{m} 1$ con 2.29 thexp $8.8 e-6$ spec 931

* glue joints 
prop mat $=1 j k n=1$ el2 jks=1el2 jcoh $=1$ e20 jten $=1$ e 20

* 45 degree joints

change $0 \quad 0.65 \quad 0 \quad 0.65$ angle $-46-44$ jmat 2 jcon $=5$

prop $m 2 j k n$ lell jks lell jfrlc 0.80 jcoh=1.0e 6

* conditions during solution.

damp auto

mscale on

set dscan 10000

* use Mohr-Coulomb constitutive relation

change con 3

* Assume uniform stress field

insitu stress $-7 e 6 \quad 0 \quad-7 e 6$

* boundary conditions for symmetry

bound $-1.12-1251$ xvel 0

bound $-1 \quad 25-1.1$ yvel 0

bound $10.3 \quad 10.4-1251$ xvel 0

bound -1 25249251 yvel 0

* excavate borehole

del bl 669

hist ncyc 100 ty 1 xdis $(0.47,0)$ ydis $(0,0.47)$ damp unbal

hist xdis 0.320 .32 ydis $0.32 \quad 0.32$

*

cy 2500

save mechojd.sav

pr h 1256

*

* 45 degree joints "limit" values

rest hgeomj.sav

* define material properties (CDR Chapter 2)

prop $\mathrm{m} 1$ k 9.05e9 g 6.23e9 dens 2320

prop $m 1$ fric 0.285 coh 12.1 e 6

* rock thermal properties (CDR Chapter 2)

prop $\mathrm{m} 1$ con 2.29 thexp $8.8 \mathrm{e}-6$ spec 931

* glue joints

prop mat $=1$ jkn=1e12 jks=1e12 jcoh=1e20 jten=1e20

* 45 degree joints

change $0 \quad 0.65 \quad 0 \quad 0.65$ angle $-46 \quad-44$ jmat 2 jcon $=5$

prop $\mathrm{m} 2 \mathrm{jkn}$ lell jks lell jfric $0.20 \mathrm{jcoh}=0.0 \mathrm{e} 6$

* conditions during solution

damp auto

mscale on

set dscan 10000

* use Mohr-Coulomb constitutive relation

change con 3

* Assume uniform stress field

insitu stress $-7 e 6 \quad 0 \quad-7 e 6$

* boundary conditions for symmetry

bound $-1.1^{\prime}-1251$ xvel 0 


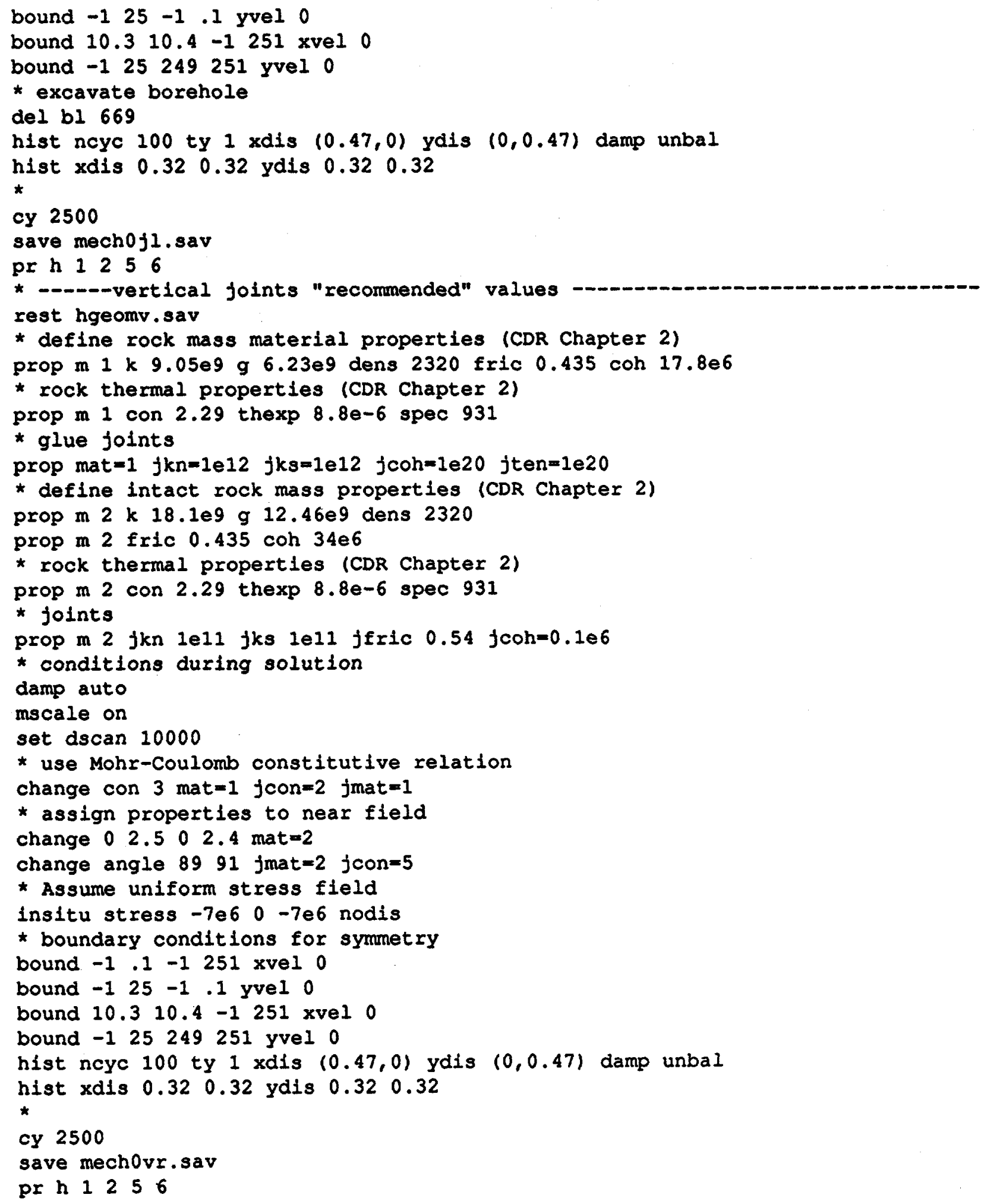



rest hgeomv.sav

* define rock mass material properties (CDR Chapter 2) prop $\mathrm{m} 1 \mathrm{k} 9.05 \mathrm{e} \mathrm{g} 6.23 \mathrm{e} 9$ dens 2320

prop m 1 fric 0.56 coh $22.1 e 6$

* rock thermal properties (CDR Chapter 2)

prop in 1 con 2.29 thexp 8.8 e-6 spec 931

* glue joints

prop mat $=1 j k n=1$ e12 jks=1e12 jcoh=1e20 jten=1e20

* define intact rock mass properties (CDR Chapter 2)

prop m 2 k 18.1 e9 g 12.46 e9 dens 2320

prop m 2 fric 0.56 coh $50 e 6$ ten $16.9 e 6$

* rock thermal properties (CDR Chapter 2)

prop m 2 con 2.29 thexp $8.8 e-6$ spec 931

* joints

prop m 2 jkn le11 jks lell jfric 0.8 jcoh=1.0e6

* conditions during solution

damp auto

mscale on

set dscan 10000

* use Mohr-Coulomb constitutive relation

change con 3 mat $=1$ jcon=2 jmat=1

* assign properties to near field

change 02.502 .4 mat $=2$

change angle 8991 jmat $=2$ jcon $=5$

* Assume uniform stress field

insitu stress $-7 e 60-7 e 6$ nodis

* boundary conditions for symmetry

bound $-1.1-1251$ xvel 0

bound $-1 \quad 25-1.1$ yvel 0

bound $10.310 .4-1251$ xvel 0

bound -125249251 yvel 0

hist neyc 100 ty 1 xdis $(0.47,0)$ ydis $(0,0.47)$ damp unbal

hist xdis 0.320 .32 ydis $0.32 \quad 0.32$

*

cy 2500

save mechovd.sav

pr h 1256

$\star$

* ----vertical joints "Iimit" values

rest hgeomv.sav

* define rock mass material properties (CDR Chapter 2)

prop m 1 k $9.05 e 9 \mathrm{~g} 6.23 \mathrm{eg}$ dens 2320

prop m 1 fric 0.285 coh 12.1 e 6

* rock thermal properties (CDR Chapter 2)

prop m 1 con 2.29 thexp 8.8 e-6 spec 931

* glue joints 


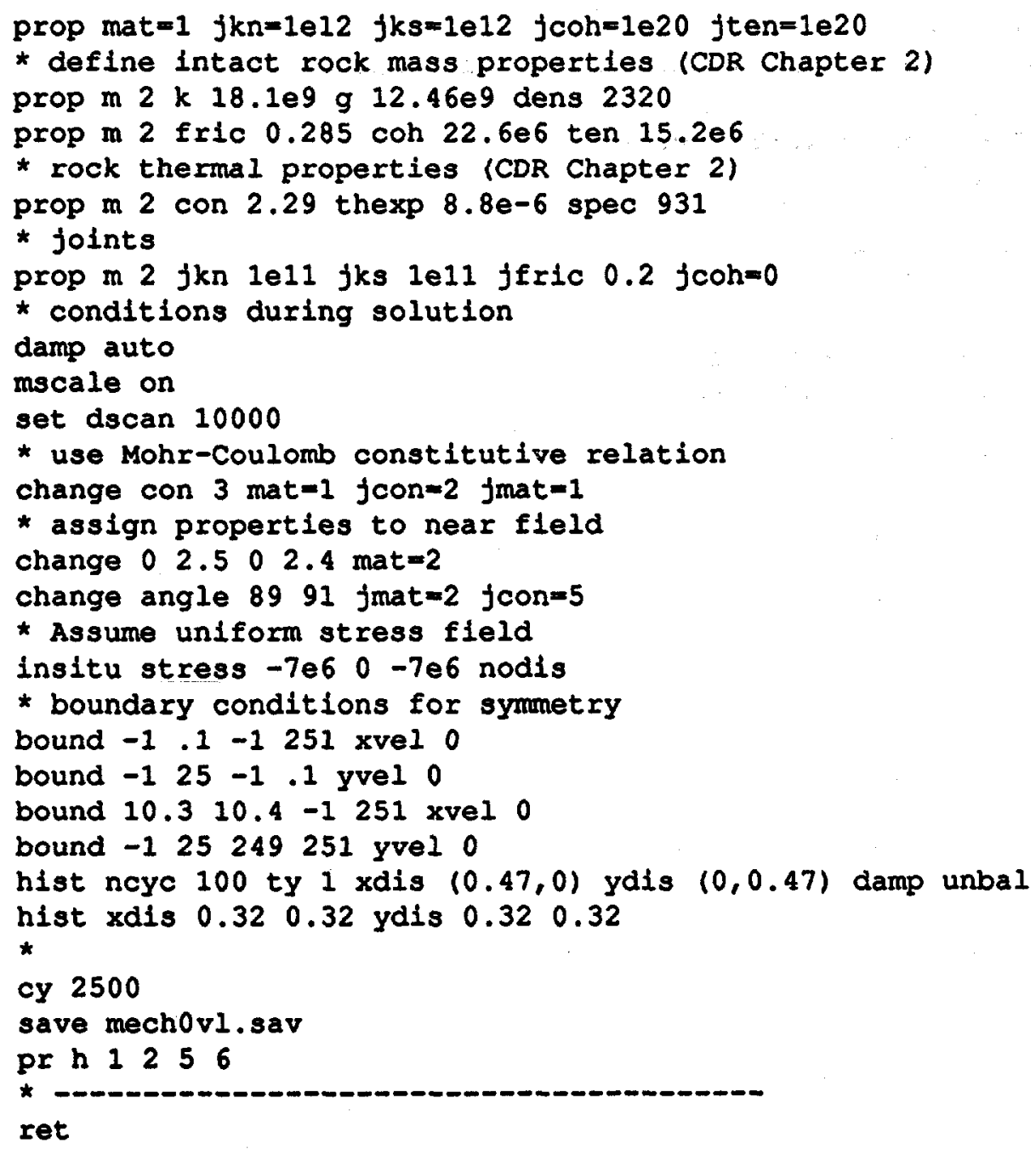




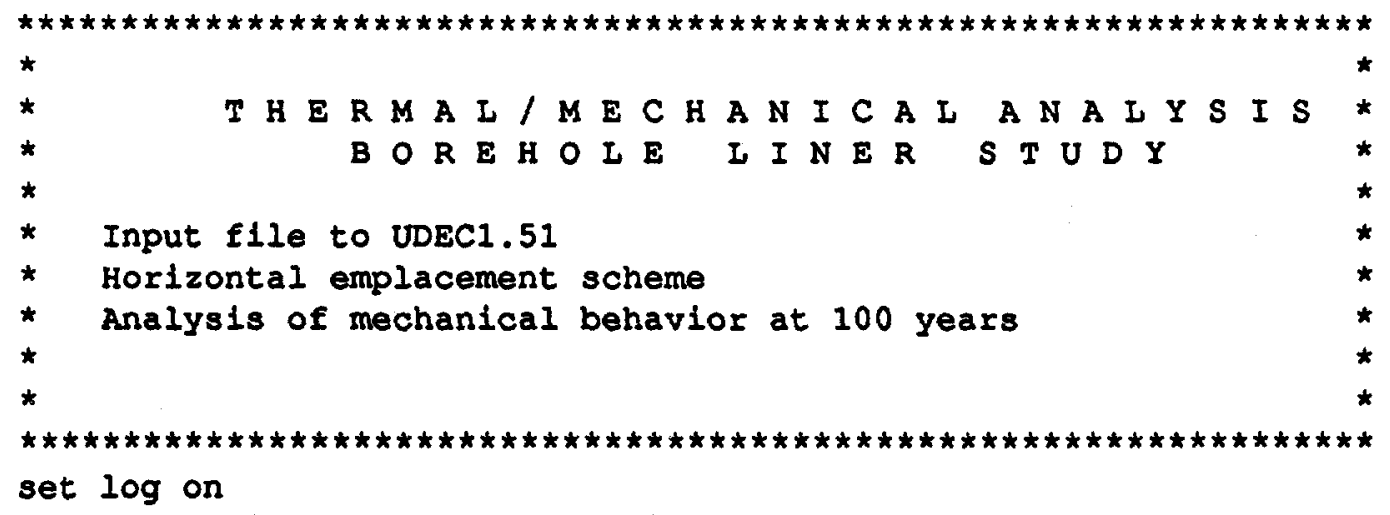

* do mechanical steps for vertical joint case --CDR values------rest thlooyv.sav

prop m 2 jkn lel1 jks lell jfric 0.54 jcoh $=0.1 \mathrm{e} 6$

prop m 2 fric 0.435 coh 34 e 6

hist $n 250$

cy 3000

print hist 1256

save mlo0yvv.sav

*

rest th100yv.sav

prop $m 2$ jkn lell jks lell jfric 0.54 jcoh $=0.1 e 6$

prop m 2 fric 0.435 coh $34 e 6$

$\begin{array}{lllllllll}\text { bound } & -1 & .5 & -1 & .5 & \text { stress } & -5 e 6 & 0 & -5 e 6\end{array}$

bound $-1 \quad 11-1.01$ yvel 0

bound $-1.01-111$ xvel 0

hist $n 250$

cy 3000

pr his 12256

* - -

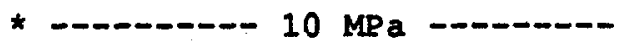

rest th100yv.sav

prop m 2 jkn lell jks lell jfric 0.54 jcoh=0.1e 6

prop m 2 fric 0.435 coh 34 e6

bound $-1 \quad .5-1 \quad .5$ stress -10 e $6 \quad 0 \quad-10$ e 6

bound $-1 \quad 11-1.01$ yvel 0

bound $-1.01-1 \quad 11$ xvel 0

hist $n 250$

cy 3000

pr his 1256

* $15 \mathrm{MPa}$

rest th100yv.sav

prop m $2 j k n$ lell jks 1 ell jfric 0.54 jcoh=0.1e6

prop m 2 fric 0.435 coh $34 \mathrm{e} 6$

bound $-1 \quad .5 \quad-1 \quad .5$ stress -15 e $6 \quad 0 \quad-15 e 6$

bound $-1 \quad 11-1.01$ yvel 0 


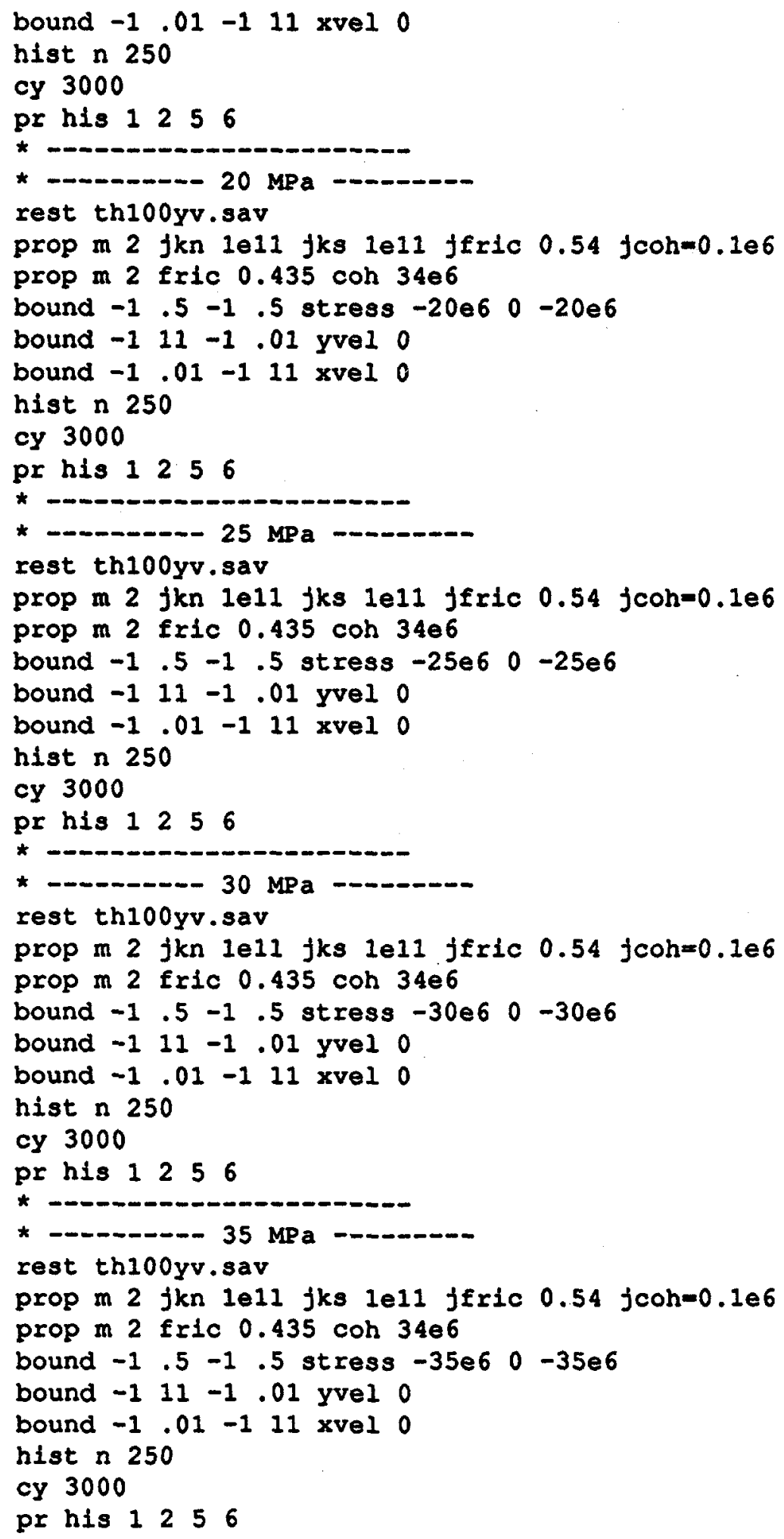




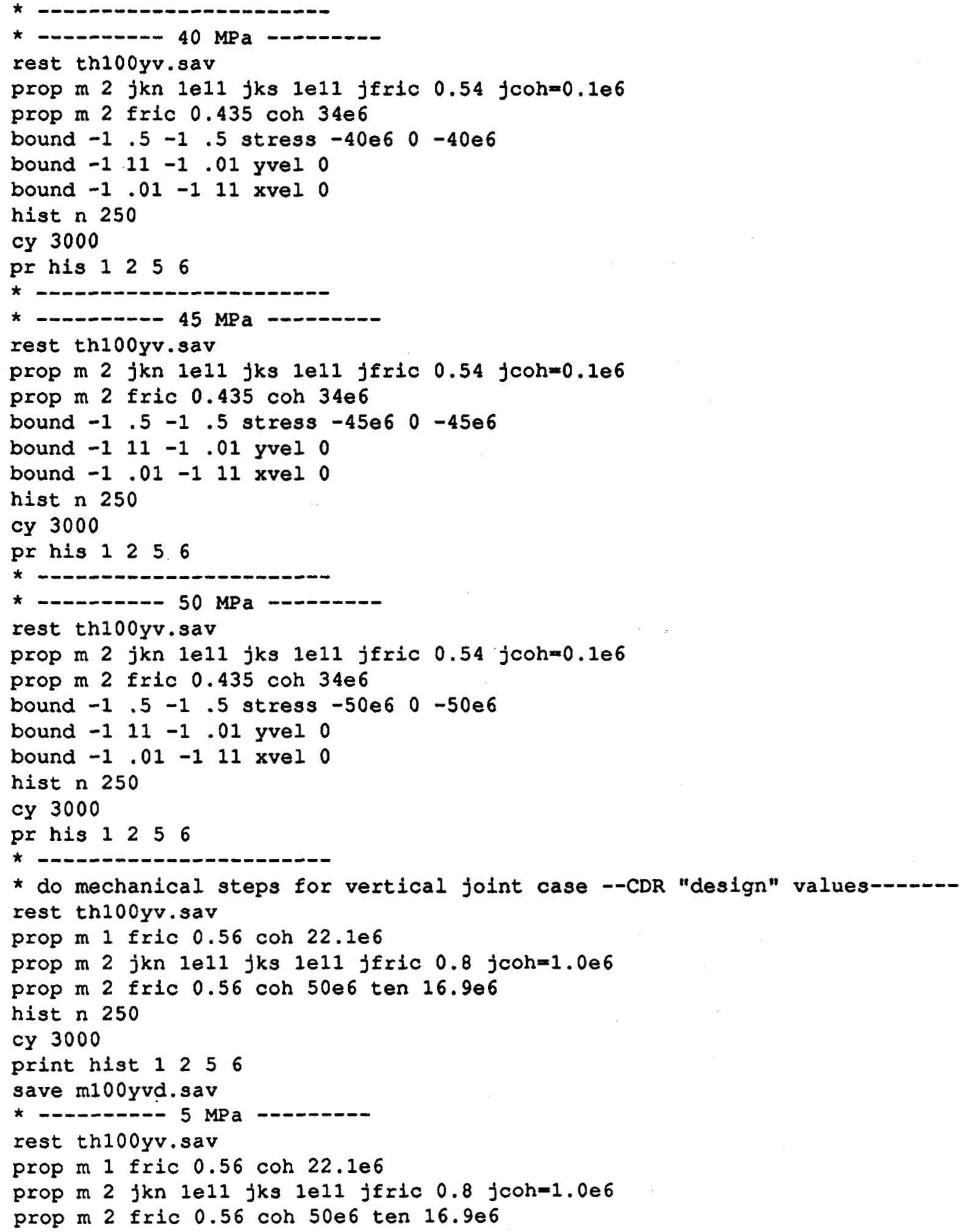




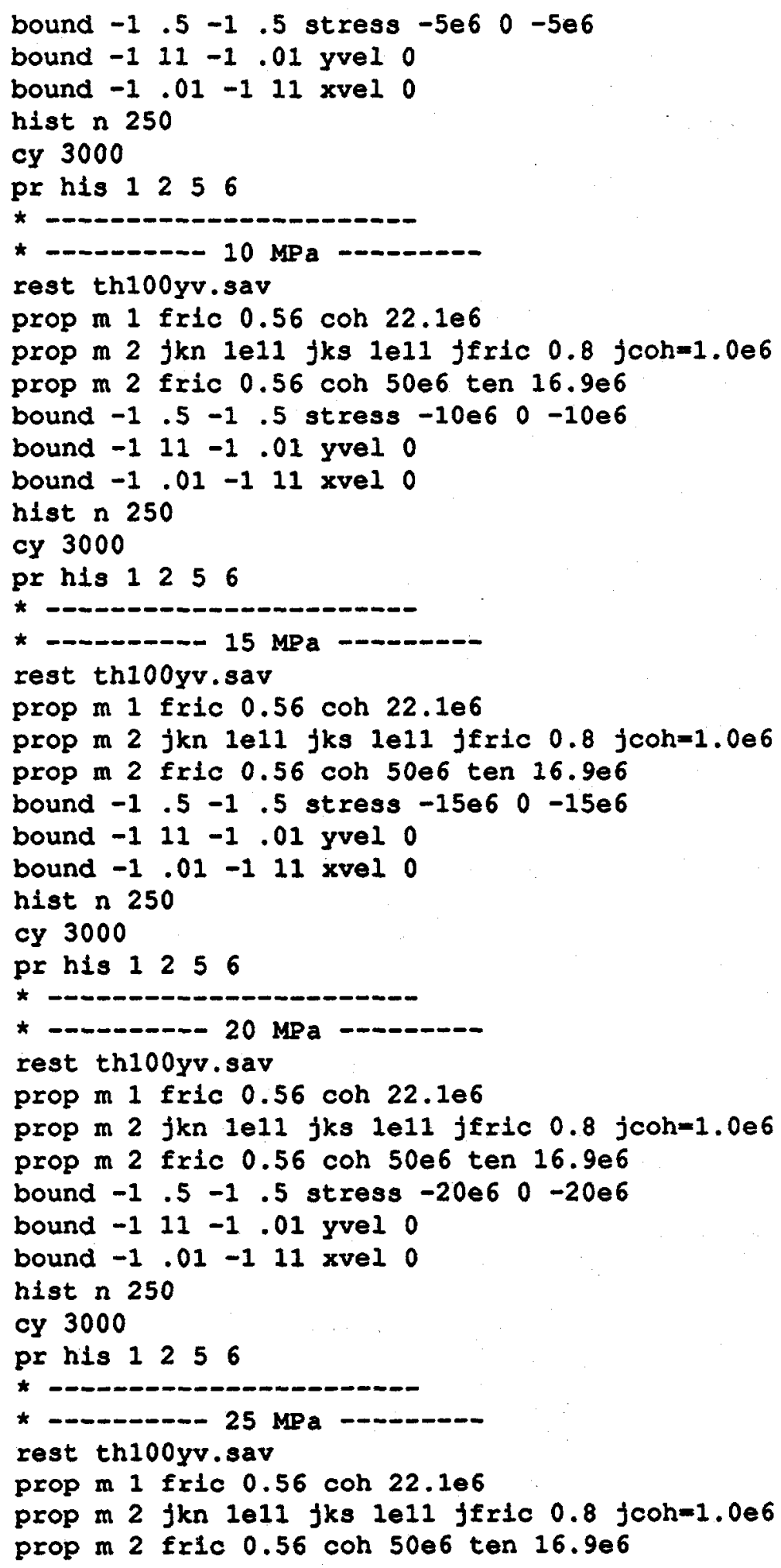




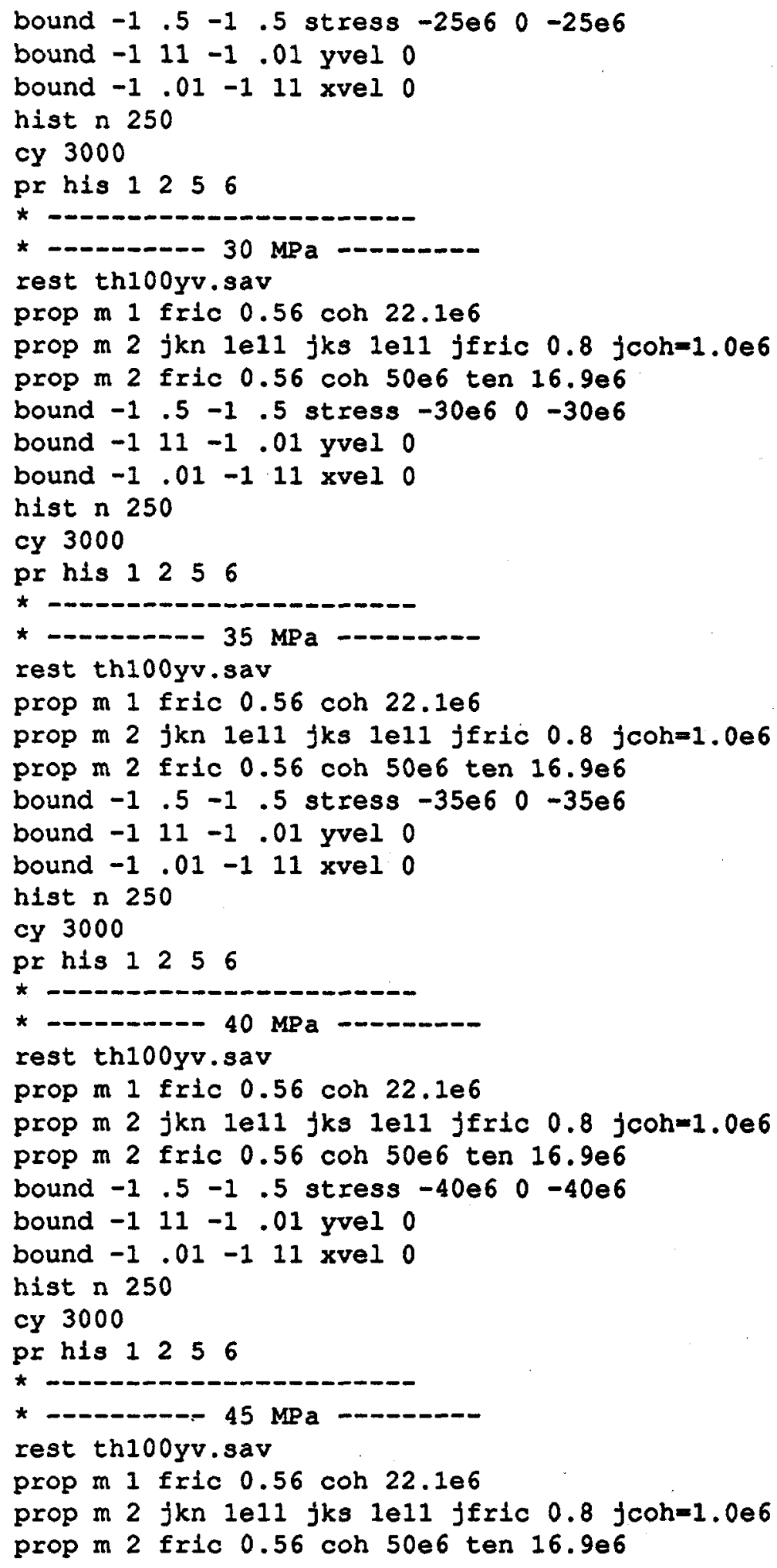




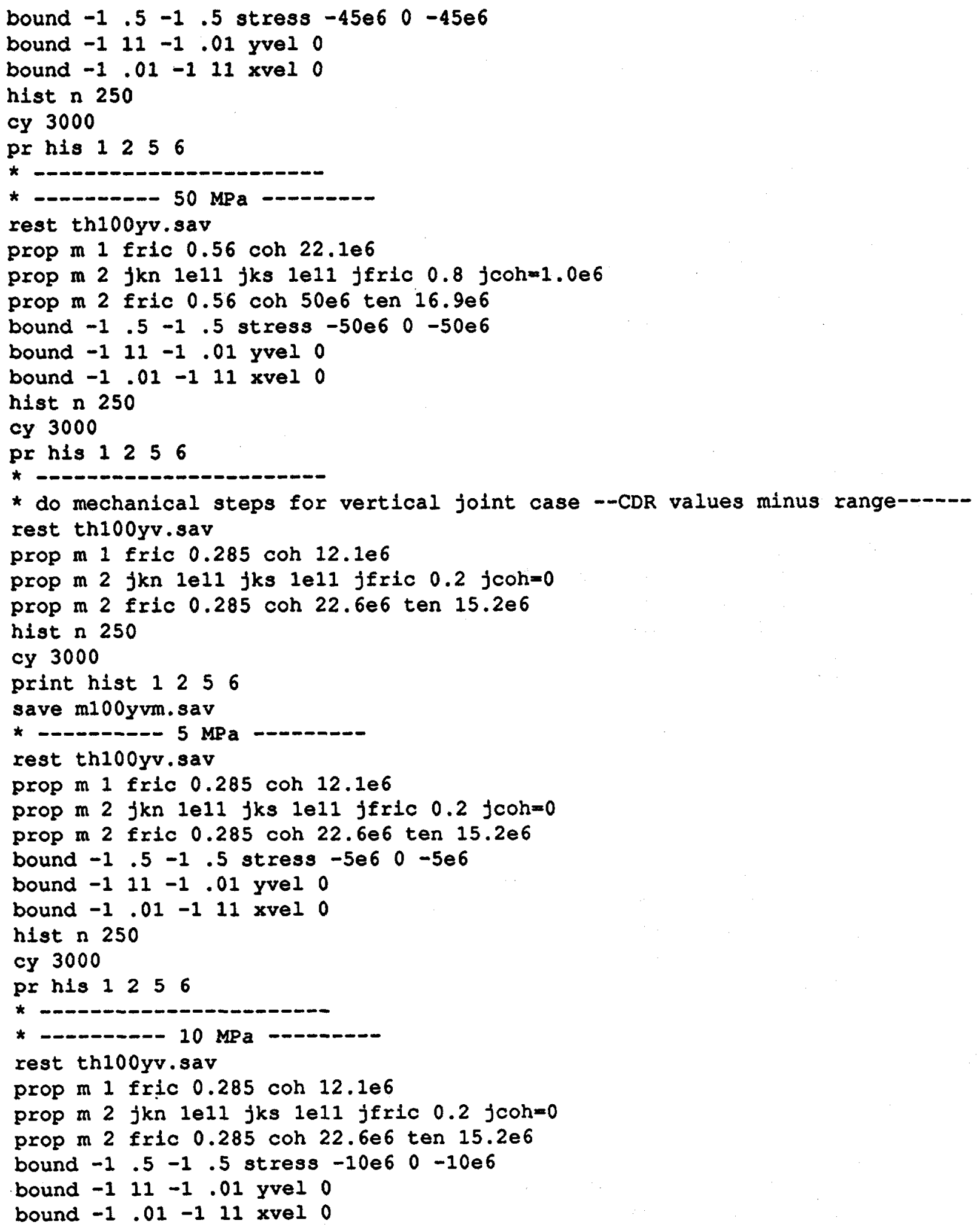




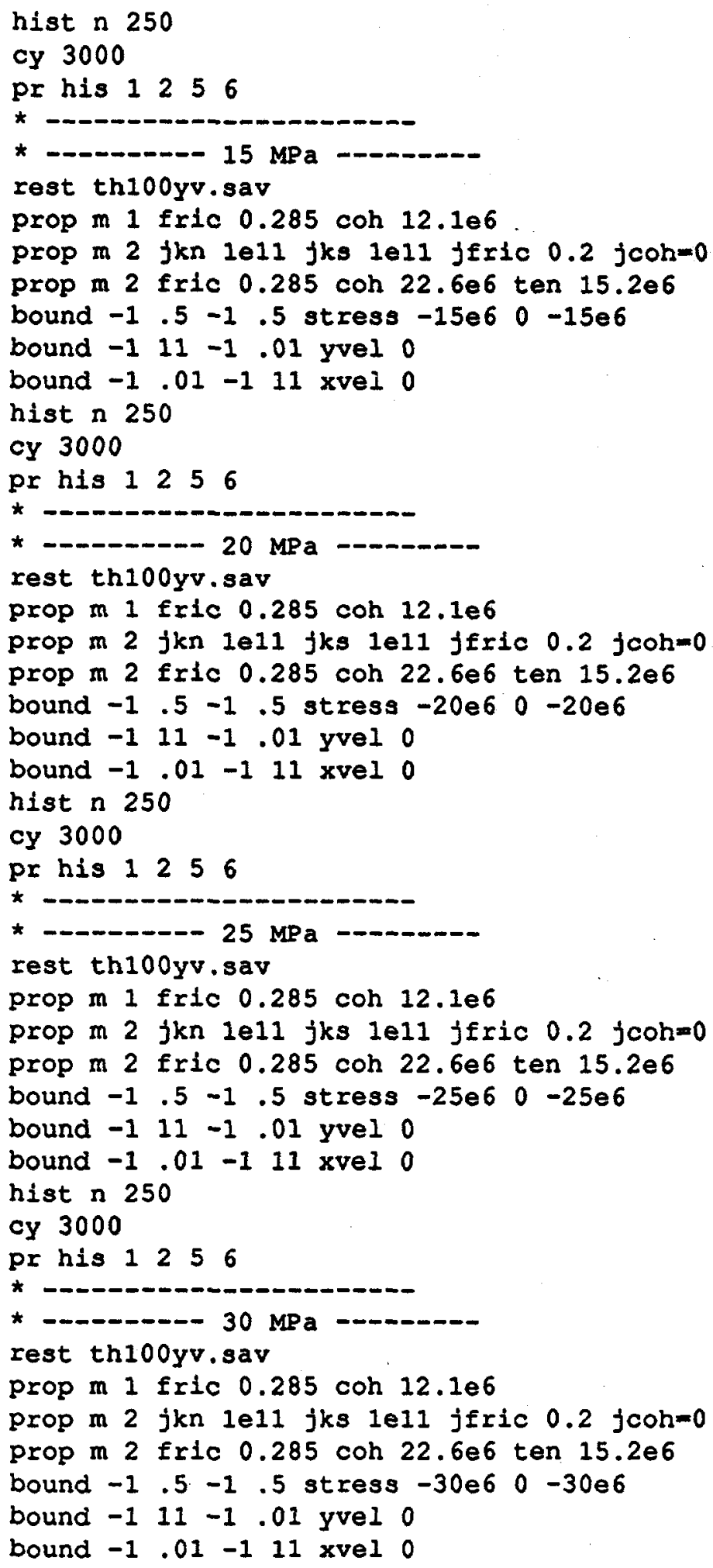


hist n 250

cy 3000

pr his 1256

*

rest th100yv.sav

prop m 1 fric 0.285 coh 12.1 e 6

prop in 2 jkn lell jks lell jfrlc 0.2 jcoh $=0$

prop $m 2$ fric 0.285 coh $22.6 e 6$ ten $15.2 e 6$

bound $-1 \quad .5-1 \quad .5$ stress $-35 e 6 \quad 0 \quad-35 e 6$

bound $-1 \quad 11-1.01$ yvel 0

bound $-1.01-1 \quad 11$ xvel 0

hist $n 250$

cy 3000

pr his 1256

* -

* - - - - $40 \mathrm{MPa}-\ldots-\ldots$

rest th100yv.sav

prop $m 1$ fric 0.285 coh $12.1 e 6$

prop m 2 jkn lel1 jks lell jfrlc 0.2 jcoh=0

prop $m 2$ fric 0.285 coh $22.6 e 6$ ten $15.2 \mathrm{e} 6$

bound $-1 \quad .5-1 \quad .5$ stress $-40 e 6 \quad 0 \quad-40 e 6$

bound $-1 \quad 11-1.01$ yvel 0

bound $-1.01-111$ xvel 0

hist $n 250$

cy 3000

pr his 12556

* -

* --

rest th100yv.sav

prop in 1 fric 0.285 coh 12.1 e 6

prop m 2 jkn lell jks lell jfric 0.2 jcoh $=0$

prop $\mathrm{m} 2$ fric 0.285 coh $22.6 \mathrm{e} 6$ ten $15.2 \mathrm{e} 6$

bound $-1 \quad .5-1.5$ stress $-45 e 6 \quad 0 \quad-45 e 6$

bound $-1 \quad 11-1.01$ yvel 0

bound $-1.01-111$ xvel 0

hist $n 250$

cy 3000

pr his 12256

* -

* - - -

rest th100yv.sav

prop $\mathrm{m} 1$ fric 0.285 coh $12.1 \mathrm{e} 6$

prop m 2 jkn lell jks lell jfric 0.2 jcoh=0

prop in 2 fric 0.285 coh $22.6 e 6$ ten $15.2 e 6$

bound $-1 \quad .5-1 \quad .5$ stress $-50 e 6 \quad 0 \quad-50 e 6$

bound $-1 \quad 11-1.01$ yvel 0

bound $-1.01-111$ xvel 0 


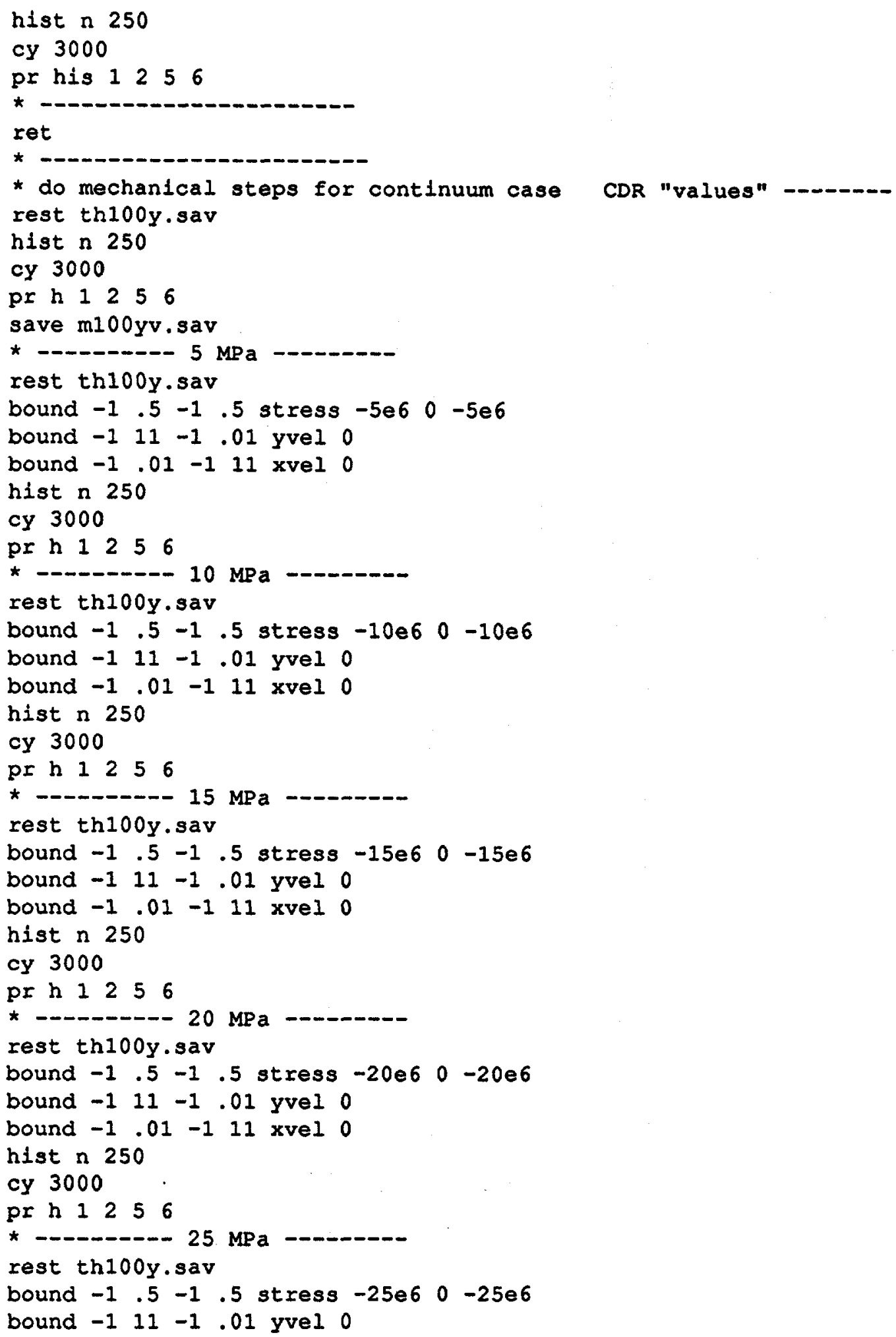




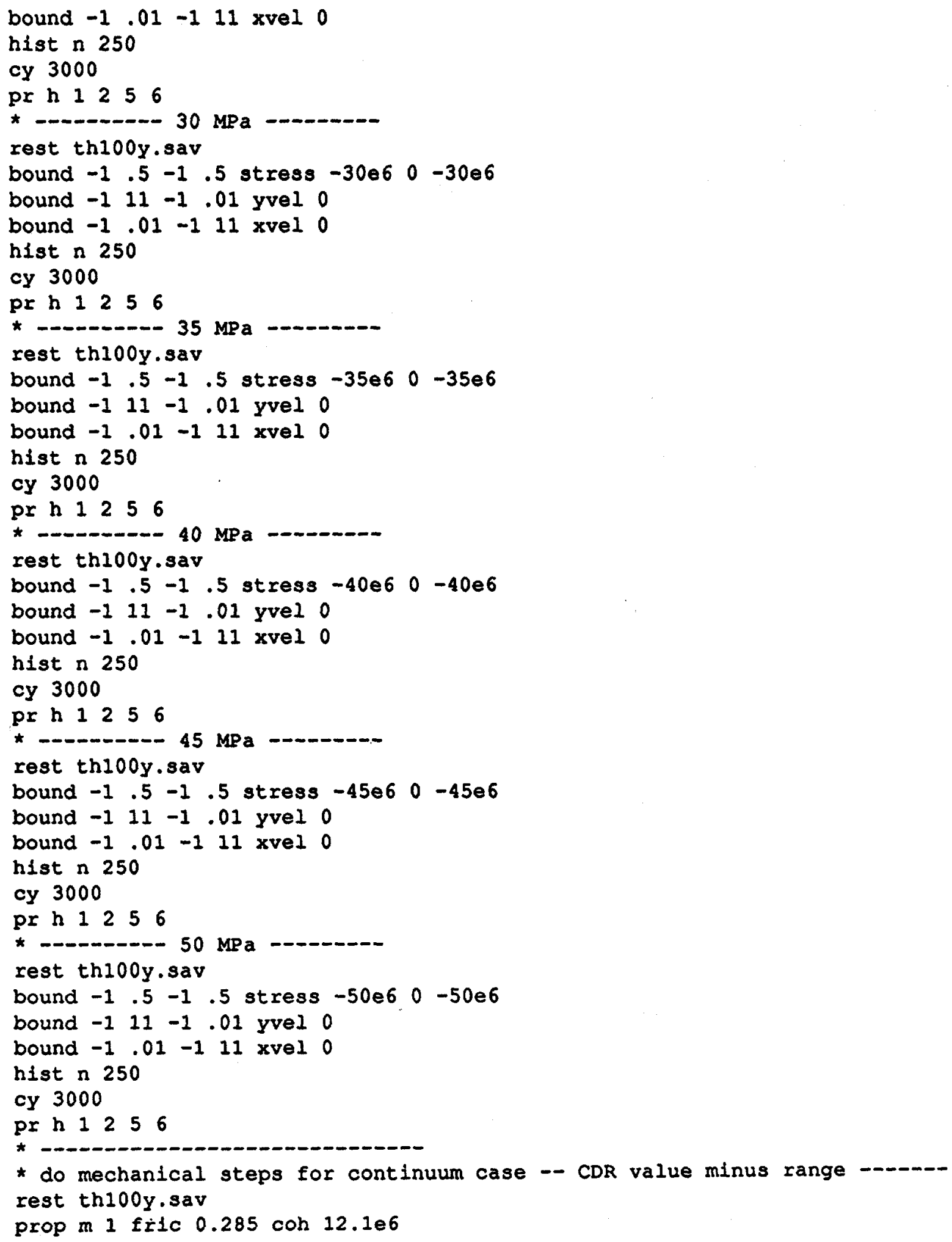


hist $n 250$

cy 3000

print hist 1256

save m100ym.sav

* - -

rest th100y.sav

prop $\mathrm{m} 1$ fric 0.285 coh $12.1 \mathrm{e} 6$

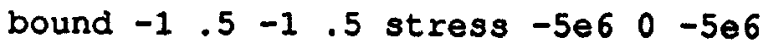

bound $-1 \quad 11-1.01$ yvel 0

bound $-1.01-1 \quad 11$ xvel 0

hist in 250

cy 3000

pr his 1256

* -

* -.---.--- $10 \mathrm{MPa}-\ldots-. .-$

rest th100y.sav

prop $\mathrm{m}$ I fric 0.285 coh $12.1 \mathrm{e} 6$

$\begin{array}{lllllllll}\text { bound } & -1 & .5 & -1 & .5 & \text { stress } & -10 e 6 & 0 & -10 e 6\end{array}$

bound $-1 \quad 11-1.01$ yvel 0

bound $-1.01-111$ xvel 0

hist n 250

cy 3000

pr his 1256

* - -

* -..-

rest th100y.sav

prop in 1 fric 0.285 coh 12.1 e 6

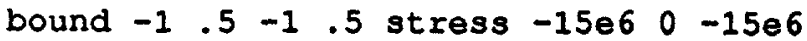

bound $-1 \quad 11-1 \quad .01$ yvel 0

bound $-1.01-1 \quad 11$ xvel 0

hist n 250

cy 3000

pr his 12556

* - -

* - -

rest throoy.sav

prop in 1 fric 0.285 coh 12.1 e 6

bound $-1.1 .5-1 \quad .5$ stress $-2006 \quad 0 \quad-20 e 6$

bound $-1 \quad 11-1 \quad .01$ yvel 0

bound $-1.01-1 \quad 11$ xvel 0

hist in 250

cy 3000

pr his 1256

* -

* - - -

rest th100y.sav

prop $\mathrm{m} 1$ fric 0.285 coh $12.1 \mathrm{e} 6$

$\begin{array}{llllllll}\text { bound }-1 & .5 & -1 & .5 & \text { stress } & -25 e 6 & 0 & -25 e 6\end{array}$ 


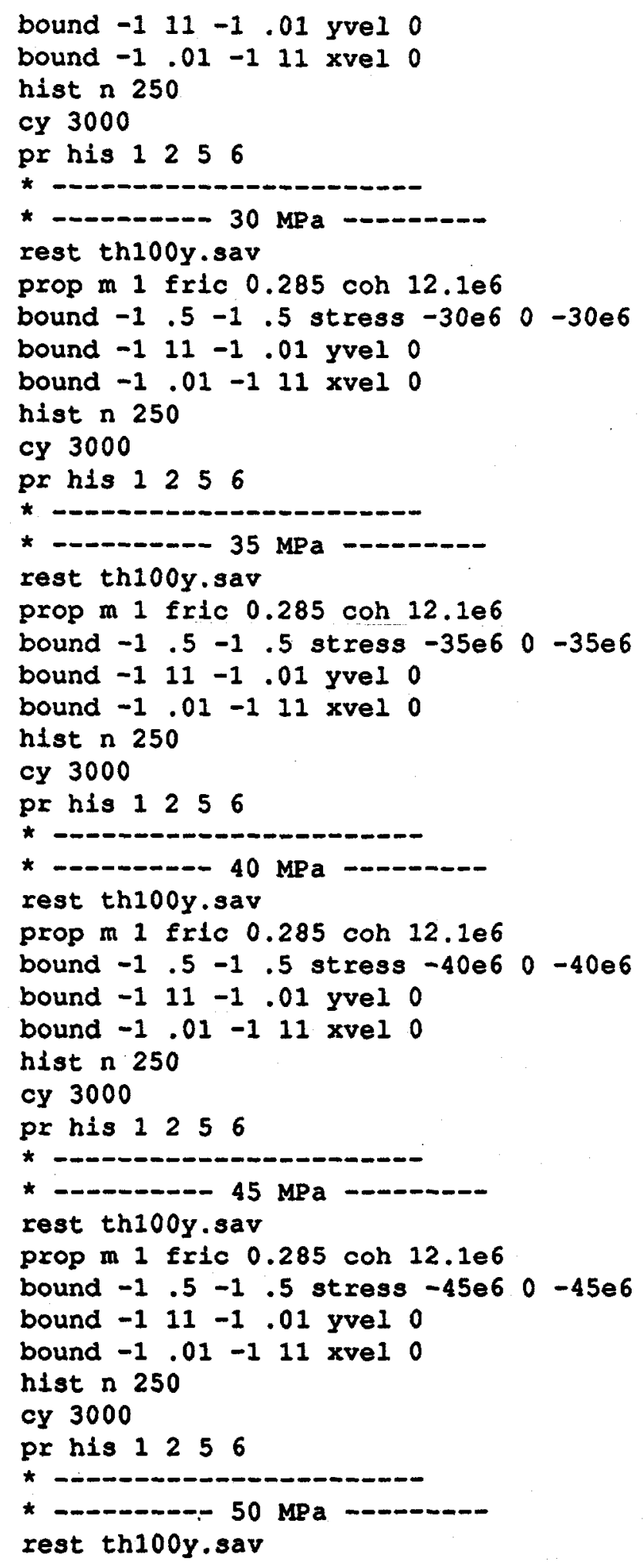




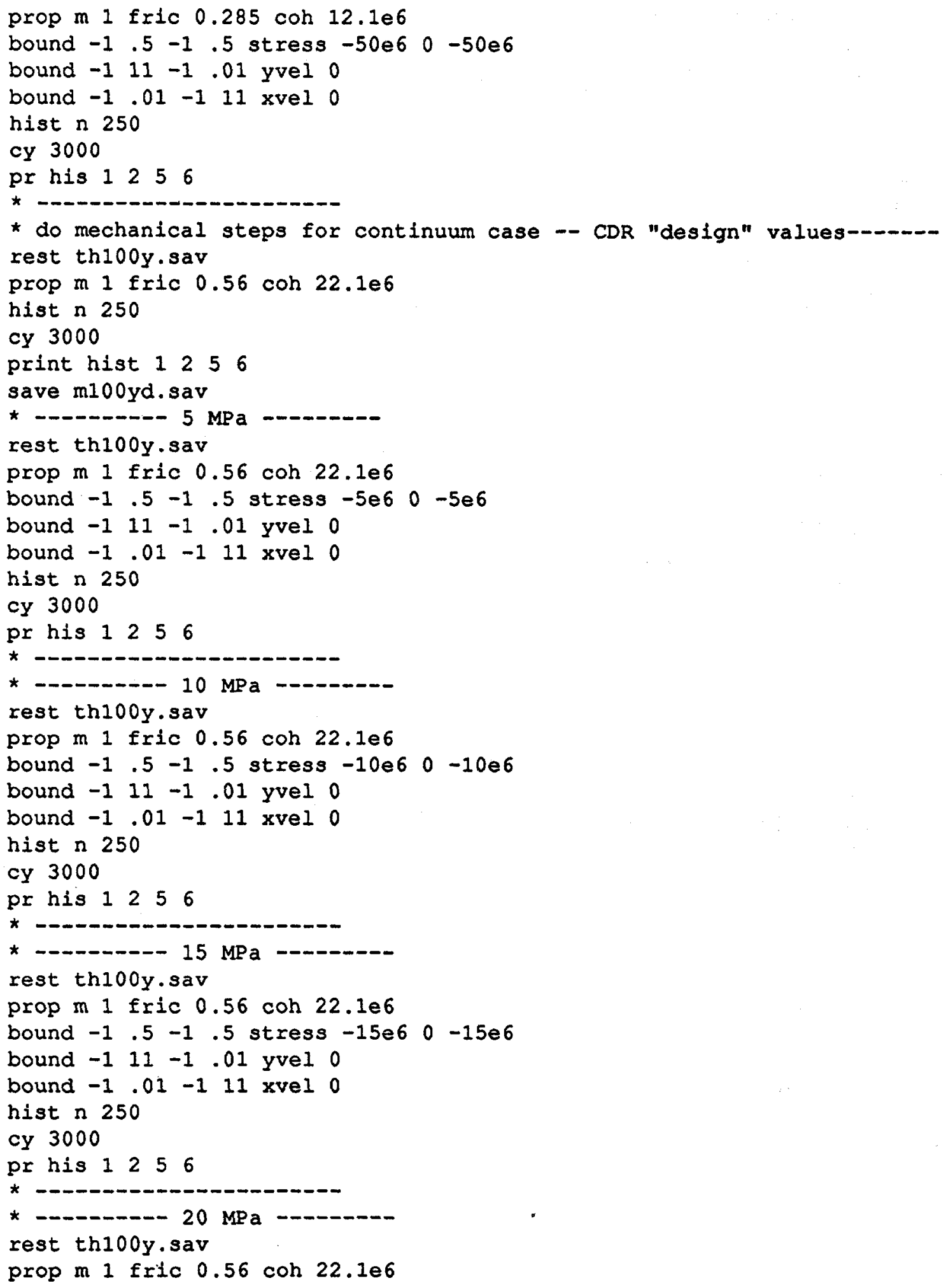




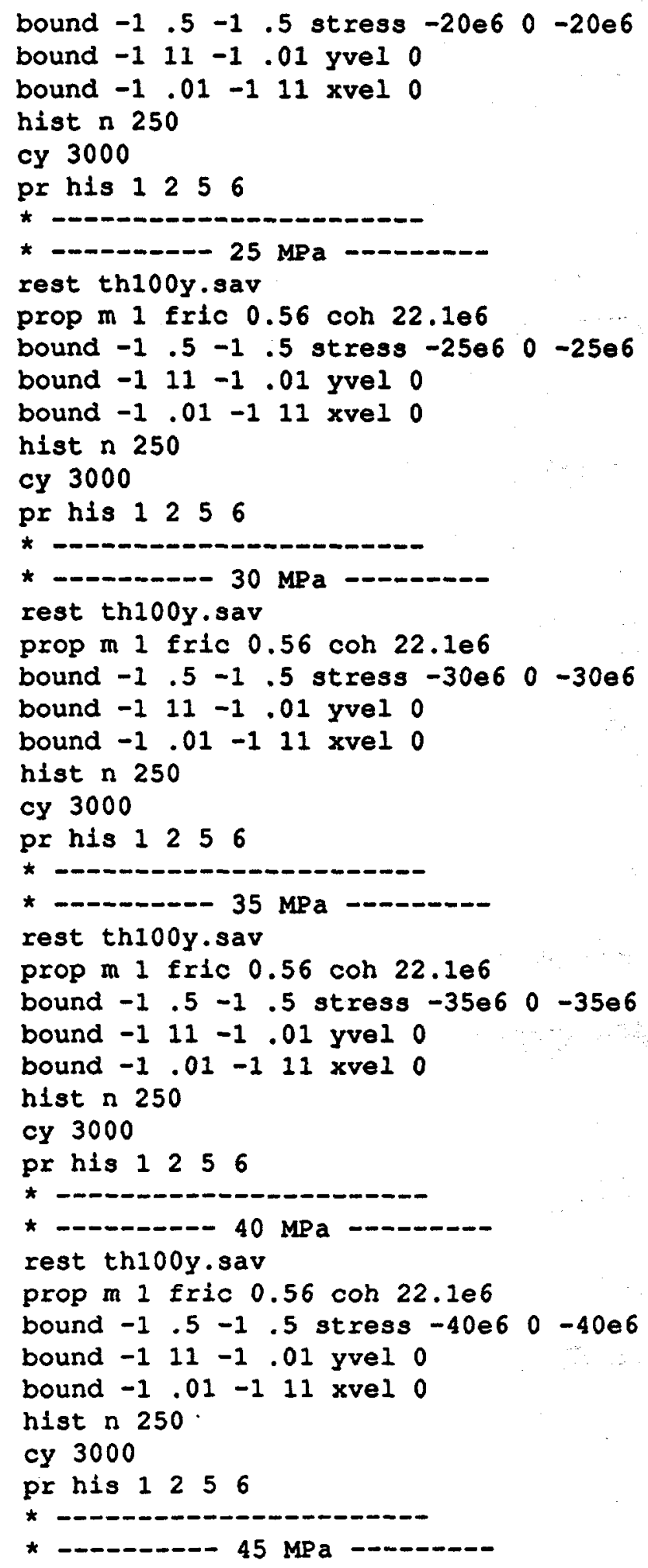




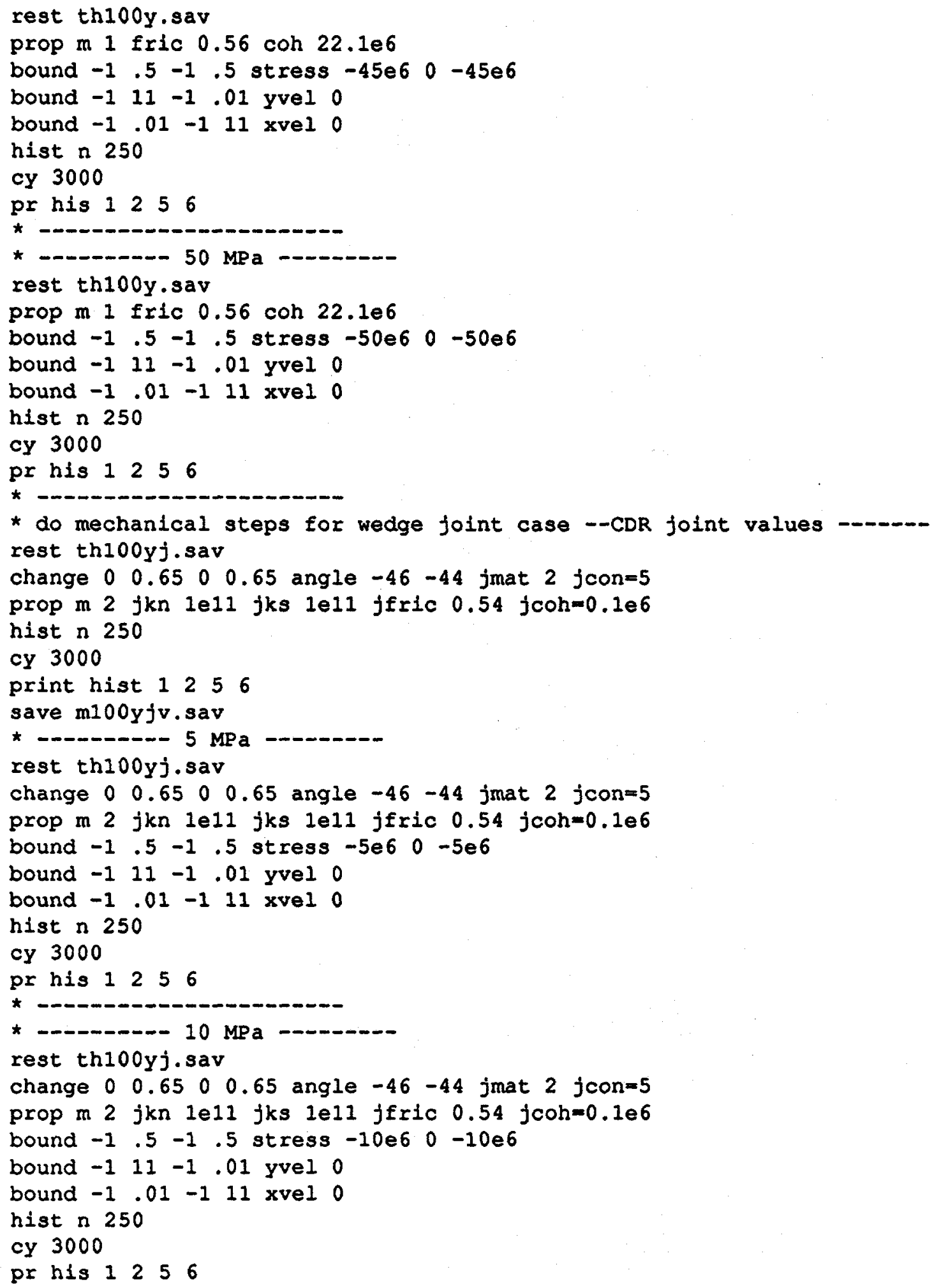




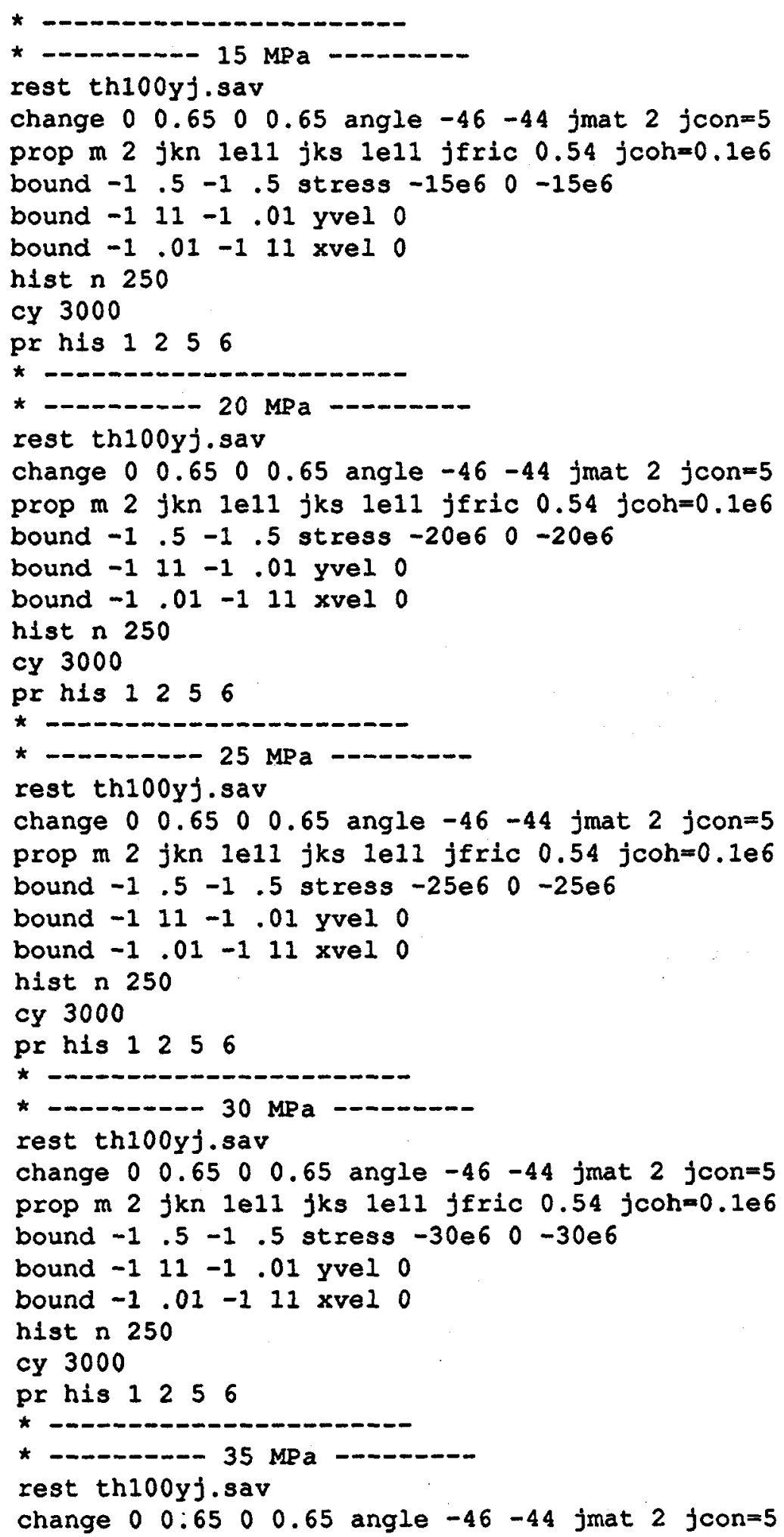


prop m 2 jkn lell jks lell jfric 0.54 jcoh $=0.1 \mathrm{e} 6$

bound $-1 \quad .5-1 \quad .5$ stress $-35 e 6 \quad 0 \quad-35 e 6$

bound $-1 \quad 11-1.01$ yvel 0

bound $-1.01-1 \quad 11$ xvel 0

hist n 250

cy 3000

pr his 1256

*

* ------- $40 \mathrm{MPa}-------$

rest th100yj.sav

change $0 \quad 0.65 \quad 0 \quad 0.65$ angle $\begin{array}{llll}-46 & -44 & \text { jmat } 2 & j \mathrm{jcon}=5\end{array}$

prop m 2 jkn lell jks lell jfric 0.54 jcoh $=0.1 e 6$

bound $-1 \quad .5-1 \quad .5$ stress $-40 e 6 \quad 0 \quad-40 e 6$

bound $-1 \quad 11-1 \quad .01$ yvel 0

bound $-1.01-111$ xvel 0

hist $\mathrm{n} 250$

cy 3000

pr his 12256

*

*

$45 \mathrm{MPa}$

rest th100yj.sav

change $0 \quad 0.65 \quad 0 \quad 0.65$ angle $-46 \quad-44$ jmat 2 jcon $=5$ prop $m 2 j k n$ lell jks lell ffric 0.54 jcoh $=0.1 e 6$

bound $-1 \quad .5-1 \quad .5$ stress $-45 e 600$

bound $-1 \quad 11-1.01$ yvel 0

bound $-1.01-1 \quad 11$ xvel 0

hist $n 250$

cy 3000

pr his 1256

* - -

* - -

rest thlo0yj.sav

change $0 \quad 0.65 \quad 0 \quad 0.65$ angle $-46-44$ jmat 2 jcon $=5$

prop $\mathrm{m} 2 \mathrm{jkn}$ lell jks lell jfric 0.54 jcoh $=0.1 \mathrm{e} 6$

bound $-1 \quad .5-1 \quad .5$ stress $-50 e 6 \quad 0 \quad-50 e 6$

bound $-1 \quad 11-1.01$ yvel 0

bound $-1.01-1 \quad 11$ xvel 0

hist $n 250$

cy 3000

pr his 1256

* - -

* do mechanical steps for wedge foint case --CDR "design" values -----rest th100yj.sav

change $0 \quad 0.65 \quad 0 \quad 0.65$ angle $-46 \quad-44$ jmat 2 jcon=5

prop $m 2 j k n$ lell jks lell jfric 0.80 jcoh $=1.0 \mathrm{e} 6$

prop $m 1$ fric 0.56 coh $22.1 e 6$

hist $n 250$

cy 3000 
print hist 1256

save mlo0yjd.sav

* --.----- $5 \mathrm{MPa}$

rest thlo0yj.sav

change $0 \quad 0.65 \quad 0 \quad 0.65$ angle $-46 \quad-44$ jmat 2 jcon=5

prop $\mathrm{m} 2 \mathrm{jkn}$ lell jks lell jfric $0.80 \mathrm{jcoh}=1.0 \mathrm{e} 6$

prop $m 1$ fric 0.56 coh 22.1 e 6

$\begin{array}{llllllll}\text { bound }-1 & .5 & -1 & .5 & \text { stress } & -5 e 6 & 0 & -5 e 6\end{array}$

bound $-1 \quad 11-1.01$ yvel 0

bound $-1.01-111$ xvel 0

hist n 250

cy 3000

pr his 12556

*

* -.-.-. $10 \mathrm{MPa}$

rest th100yj.sav

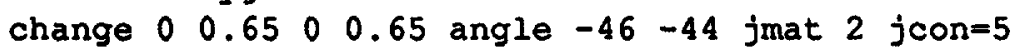

prop $m 2 j k n$ lell jks lell jfric 0.80 jcoh $=1.0 \mathrm{e} 6$

prop $\mathrm{m} 1$ fric 0.56 coh $22.1 \mathrm{e} 6$

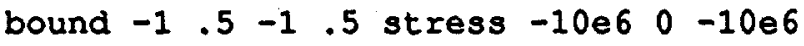

bound $-1 \quad 11-1.01$ yvel 0

bound $-1.01-1 \quad 11$ xvel 0

hist $n 250$

cy 3000

pr his 1256

*

rest thlooyj.sav

change $0 \quad 0.65 \quad 0 \quad 0.65$ angle $-46 \quad-44$ jmat 2 jcon $=5$ prop $m 2$ jkn lell jks lell jfric 0.80 jcoh=1.0e6 prop m 1 fric 0.56 coh 22.1 e 6

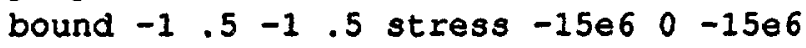

bound $-1 \quad 11-1.01$ yvel 0

bound $-1.01-1 \quad 11$ xvel 0

hist $\mathrm{n} 250$

cy 3000

pr his 1256

* - - - - - -

* - -

rest th100yj.sav

change $0 \quad 0.65 \quad 0 \quad 0.65$ angle $-46 \quad-44$ jmat 2 jcon=5 prop $m 2 j k n$ lell jks lell jfric $0.80 \mathrm{jcoh}=1.0 \mathrm{e} 6$ prop $\mathrm{m} 1$ fric 0.56 coh $22.1 \mathrm{e} 6$

bound $-1 \quad .5 \cdot-1 \quad .5$ stress $-2006 \quad 0 \quad-20 e 6$

bound $-1 \quad 11-1.01$ yvel 0

bound $-1.01-1 \quad 11$ xvel 0

hist $n 250$

cy 3000 
pr his 1256

*

rest th100yj.sav

change $0 \quad 0.65 \quad 0 \quad 0.65$ angle $-46 \quad-44$ jmat 2 jcon=5

prop m 2 jkn lell jks lell jfric 0.80 jcoh $=1.0 \mathrm{e} 6$

prop $m 1$ fric $0.56 \mathrm{coh} 22.1 \mathrm{e} 6$

bound $-1 \quad .5 \quad-1 \quad .5$ stress $-25 e 6 \quad 0 \quad-25 e 6$

bound $-1 \quad 11-1.01$ yvel 0

bound $-1.01-111$ xvel 0

hist n 250

cy 3000

px his 1256

* - -

* - -

rest th100yj.sav

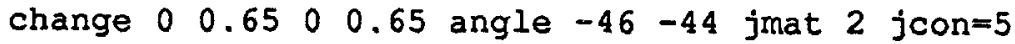

prop $\mathrm{m} 2 \mathrm{jkn}$ lell jks lell jfric $0.80 \mathrm{jcoh}=1.0 \mathrm{e} 6$

prop $\mathrm{m} 1$ fric $0.56 \mathrm{coh} 22.1 \mathrm{e} 6$

bound $-1 \quad .5-1 \quad .5$ stress $-30 \mathrm{e} 6 \quad 0 \quad-30 \mathrm{e} 6$

bound $-1 \quad 11-1.01$ yvel 0

bound $-1.01-1 \quad 11$ xvel 0

hist $n 250$

cy 3000

pr his 12556

* - -

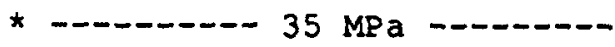

rest thlo0yj.sav

change $0 \quad 0.65 \quad 0 \quad 0.65$ angle $-46 \quad-44$ jmat 2 jcon $=5$ prop m 2 jkn le11 jks lell jfric 0.80 jcoh $=1.0$ e 6

prop m 1 fric 0.56 coh $22.1 e 6$

$\begin{array}{lllllllll}\text { bound }-1 & .5 & -1 & .5 & \text { stress } & -35 e 6 & 0 & -35 e 6\end{array}$

bound $-1 \quad 11-1.01$ yvel 0

bound $-1.01-111$ xvel 0

hist $n 250$

cy 3000

pr his 12256

*

* -..-.-.-- $40 \mathrm{MPa}$

rest th100yj.sav

change $0 \quad 0.65 \quad 0 \quad 0.65$ angle $-46 \quad-44$ jmat $2 j$ jcon $=5$ prop $\mathrm{m} 2 \mathrm{jkn}$ lell jks lell jfric $0.80 \mathrm{jcoh}=1.0 \mathrm{e} 6$ prop m 1 fric 0.56 coh $22.1 \mathrm{e} 6$

bound $-1 \quad .5-1 \quad .5$ stress $-40 e 6 \quad 0 \quad-40 e 6$

bound $-1 \quad 11-1.01$ yvel 0

bound $-1.01-1 \quad 11$ xvel 0

hist n 250

cy 3000 


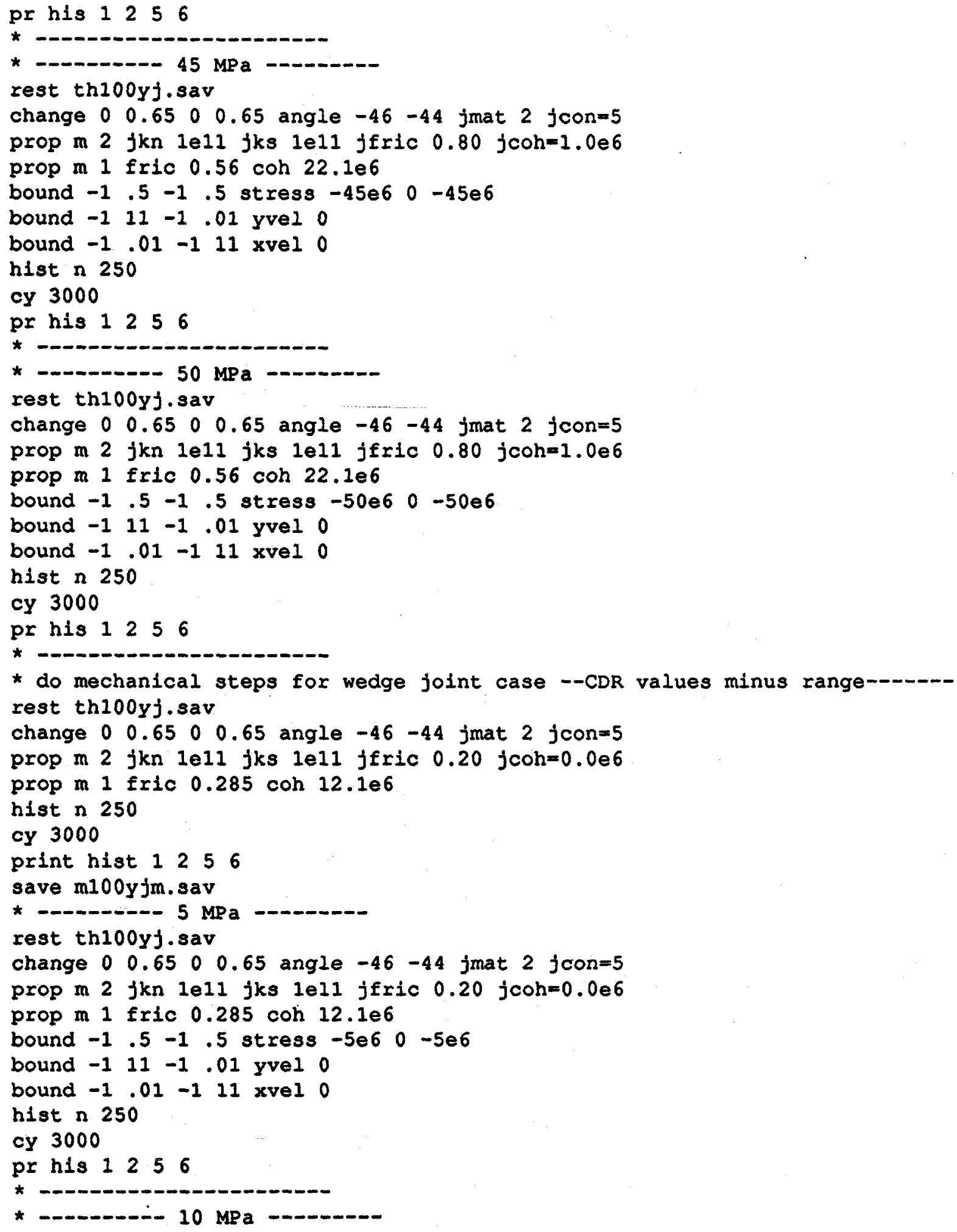




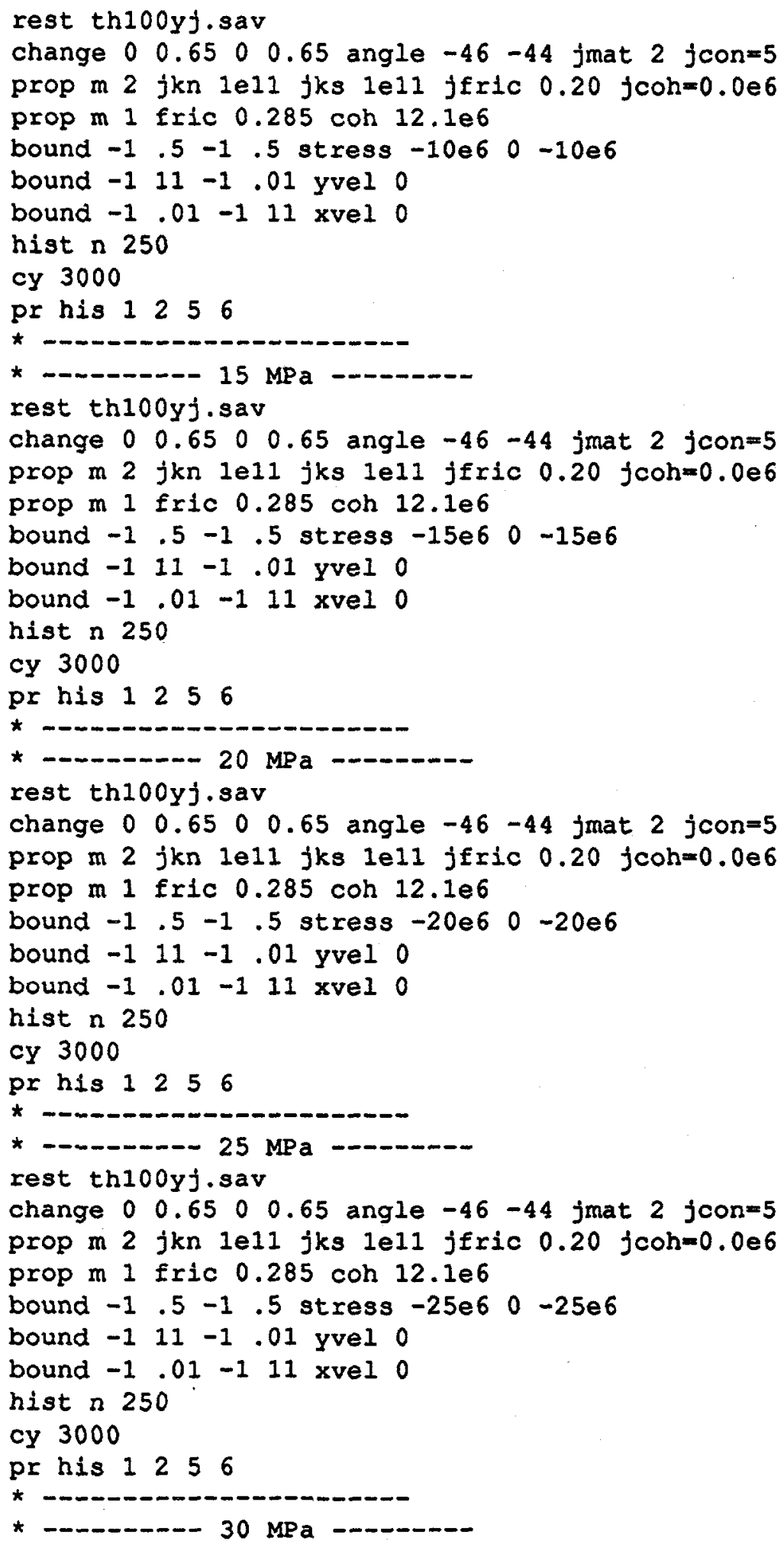


rest th100yj.sav

change $0 \quad 0.65 \quad 0 \quad 0.65$ angle $-46 \quad-44$ jmat 2 jcon=5 prop $\mathrm{m} 2 \mathrm{jkn}$ le11 jks lell jfric $0.20 \mathrm{jcoh}=0.0 \mathrm{e} 6$ prop in 1 fric 0.285 coh 12.1 e 6

bound $-1 \quad .5-1 \quad .5$ stress -30 e $6 \quad 0 \quad-30 e 6$

bound $-1 \quad 11-1.01$ yvel 0

bound $-1.01-1 \quad 11$ xvel 0

hist $n 250$

cy 3000

pr his 1256

*

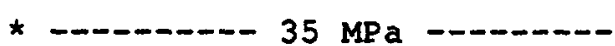

rest th100yj.sav

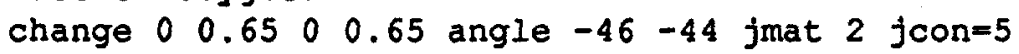
prop m $2 \mathrm{jkn}$ lell jks lell jfric $0.20 \mathrm{jcoh}=0.0 \mathrm{e} 6$ prop $\mathrm{m} 1$ fric 0.285 coh $12.1 \mathrm{e} 6$

bound $-1.1 .5-1 \quad .5$ stress $-35 e 6 \quad 0 \quad-35 e 6$

bound $-1 \quad 11-1.01$ yvel 0

bound $-1.01-111$ xvel 0

hist $n 250$

cy 3000

pr his 12556

* - -

*

rest th100yj.sav

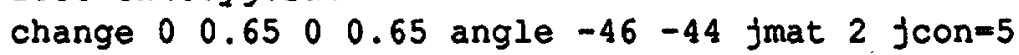
prop $m 2 j k n$ lell jks lell jfric 0.20 jcoh $=0.0 e 6$ prop m 1 fric 0.285 coh 12.1 e 6

bound $-1 \quad .5-1 \quad .5$ stress $-40 e 6 \quad 0 \quad-40$ e 6

bound $-1 \quad 11-1.01$ yvel 0

bound $-1.01-1 \quad 11$ xvel 0

hist n 250

cy 3000

pr his 1256

* -

* - - - - $45 \mathrm{MPa}-\ldots-\ldots$

rest th100yj.sav

change $0 \quad 0.65 \quad 0 \quad 0.65$ angle $-46 \quad-44$ jmat 2 jcon $=5$ prop $\mathrm{m} 2 \mathrm{jkn}$ lell jks lell jfric $0.20 \mathrm{jcoh}=0.0 \mathrm{e} 6$ prop in 1 fric 0.285 coh 12.1 e 6

bound $-1.1 .5-1 \quad .5$ stress $-45 e 6 \quad 0 \quad-45 e 6$

bound $-1 \quad 11-1.01$ yvel 0

bound $-1.01-1 \quad 11$ xvel 0

hist $n 250$

cy 3000

pr his 1256

* -

* - $-\ldots-\ldots$ 
rest thlo0yj.sav

change $00.65 \quad 0 \quad 0.65$ angle $-46 \quad-44$ jmat 2 jcon $=5$

prop m 2 jkn lell jks lell jfric 0.20 jcoh $=0.0 e 6$

prop m 1 fric 0.285 coh 12.1 e 6

$\begin{array}{lllllllll}\text { bound } & -1 & .5 & -1 & .5 & \text { stress } & -50 e 6 & 0 & -50 e 6\end{array}$

bound $-1 \quad 11-1.01$ yvel 0

bound $-1.01-111$ xvel 0

hist $n 250$

cy 3000

pr his 1256

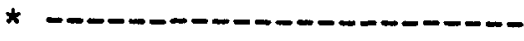




\section{APPENDIX B}

IINER I1

\section{program liner11}

this program calculates the moment (m), axial force ( $t$ ) and shear force (v) at various section of a circular liner. Load Case 1: Radial uniform load is applied on top and bottom, Load Case 2: Concentrated load on top and uniform base reaction. Formulas for moment, shear and axial forces and respective stresses sigm, sigt and sigv are obtained from "Formulas for stress and strain", Roark and Young.

c

c

c

dimension $x m(50), v(50), t(50), \operatorname{sigm}(50), \operatorname{sigv}(50), \operatorname{sigt}(50)$, xang $(50)$,

$+\mathrm{rx}(15), \operatorname{smax}(15), \mathrm{bmax}(15), \operatorname{amax}(15)$ open $\left(16, f 11 e^{\prime}\right.$ 'linerx.out')

write $(6, *)$ ' Case 1: Uniform Pressure Top and Bottom' write $(6, *)$ ' Case 2: Conc. Load Top and Unifm Pressure Bottom' write $(6, *)$ ' Read Case (1 or 2$)$ :

read $(5, *)$ icase

write $(6, *)$ ' Read alphad and betad (in deg.) : ' read $(5, *)$ alphd, betad

c

c $r=$ radius, thk thickness of liner,

c alpha rock load angle; beta = base reaction angle

c

thk $=0.5$

$w=20.4$

c

$p i=4.0 * a \tan (1.0)$

alpha $=(p 1 / 180)$.$* alphd$

beta $=(p 1 / 180)$.$* betad$

c

c

pp = uniformly distributed load, w= concentrated load

theta= pi-alpha/2.

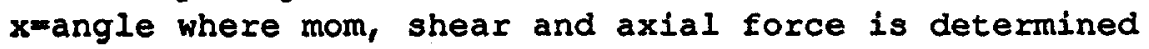

If (1case.eq.1) then

write $(16, *)$ 'IINER ANAIYSIS Case 1 '

write $(16, *)$ ' Uniform Load Top and Uniform Reaction Bottom'

write $(16,105)$ w, alphd, betad

105 format $(2 x$, 'Total Load $=\prime, f 10,3,1,2 x$, 
+ top angle $($ deg.) $=\{, f 10.3,3 x$, 'bottom angle (deg.) $=(, f 10.3)$ elseif (1case.eq.2) then write $(16, *)$ 'LINER ANALYSIS Case 2 ' write $(16, *)$ ' Concentrated Load Top and Uniform Reaction Bottom' write $(16,125) w$, betad

125 format $(2 x$, 'Total Load $=\prime, f 10.3,1,2 x$,

+ 'bottom angle $($ deg.) $=(, f 10.3)$

endif

c

c : vary radius of the liner from 10 inch to 20 lnch $\mathrm{rx}(1)=28,0 / 2.0$

$\mathrm{rx}(2)=36.0 / 2.0$

$1 \mathrm{r}=2$

do $4 n=1$, ix

$r=r \times(n)$

c

ppa $=w /(2.0 * r * \sin (p i-a l p h a / 2)$.

$\mathrm{ppb}=\mathrm{w} /(2.0 * \mathrm{r} * \sin (\mathrm{pi}$-beta/2.))

write $(16, *)$ 'Applied Pressure top and bottom (1b/1nch): ',ppa,ppb

$c$

c :vary angle $x$ from 0 to $180 \mathrm{deg}$, increment 5 deg

$\mathbf{x}=0.0$

$\mathrm{xx}=\mathrm{pi}-\mathrm{x}$

$i=0$

$c$

$\operatorname{xmax}=p i$

$c$

$\operatorname{del} \mathrm{x}=\mathrm{pi} / 36$

symmetric problem

continue

$i=i+1$

c

write $(6, *), i, i$

xang $(i)=x$

$z=\sin (x)$

$u=\cos (x)$

case 1

concentrated load applied at top and bottom

write $(16, *)$ 'case 1 '

$\mathrm{xma} 1=\mathrm{w}^{\star} \mathrm{r} / \mathrm{pi}$

$\mathrm{ta} 1=0.0$

val $=0.0$

a $\operatorname{ltm} 1=-w * r * z / 2.0$

alt $1=-w \star z / 2.0$

$\operatorname{altv} 1=-w^{\star} u / 2.0$

C 
$\operatorname{xml} 1=x \operatorname{mom}(x m a 1, t a 1, x, u, v a 1, z, a l t m 1)$

$t 1=x t(t a 1, v a 1, z, u, a l t t 1)$

$v 1=x v(t a 1, v a 1$, altv1, $z, u)$

c

c

$c$

c

c

$c$

c

c

c

c

c

c

c

c

case 2

concentrated load applied at bottom and uniform reaction

thet $a=p i-b e t a / 2.0$

$s=\sin (t h e t a)$

$c=\cos$ (theta)

c

$$
\begin{aligned}
& x m 2=\operatorname{xmom}(x m a 2, t a 2, x, u, v a 2, z, a l t m 2) \\
& t 2=x t(t a 2, v a 2, z, u, a l t t 2) \\
& v 2=x v(t a 2, v a 2, a l t v 2, z, u)
\end{aligned}
$$

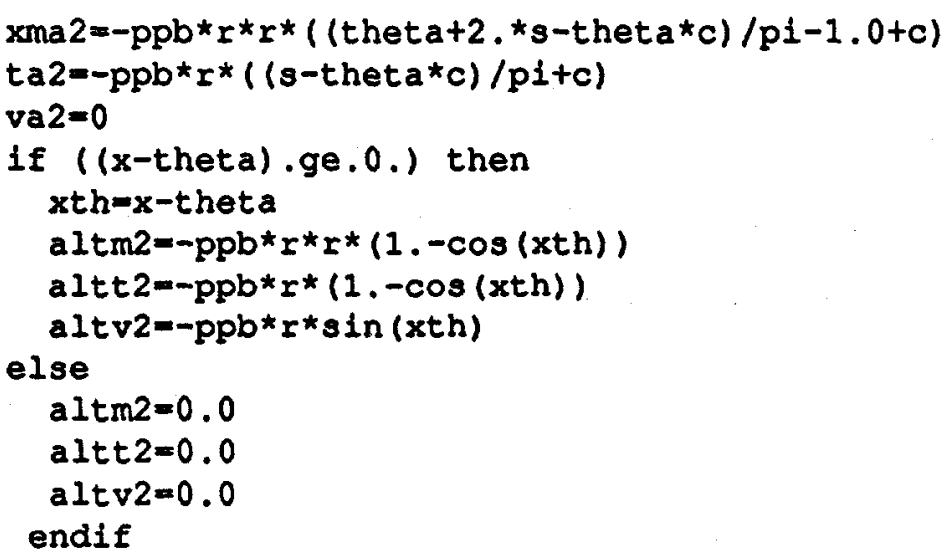

\section{if (icase.eg.1) then}

$$
\text { case } 3
$$

concentrated load applied at top and uniform reaction

write $(16, *)$ 'case $3^{\prime}$

theta=pi-alpha $/ 2.0$

$21=\sin (x x)$

$u 1=\cos (x x)$

$s=\sin ($ theta)

$c=\cos$ (theta)

c

xma 3=-ppa*r*r* ( (theta+2.*s-theta*c) $/ p i-1.0+c)$

ta $3=-p p a * r *((s-$ theta*c) $/ p i+c)$

$\operatorname{va} 3=0$ 
c

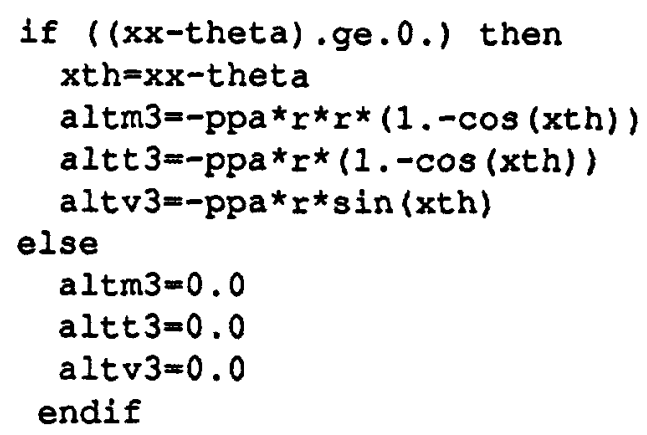

c

$\operatorname{xm} 3=\operatorname{xmom}(x \operatorname{ma} 3, t a 3, r, u 1$, va $3, z 1$, altm3)

$t 3=x t(t a 3, v a 3, z 1, u 1, a 1 t t 3)$

$v 3=x v(t a 3, v a 3, a l t v 3, z 1, u 1)$

endif

c

if (icase.eq.1) then

$x \mathrm{xm}(i)=\mathrm{xm} 1+\mathrm{xm} 2+\mathrm{xm} 3$

$t(i)=t 1+t 2+t 3$

c $\quad v(i)=v 1+v 2+v 3$

c shear is antisymmetry for case 3 w.r.t. case 2

$v(i)=v 1+v 2-v 3$

elseif (icase.eq.2) then

$\mathrm{xm}(i)=\mathrm{xm} 1+\mathrm{xm} 2$

$t(i)=t 1+t 2$

$v(i)=v 1+v 2$

endif

c

c calculate stresses

$\operatorname{ara}=1.0 * t h k$

ymomi $=(1 . / 12) *.(t h k * t h k * t h k)$

c=thk $/ 2.0$

$\operatorname{sigm}(i)=x m(i) * c / y m o m i$

sigt (i) $=t$ (i)/ara

sigv (i) $=v(i) / a r a$

$c$

$x=x+d e l x$

$x x=x x-$ del $x$

if (x.le.xmax) go to 1

c

c

determine maximum value of bending moment and shear force

bmmax $=0$.

axmax $=0$.

shmax $=0$.

bmmin $=0$. 


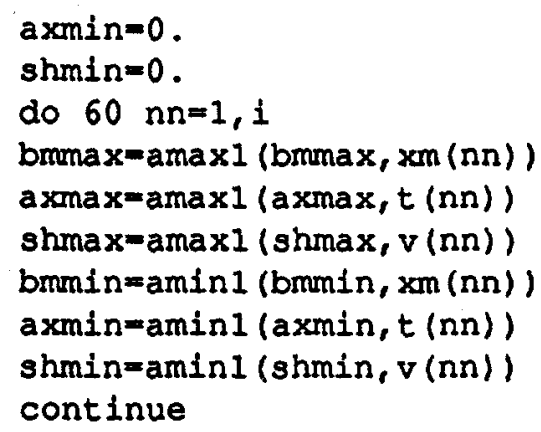

c

if (abs (bmmax).gt.abs (bmmin)) then $\operatorname{bmax}(n)=$ brmax

else

$\operatorname{bmax}(n)=$ bmmin

endif

c

if (abs (axmax).gt.abs (axmin)) then

$\operatorname{amax}(n)=\operatorname{axmax}$

else

$\operatorname{amax}(n)=\operatorname{axmin}$

endif

c

if (abs (shmax).gt.abs (shmin)) then $\operatorname{smax}(n)=$ shmax

else

$\operatorname{smax}(n)=\operatorname{shmin}$

endif

c

write $(16,112) r$, thk

112 format $(/, 2 x$, 'Radius of bore hole (inch) $=, f 10.5, /$,

+ 'Thickness of liner (inch) $=$ ',f10.5)

write $(16,108)$

108 format (' ang',6x,'ben.m',7x,'ax.f',7x,'sh.f',6x,'ben.st',6x,

+ 'ax.st', 6x,'sh.st')

do $2 n x=1, i$

xang $1=x a n g(n x) \star 180 / p 1$

2 write $(16,109)$ xangl, xm(nx),t $(n x), v(n x), \operatorname{sigm}(n x)$, sigt $(n x)$,

$+\operatorname{sigv}(n x)$

4 continue

c 
109 format $(f 6.2,2 x, 6(e 9.3,2 x))$

c

114 write $(16,114)$ format $\left(/, /, 2 \mathrm{x}\right.$, Maximum values of $\mathrm{BM}, \mathrm{AF}$ and $\left.\mathrm{SF}^{\prime}\right)$

write $(16,111)$

111 format ('radius', 4x,'ben.m',7x,'ax.f',7x,'sh.f',6x,'flex.r', 6x,

+ 'nd bst', $6 x_{r}^{\prime}$ '

ymomi $=(1 . / 12) *.(t h k \star t h k \star t h k)$

$\mathrm{c}=\mathrm{thk} / 2.0$

do $3 \mathrm{n}=1$, in

Elexr $=r x(n) * r x(n) * r x(n) /(6 . * y \operatorname{yomi})$

$\mathbf{C}$

$b \operatorname{mamax}(n) /(w * r x(n))$

bstres $=b \max (n) * c /($ ymomi*ppb)

3 write $(16,109) \mathrm{rx}(n), \mathrm{bmax}(n), \operatorname{amax}(n), \operatorname{smax}(n)$, flexx, bstres

c

c

:vary thickness liner from 0.1 inch to 1.0 inch, increment 0.1 write $(16,118)$

118 format $(/, '$ Maximum stresses:')

it $=1$

do $5 n=1$, ir

$r=\operatorname{rx}(n)$

write $(16,116) r$

116 format $(/, /, 2 x$, 'Radius of bore hole $($ inch $)=', f 10.5)$

write $(16,115)$

115 format $f^{\prime} t h k^{\prime}, 6 x_{,}$'flex.rt', 3x,'nd bn.st', 4x, 'comp.rt', 3x,

+'nd ax.st', 3x,'nd sh.st')

dthk $=0.1$

thk $=0.2$

31 continue

c

c calculate stresses

area $=1.0 *$ thk

ymomi $=(1.112) *.(t h k * t h k * t h k)$

$\mathrm{c}=\mathrm{thk} / 2.0$

c stresses non-deminsionalized w.r.t. base reaction ppb

sigmmax $=b \max (n) * c /(y$ momi $* p p b)$

sigtmax $=\operatorname{amax}(n) /($ a rea $* p p b)$

sigvmax $=\operatorname{smax}(n) /($ a rea $* p p b)$

c

c flexibility ratio and compressiblity ratio

flex $r=r^{\star} r^{\star} r /\left(6 .{ }^{*}\right.$ ymomi)

compr $=r /$ thk

write $(16,109)$ thk, flexr, sigmmax, compr, sigtmax, sigumax

thk $=$ thk $+d t h k$

if (thk.le.1.1) go to 31

5 continue

c 
stop

end

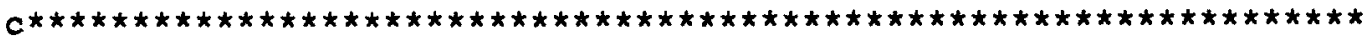

function xmom (ama, ta, rc, uc, va, zc,altm)

c moment

$x m o m=a m a-t a * r c *(1 .-u c)+v a * r c * z c+a l t m$

return

end

c

function $x t$ (ta, va, zc, uc, altt)

c axial force

$x t=t a * u c+v a * z c+a l t t$

return

end

$c$

function $x v(t a, v a, a l t v, z c, u c)$

c shear force

$x v=-t a * z c+v a * u c+a l t v$

return

end

c 
Analysis of Emplacement Borehole Rock and Liner

Behavior for a Repository at Yucca Mountain

\begin{tabular}{|c|c|}
\hline \multicolumn{2}{|c|}{ 3. DATE GEPORT PUBLISHED } \\
\hline MONTM & $\overline{T E A A}$ \\
\hline September & 1989 \\
\hline \multicolumn{2}{|c|}{$\begin{array}{l}\text { 4. FIN OR GAANT NUMBER } \\
\text { D1016 }\end{array}$} \\
\hline $\begin{array}{l}\text { 6. TYPE OF REPORT } \\
\text { TOPICal }\end{array}$ & 101016 \\
\hline
\end{tabular}

L. J. Lorig, B. Dasgupta

Itasca Consulting Group, Inc.

1313 5th Street SE, Suite 210

Minneapolis, MN 55414

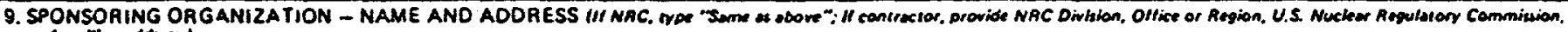
ind mating odersen

Division of High-Level Waste Management

Office of Nuclear Material Safety and Safeguards

U. S. Nuclear Regulatory Commission

Washington, DC 20555

10. SUPPLEMENTAAY NOTES

\section{AASTAACT 1200 mon or wal}

This report presents the results of studies aimed at assessing the quasi-static behavior of both the rock surrounding an emplacement borehole and the lining within an emplacement borehole for a nuclear waste repository in tuff. Two-dimensional thermomechanical analyses of conditions similar to those representative of the horizontal emplacement option were performed using a distinct element code. Three different behavior models (equivalent continuum, wedge, and parallel joint) were used to investigate the state of deformation at 0 and 100 years following waste emplacement. Three different rock strength assumptions were studied corresponding to "design," "recommended" and "limit" values given in the Nevada Nuclear Waste Storage Investigation (NNWSI) Project Site Characterization Plan Conceptual Design Report (MacDougall et al., 1987). The ground reaction curve concept is introduced to study the potential liner loading resulting from thermally induced borehole closure.

Analytical solutions for various ring loadings given by Roark and Young (1975) were combined to develop solutions for appropriate liner loading configurations. Results are presented in terms of dimensionless bending stress versus flexibility ratio.

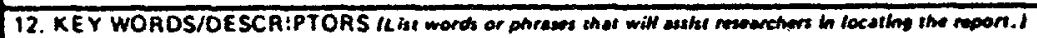

nuclear waste geologic disposal

retrieval

borehole

liner

tuff

thermal-mechanical analysis

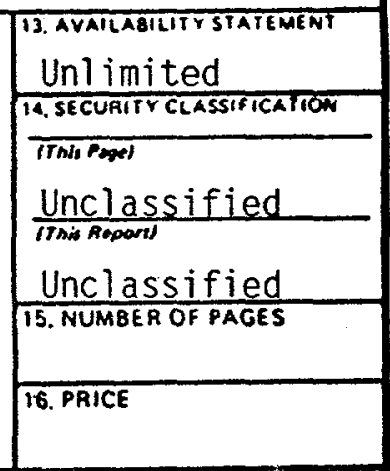

